University of Rhode Island

DigitalCommons@URI

Open Access Master's Theses

2002

\title{
Green in Everybody's Neighborhood: Assessing the Distribution of Parks and Open Spaces in the City of Providence
}

Krista Alessandro

University of Rhode Island

Follow this and additional works at: https://digitalcommons.uri.edu/theses

\section{Recommended Citation}

Alessandro, Krista, "Green in Everybody's Neighborhood: Assessing the Distribution of Parks and Open Spaces in the City of Providence" (2002). Open Access Master's Theses. Paper 733. https://digitalcommons.uri.edu/theses/733

This Thesis is brought to you for free and open access by DigitalCommons@URI. It has been accepted for inclusion in Open Access Master's Theses by an authorized administrator of DigitalCommons@URI. For more information, please contact digitalcommons-group@uri.edu. 
Green In Everybody's Neighborhood:

Assessing The Distribution Of Parks And Open Spaces

In The City Of Providence

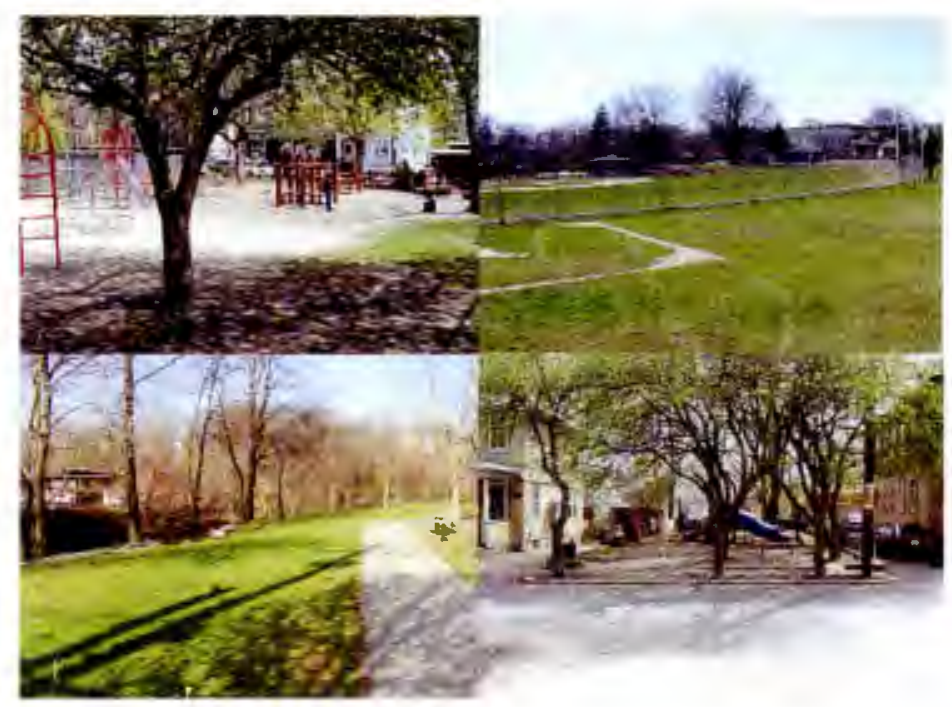

By

Krista Alessandro

A Research Project Submitted In

Partial Fulfillment Of The Requirements

For The Degree Of Master Of

Community Planning

University Of Rhode Island 


\section{MASTER OF COMMUNITY PLANNING \\ RESEARCH PROJECT}

OF

KRISTA ALESSANDRO

Approved:

Major Professor

Acknowledged:

Director

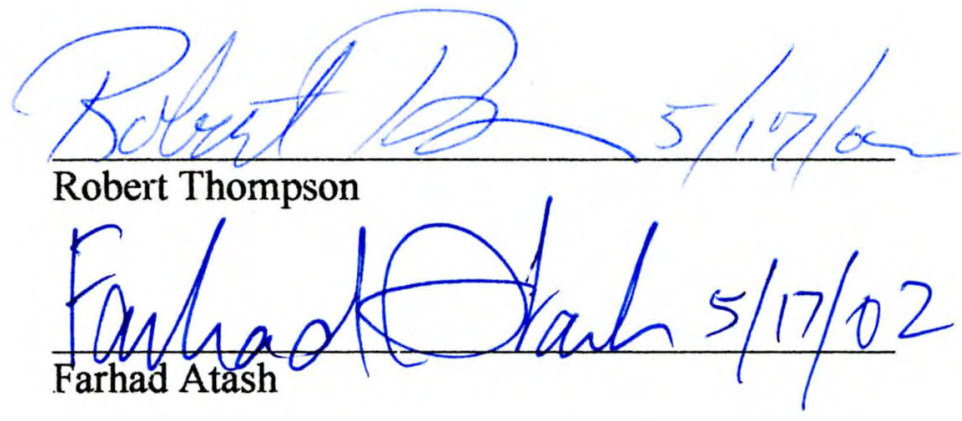




\section{ABSTRACT}

Scholarship on environmental justice has focused on such issues as the concentration of hazardous commercial activities and lack of transportation options in poorer, minority communities. Although we must recognize and address the discriminatory distribution of environmental harms, real environmental justice also requires a fair distribution of such environmental goods as the presence of high quality green space and different forms of recreational activities. Ulrich (1993) argues that urban civilizations throughout the centuries have made continuous efforts to maintain contact with natural settings through gardens or parks. Furthermore, he states that providing parks can improve psychological and physical well-being in addition to reducing stress associated with urban living.

There often appears to be an inequitable distribution of green spaces and outdoor recreational opportunities within urban areas; low-income and minority neighborhoods lack such resources or have poor quality facilities and spaces while upper income neighborhoods have more resources that are adequately maintained. This study will first, examine the distribution of green spaces and outdoor recreational opportunities and determine if there is a correlation between the quantity of these resources and socioeconomic characteristics of the neighborhoods where they are located. Second, the quality of these resources will be analyzed and compared to demographics. For the purpose of this proposal, parks and open space under the administration of a municipality will be analyzed.

A case study of Providence, Rhode Island, a small urban area of approximately 11,800 acres and a population of 173,000 , is used to test the hypothesis. Using statistical analyses and quality assessment through field observations, conclusions are made about the relationship between the distribution of accessible, quality parks and open spaces and the social and economic indicators. It was found that the distribution of parks and open spaces within the city are equitable; however, the quality of these resources varies. The city meets the national standard of 6 to 10 parks per 1,000 residents as set by the National Parks and Recreation Association. The highest ranked parks are located in areas that are diverse in race and ethnicity as well as income indicators, but the truly lower income areas with a majority of the 
minority populations do not have high quality parks. The lowest ranking parks are also located in areas of diverse race, ethnicity and incomes. The biggest difference in the quality of parks is the cleanliness, such as litter, graffiti and glass. Parks in lower-income areas had the biggest problem with litter along chain link fences that surrounded the parks and graffiti on buildings and play equipment. There are also issues of security where parks are locked, even during the day, which creates a barrier to access.

There needs to be further research into the social, economic and political context of the city to better understand the reasons for the distribution varying qualities of parks and open spaces. For example, users might be surveyed to understand usability and functionality of existing parks and determine the need for additional facilities. Additionally, the political relationships and resources for maintenance within the study area might also influence the distribution of parks and open spaces. If these relationships could be analyzed, park development in the city could be understood at an even different level. Factors that could be looked at may include city budgets, allocation of funding, projects supported by various councilpersons or activities of grassroots and neighborhood organizations. This paper is intended to provide a base for further, more in depth research into the equality in green spaces in the neighborhoods of urban areas. 


\section{ACKNOWLEDGEMENTS}

I would like to acknowledge Dr. Robert Thompson for his role as major reader for this study, particularly in his knowledge of the subject matter and recommendations of resource materials and data analysis strategies. I would also like to recognize Dr. Farhad Atash and Jane Sherman for their time as secondary readers. Staff at the City of Providence was also supportive in data collection, including Bob Azar and Bonnie Nickerson. Maguire Group Inc. was equally supportive in allowing me to use their resources off the clock and being extremely flexible with time off. Special thanks go to Jim Lucht at Providence Plan, Inc. for his time in preparing data for the geographic information system and assistance in shaping data analysis techniques. Finally, I would like to thank Bruce Moravec for being my escort to areas of the city where I did not feel comfortable going by myself. His knowledge of the city's layout made him a great navigator. 


\section{Table of Contents}

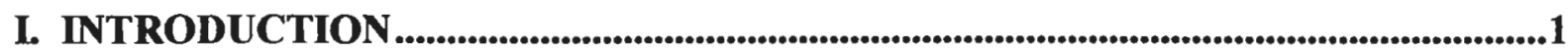

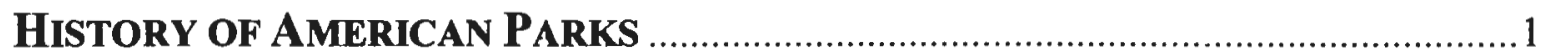

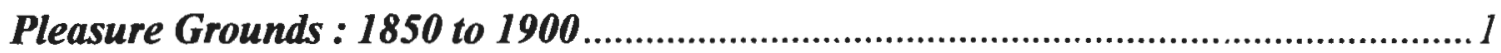

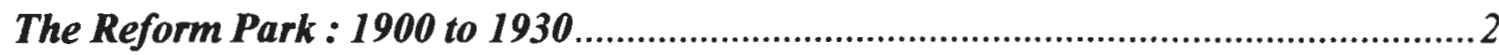

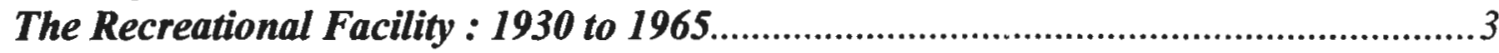

The Open Space Network : 1965 and After ................................................................

II. MAJOR QUESTIONS AND POLICY ISSUES .....................................................................7

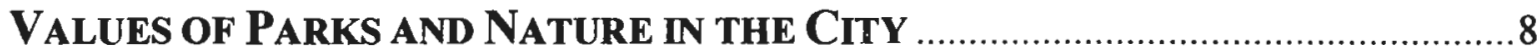

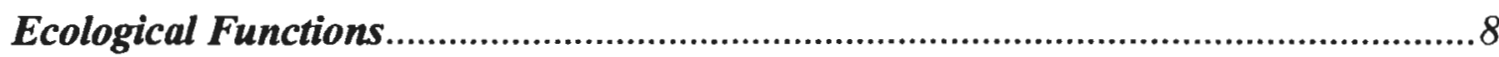

Psychological Functions....................................................................................... 10

Social Functions ............................................................................................

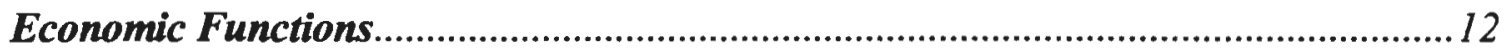

IMPORTANCE OF NATURe ANd Parks to POOR AND MinORITy

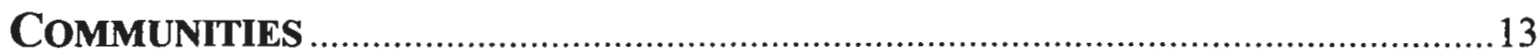

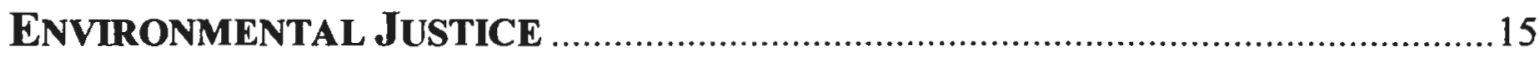

III. METHOD OF ANALYSIS............................................................................................19

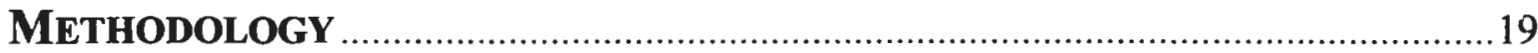

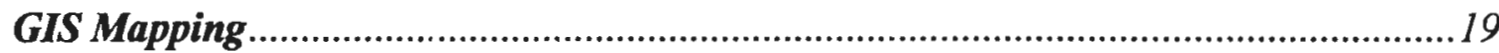

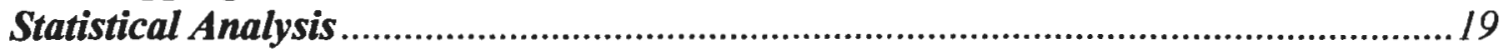

Access and Quality Assessment .................................................................................20

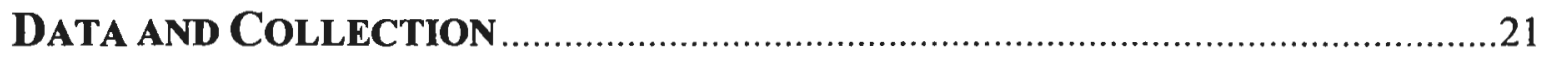

IV. ANALYSIS AND FINDINGS ......................................................................................................22

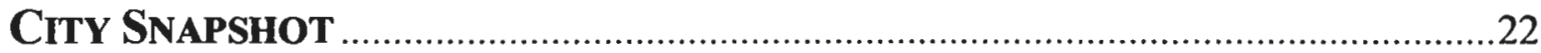

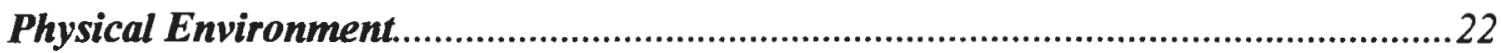

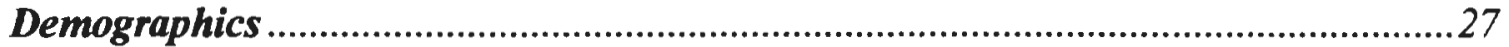

Census Blocks with Parks or Open Space ……….................................................................. 39

Census blocks within 660 feet of a park or open space....................................................45

Census blocks more than 660 feet from a park or open space ..........................................4

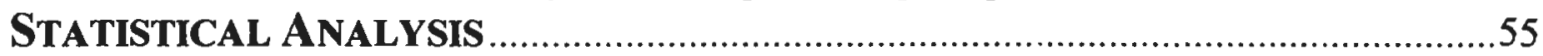

ACCESS ANd Quality ASSESSMENT OF PARKS ANd OPEN SPACE .................58

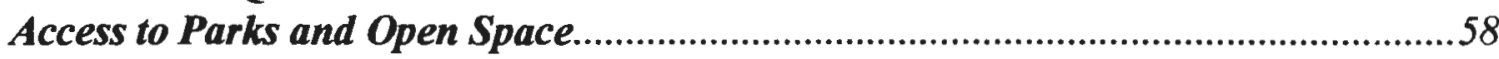

Quality Assessment of Parks and Open Space ………...................................................59

Statistical Analysis of Rankings........................................................................................ 74

V. CONCLUSIONS \& RECOMMENDATIONS.......................................................................75

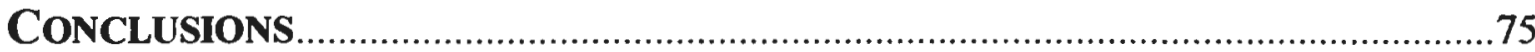

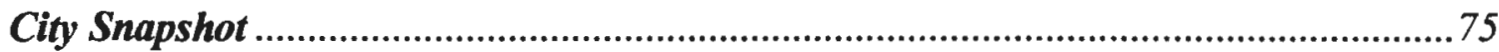

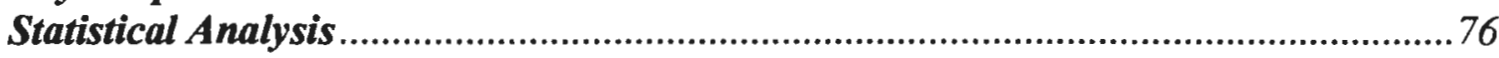

Access and Quality Assessment of Parks and Open Space ............................................76 


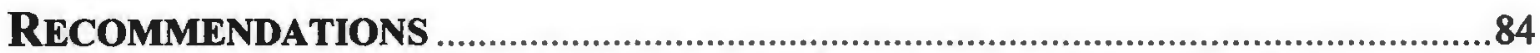

Maintain existing parks and open spaces and explore new opportunities ...................84

Further Research .....................................................................................................................................85

Final Thoughts .................................................................................................................8

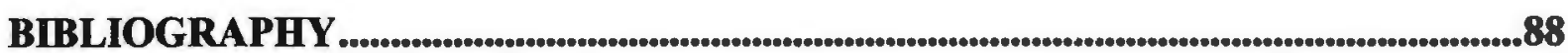

\section{List of Figures}

Figure 1. Race and ethnicity breakdown from the 2000 Census for Providence, RI. .............28

Figure 2. Hispanic population breakdown from the 2000 Census for Providence, RI............28

Figure 3. Race and ethnic breakdown for population under 18 from 2000 Census for

Providence, RI

Figure 4. Census blocks with parks or open space: Percent of non-Hispanic white by square

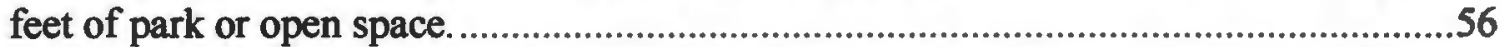

Figure 5. Census blocks with parks or open space: Percent of population non-Hispanic white

by square feet of park or open space less than 100,000 square feet. ...............................57

Figure 6. Census blocks with a park or open space: Percent of population non-Hispanic white

by parks or open space less than 50,000 square feet. .................................................5. 57

Figure 7. Neighborhoods of Woonasquatucket Greenway (Source: Woonasquatucket Greenway Plan)

\section{List of Tables}

Table 1. Central cities of the largest metropolitan areas in US, ranked population density and comparing acres of parks and open spaces per 1,000 residents......................................26

Table 2. Census blocks with parks: Selected demographic subjects.......................................39

Table 3. Census blocks within 660 feet of a park or open space: Selected demographic

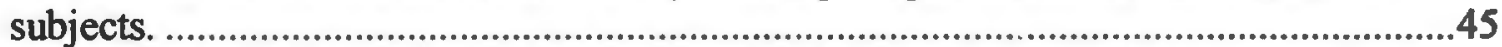

Table 4. Census blocks more than 660 feet from a park or open space: Selected demographic subjects.

Table 5. Linear Regression Model Summary for Census Blocks with Parks or Open Space. 58

Table 6. Linear regression model summary for parks and open spaces ranked below the

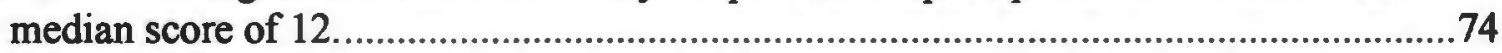

Table 7. Summary of Census block categories for the proportions within each grouping.....75

\section{List of Maps}

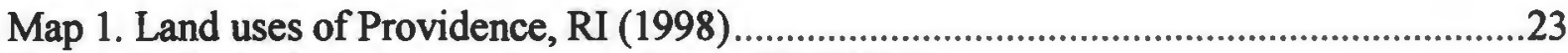

Map 2. Parks and open space in Providence, RI (2000) ........................................................24

Map 3. Non-white population as a percent of total population, Providence, RI (2000).........29

Map 4. Non-Hispanic white population as a percent of total population, Providence, RI

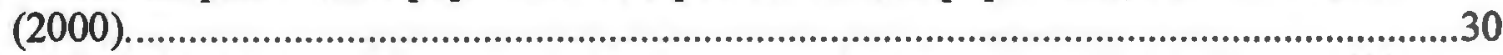

Map 5. Non-white Hispanic population as a percent of total population, Providence, RI

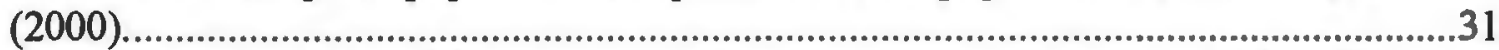

Map 6. Population under age 18 as a percent of total population, Providence, RI (2000)......32 
Map 7. Single parent households with children under 18 as a percent of total population,

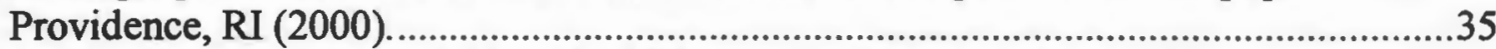

Map 8. Female-headed households with children under 18 and no husband present,

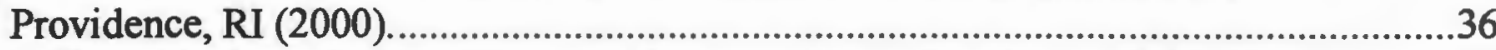

Map 9. Household size for non-Hispanic white population, Providence, RI (2000)................37

Map 10. Household size for Hispanic population, Providence, RI (2000).............................38

Map 11. Census blocks that contain a park or open space, Providence, RI (2000)................40

Map 12. Census blocks with a park or open space: Children under 18 as a percent of total population, Providence, RI (2000)...............................................................................41

Map 13. Census blocks with a park or open space: Non-white population as a percent of total population, Providence, RI (2000)...................................................................................42

Map 14. Census blocks with a park or open space: Non-Hispanic white population as a percent of total population, Providence, RI (2000). .......................................................43

Map 15. Census blocks with a park or open space: Non-white Hispanic population as a percent of total population, Providence, RI (2000). .......................................................44

Map 16. Census blocks within 660 feet (1/8 mile) of a park or open space, Providence, RI (2000)

Map 17. Census blocks more than 660 feet (1/8 mile) of a park or open space, Providence, RI

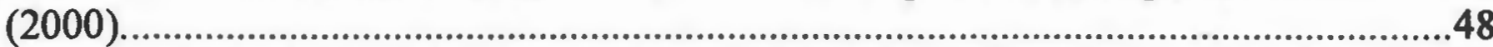

Map 18. Census blocks more than 669 feet ( $1 / 8$ mile) of a park or open space: Children under 18 as a percent of total population, Providence, RI (2000) ...............................................49

Map 19. Census blocks more than 660 feet (1/8 mile): Non-white population as percent of total population, Providence, RI (2000)......................................................................50

Map 20. Census blocks more than 660 feet (1/8 mile) of a park or open space: Non-Hispanic white population as a percent of total population, Providence, RI (2000).....................51

Map 21. Census blocks more than 660 feet (1/8 mile) from a park or open space: Non-white Hispanic population as a percent of total population, Providence, RI (2000).................52

Map 22. Census blocks more than 660 feet (1/8 mile) of a park or open space: Single parent households with children under 18 as a percent of total households, Providence, RI (2000).

Map 23. Census blocks more than 660 feet (1/8 mile) of a park or open space: Femaleheaded households with children under 18 and no husband present, Providence, RI

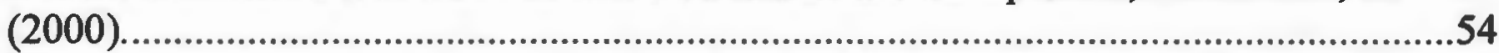

Map 24. Distribution of parks and open spaces and quality assessment score, Providence, RI

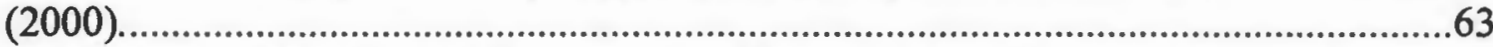

Map 25. Highest ranking parks and open spaces: Non-white population as a percent of total population, Providence, RI (2000)...................................................................................64

Map 26. Highest ranking parks and open spaces: Female-headed households with children under 18 and no husband present, Providence, RI (2000).

Map 27. Lowest ranking parks and open spaces: Non-white population as a percent of total population, Providence, RI (2000)..............................................................................67

Map 28. Lowest ranking parks and open spaces: Female-headed households with children under 18 and no husband present, Providence, RI (2000).

Map 29. Parks and open spaces between Elmwood Avenue, Broad Street and Eddy Street: Non-white population as a percent of total population, Providence, RI (2000).............78 
Map 30. Parks and open spaces between Elmwood Avenue, Broad Street and Eddy Street: Female-headed households with children under 18 and no husband present as a percent of total households, Providence, RI (2000). 


\section{INTRODUCTION}

This study examines the distribution of parks, open spaces and outdoor recreational opportunities in urban areas to see if a correlation exists between the quantity and quality of these resources and the socioeconomic make-up of the area in which they are, or are not, located. The hypothesis to be tested is low-income and minority neighborhoods have fewer lower-quality parks and services than middle and upper income neighborhoods. This study is based on the theory that low-income and minority populations disproportionately bare the burden of negative environmental land use decisions.

To test the hypothesis, Providence, Rhode Island, is used as a case study. Data on the city is collected and tested through statistical analyses and field observations. The basis on which conclusions are made is derived from the history of parks in America, introduced here, theories of environmental justice and literature on the values of nature in urban environments to improve quality of life, discussed in Chapter III.

\section{History of American Parks}

Tracing the development of parks gives us insight into the motives of park placement and its potential relationship to economic and social characteristics of its surrounding community. Cranz (1982) has documented the history of parks in American from the late nineteenth century. His discussion categorizes the evolution into four eras: Pleasure Grounds (1850 to 1900); The Reform Park (1900 to 1930); The Recreational Facility (1930 to 1965); and The Open Space System (1965 and after).

\section{Pleasure Grounds : 1850 to 1900}

During the late part of the nineteenth century, American cities developed parks around passive uses or all outdoor activities. Designs attempted to bring pastoral landscapes into the city, mimicking the countryside. It was thought that interaction with this form of nature would alleviate the stresses of the working class associated with increased working hours indoors under artificial lighting. Early parks were informal and organized around the 
landscape of the site, providing a contrast to the hard elements of the city. Finding large expanses of land was difficult because of the generally little amount available in congested urban areas and the competition with other land uses. Parks essentially were located in areas that were unsuitable for other purposes. Secondary concerns were views, cross-ventilation, circulation, and topography.

As Spirn (1984) points out, the later part of the nineteenth century also saw large investments in civic infrastructure, such as new sewer and water lines. The comprehensive effort of infrastructure improvements and the creation of large public parks were intended to improve the quality of life for city residents through alteration of the physical environment. As the era moved towards the end of the century, park design became very formal and incorporated man-made lakes, fountains, statues and boulevards and drives, as advocated by Fredrick Law Olmsted, to create a connected system of parks throughout the city. It was at this point in park history that Cranz argues park managers and designers began to deviate the original function of parks, as alleviating the problems of city life. Parks developed during this era include Central Park, Golden Gate Park and Washington Park in Chicago.

\section{The Reform Park : 1900 to 1930}

The new century brought greater prosperity for some city residents. Incomes were larger, people took early retirement, the workweek was shorter and people were taking vacations. Overall, people were left with more time to pursue other activities outside of work. As a result, cities began to take a larger role in park development and investment. They offered a wider range of recreational services such as beaches, golf courses, stadiums, tennis courts, swimming pools and picnic areas to help people organize their free time, in particular children and adult men of the urban working class. Overall, parks were developed based on the segregation of age and sex that focused on schedules of active, passive and social activities such as dancing lessons, arts and crafts, tournaments and competitions in sports. The organized activities of the Reform Park era contrasted with the unstructured pleasure parks; however, new facilities still promoted the restorative function of fresh air and the natural landscape. 
Reformers, with the involvement of social workers, began to look at the social conditions of cities and incorporate park development around these issues. The streets were used by children as play areas and posed serious dangers to their health and well-being. Park advocates used this as an argument for their cause. The playground movement had begun in the late 1890 s and park reformers pushed for these parks to be sited in areas more accessible to the working class and their families. New parks were developed in the densest neighborhoods, following the theme of reformers wanting to reach the largest segment of the population, which included immigrants (New York City), laboring classes (Chicago), and working-class districts (San Francisco). Siting of the new facilities were still associated with areas that were undesirable for other uses, including city dumps, cemeteries, slums, the empty grounds of defunct reformatories or breweries, old piers and vacant lots.

\section{The Recreational Facility : 1930 to 1965}

Cranz's next era of park development focused on the recreational facility. After 1930, park development no longer needed justification; parks were an expected feature in the urban environment and their development was an important function of municipal government. The park was no longer understood primarily for its restorative role for the working class, but also as an important part of the pursuit of happiness itself, improving the quality of life.

During the Depression many factors contributed to increased demand for parks and faciiities during this era. Leisure time increased with more people not working, which also led to the shorter workweek and longer weekends. Parks provided activities that kept people occupied and park creation increased as a way to employ people.

After WWII, the social and economic context of the country began to change and influence the demand for park services. The urban population was growing, the standard of living increased, daylight-savings time was introduced, automobiles and the road system improved, retirement ages were earlier, and people lived longer lives. Recreational pastimes like baseball games were thought to boost moral during the war and provided venues for people to congregate and support each other. 
There was an exodus of the middle and upper classes to the suburbs. Cities became more congested with public housing developments in the inner city and new acquisitions for parks were small in size. Urban renewal, highway development, shopping centers, public housing and hospitals all competed with parks for available land. In addition, park administration became more bureaucratic. Cities began to do quantitative studies on the population served by parks and develop standards for park facilities. Parks departments became more technical and complex and required staff with more professional qualifications. These new aspects of the departments also ate at budgets, further decreasing the amount of funds directly going to park services.

Cranz argues that the parks during the Recreational Facility era provided lots of activities with little regard to the quality or purpose of the services. Municipal parks departments lacked a philosophy, and the ideal design was the multi-use facility. With this general lack of interest in the purpose of parks, the budgets to support these efforts also lessened, and failed to rise during this era. There was less money for creation let alone maintenance and supervision. Parks began to rely on cooperative ventures with social service agencies, public schools, and libraries for development.

\section{The Open Space Network : 1965 and After}

After 1965, Cranz discusses the transition from the philosophy of providing facilities and structured activities to the need for open space networks in cities. This new policy was a response to the growing urban crisis. The middle-class had mainly demanded park services, and they had left the inner city neighborhoods for the suburbs. Existing parks and the city streets were considered unsafe as civil unrest led to riots and demonstrations during the era of the Civil Rights Movement. Parks were considered irrelevant because they were the location for violence and crime as reported by the media. "By the end of this era, parks were deserted, unsafe, littered with limited programming, old field houses, busy streets and unwelcome chain link fences" (1982: 139).

New parks during the Opens Space Network era focused on what Cranz identifies as imagery and inspiration. Parks still played their traditional role as a way to rejuvenate its users, but 
also to stimulate their cultural senses through concerts, dancing, games, celebrations and sporting events. As with previous eras, space was limited, and the idea of open space networks in urban areas was even more limited in older, developed cities. Here, the new focus was vest-pocket parks and other small parks that could utilize irregular lots and inexpensive sites previously rejected for park development. A network of small parks began to appear throughout cities, both in the inner city neighborhoods and the fringes that abutted the suburbs. The classic park now seemed inadequate, as Cranz suggests, because it did not join together with the city, residential developments or the local schools. As the classic pastoral park was on the verge of becoming extinct, the National Park Service assisted cities in preserving these areas as historic landmarks, such as Central Park and Prospect Park in New York City.

The transition from one era to another carried the same programming activities, but Cranz suggests the difference is the meaning attached to them. He sites baseball fields filling the time of idle hours during the Depression, but relieved tension and built moral during WWII. Cranz argues that overall assessment of park services has focused on large shifts in what is for the public good based on the urban economy, public health and socialization, which, in his opinion, is naive and almost offhand. Perhaps the missing link is associated with urbanites and their overall need for personal interaction with nature.

Since the mid-1990s, the creation and investment in parks and open space has changed in cities. Newer research is lead by Harnik (2000) and Garvin (1998). The theories are the same in that parks improve the quality of life in the city by cleaning the air, providing shade, providing recreation and play space, but they also offer opportunities to view and interact with nature. The approaches to developing these spaces and the ways in which they are financed have also changed. Private investment and management in public spaces and parks is increasing, creating partnerships that Garvin feels will keep generations investing and reinvesting in urban parks and open space. People develop an attachment to open space, or the idea of it, which continues to drive the continued investment in parks. Cities are trying to create a park system through public and private investment partnerships, neighborhood-based planning initiatives, reinvestment in waterfront properties, converting highways and 
abandoned rights-of-way into parkland and developing community gardens, just to name a few. The goal is to attract suburbanites back to a "greener" city with the hope to slow the pace of urban sprawl and increase investment in city centers.

Several attributes of American parks and open spaces can be taken from its history. Initially, parks were developed as pastoral landscapes to alleviate stresses associated with living in the city. Parks provided a space for leisure time, both structured and unstructured. Park advocates felt playgrounds and vest-pocket parks should be sited in dense urban areas, where most users were concentrated. By the 1930s, municipal governments had the responsibility to develop and invest in parks and open spaces. People began to expect these resources in cities. Parks competed with other activities for available land and funding, including highway development, retail and commercial development, and institutions. Land that was unsuitable for other purposes, mostly small irregular lots, usually became new parks. Budgets strained from increasing costs and decreasing funding. Cooperative ventures were the only way cities could finance the development of new parks, from partnerships with schools and libraries in the 1950 s to public-private partnerships with grassroots and neighborhood organizations in the 1990s. 


\section{MAJOR QUESTIONS AND POLICY ISSUES}

The major questions and policy issues of this study are to examine the distribution of parks, open spaces, outdoor organized recreational opportunities, and opportunities for nature exploration in urban areas. Specifically, I wanted to see if there is a correlation between the quantity and quality of these resources and the socioeconomic make-up of the neighborhood in which they are, or are not, located. The hypothesis is low-income and minority neighborhoods have fewer parks and services of a lower quality than middle and upper income neighborhoods.

Quantities of parks in cities are set by national standards and incorporated into local policies. The main objective is to provide an adequate number of parks in proportion to the population. These standards are straight-forward. The quality of a park influences the user's overall experience, but they are more difficult to explain and measure. For example, the quality of a park or open space can be measured with input just from municipal department staff or combined with the input of user groups. Portland, Oregon, assessed their city-wide park system by evaluating its infrastructure (www.pps.org/upo). They look at features that are found in most of the parks such as playground equipment, paths, lighting, restrooms, irrigation, roads and parking lots. A ranking system was applied that allows them to calculate scores for each park. Toronto conducted safety audits of their parks (www.pps.org/upo). Audits include feedback from users regarding fear of crime and perceptions of safety. The two systems come away with different results, which indicates that assessment of parks and open spaces can be subjective. A park judged as being in satisfactory condition by management staff may not be by user groups.

It is important to examine how parks improve the quality of life and add unique values and benefits to city living. But do all populations within the city receive these values and benefits? The following discussion outlines the positive values of parks and open spaces to the urban environment. It is supported by an overview of environment justice theories on resource distribution and how they are applicable to the allocation of environment "goods" such as parks and open space. 


\section{Values of Parks and Nature in the City}

As Spirn (1984) points out, most city dwellers today think nature in the city consists of trees, shrubs and grass in streets and formal landscapes of parks and private yards. These areas hardly represent natural processes and their functions. However, she further states that people still recognize the significance of natural features in urban areas, as in the discussion of parks in the past one hundred years. The development of promenades, boulevards, and suburban utopias like garden cities and greenbelts towns also contributed to this recognition.

The primary functions of parks have been for the public welfare and visual enhancement. By being the "lungs of the city," parks brought the fresh air from the countryside into the city as places where people can stroll on pathways and relax on lush green lawns. They were an antidote to the oppressive physical and psychological conditions of city life. Since ancient civilizations, people had always incorporated natural features into city design for visual and aesthetic reasons (Carr 1992). The history of parks in America strengthened the ideology of parks and open spaces in cities as places to restore and rejuvenate the residents from the stress of urban life. A vest-pocket park can give the sense of entering another world through various design elements such as textures, sounds and enclosures. These areas provide a separation from loud city streets into a restorative natural setting (Kaplan et al 1998). These are examples of the many roles natural features and systems can contribute to the quality of life in cities. Nature, in the form of parks or open space in the city, has valuable functions ecologically, psychologically, socially, and economically.

\section{Ecological Functions}

Parks and natural features do more than just provide aesthetic landscaping that softens the harsh elements of an urban environment. They perform ecological functions that contribute to the livability of a city. To better understand these roles, I address each natural feature individually, although collectively they form a larger ecosystem within the city. 


\section{Trees and Plants}

Trees and plants contribute to improving the quality of the city's environment in many ways. Primarily, trees in urban areas are found along streets and in parks. "A single tree can make a big difference" (Kaplan et al: 1998:111). For example, a view of a tree from a window can be engaging, showing the seasonal change or birds. Trees and other vegetation provide shade, reduce pollution by filtering airborne contaminants and dust, and increase energy efficiency by shading buildings and absorbing radiation from the sun (Spirn 1984).

\section{Wildlife and Natural Areas}

Natural features such as meadows, woodlands, and wetlands create a more productive landscape ecologically. Not only is wildlife habitat provided, but they also support more native vegetation and increase biodiversity. Observing more natural landscapes increases the understanding of natural processes and their importance to improved environmental quality in cities. A typical pastoral park with landscaping requires constant maintenance to keep their "natural" appearance. Natural landscapes are less costly to maintain and provide many levels of discovery (Ahern 1998). Hough (1984) also advocates this concept. He argues for the use of wildlife as providing clues to the condition of the city's natural environment and its ability to sustain itself. For example, monitoring the reproduction of aquatic birds may give clues to the condition of the city's water resources. He also sights the presence or absence of lichens as an indicator of habitat condition and diversity, which is reflective of its suitability for people.

\section{Air}

Parks provide an opportunity for air to circulate through the city. Spim (1984) explains that gusts that are usually felt by people in the city are really swirling masses of stationary air that retain pollutants, not breezes of fresh air. In downtown areas, air and its contribution to the microclimate are greatly influenced by surrounding skyscrapers, which create wind tunnels between buildings or block the sun and cast long shadows. Here air circulation is the poorest and warmest from the radiation of heat off buildings and paved surfaces. In neighborhoods, dust circulating in the air contains lead and other toxics, ingested by young children who are 
the most sensitive to even the lowest levels. Opens spaces through parks provide an outlet for air to disperse and dilute contaminants.

\section{Water}

Parks and open space contribute to the integrity of water cycles, the maintenance of water quality and flood control. A mixture of paved and natural surfaces can store water after rainstorms. Typically, pipe systems collect and direct surface runoff to outfall pipes.

Retention allows water to slowly seep into the ground for regeneration and reduces wear and tear on pipe systems as well as requiring system designs for smaller capacity. Furthermore, storage reduces erosion caused by runoff and can absorb suspended solids prior to discharge into natural water features. Retention can also improve local climate through the evaporation of water into the air and increase wildlife habitat (Hough 1984; Spirn 1984).

Overall, the natural processes that occur in parks and open spaces contribute to the improvement of the climate in cities and the quality of the natural environment. What's important is the incorporation of a network of parks performing the above-mentioned functions to produce a healthy city. A series of small parks throughout will have a greater effect than a few large ones. The small spaces allow the variance of temperatures and a balance is reached more quickly and with less resistance (Hough 1984).

\section{Psychological Functions}

Historically, the mental health of park users was a focus through the different eras of park design and programming with the hopes of creating a happier and psychologically healthier urban population (Cranz 1984). People go to public spaces for comfort, relaxation, active and passive recreation and discovery. Visual and physical contact with nature can produce mental and restorative benefits (Carr et al 1992). But at times, emotional connections to parks become deeper. Hayden (1995) discusses the importance of natural areas and their contribution to a person's sense of place, particularly after they are replaced with development People feel connections to parks and other spaces through their past and their culture. Hayden argues that many historians, including environmental and cultural, overlook the connections between social and economic aspects of cities with the natural environment 
of urban areas. They are all part of the experience of place. Cranz (1984) describes parks as works of art, their value increases as they get older. They "provide a tangible link to the past, unify the culture across time and register its successive attempts to cope with its problems" (248).

Wildlife habitats in cities' open space networks increase social well being, increasing the spiritual experiences of humans (Hough 1984). Cooper Marcus and Francis (1990) discuss Jurgen Milchert and his analysis of the spiritual components of the relationship between people and natural areas and support his suggestion for leaving portions of parks to grow naturally rather than be planned and designed. Milchert suggested that there is a basic need for people to experience "untamed nature" as a contrast to the planned urban environment. There needs to be a sufficient number of attractive open spaces with diverse qualities in a city or town. This includes everyday characteristics of nature from new growth to decaying trees.

Specifically and to an even greater extent, people feel personal ties to trees. Trees act as symbols, paralleling images of people. They are sheltering and parental. We say old trees look wise and young saplings are fresh and growing. Branches are referred to as limbs, and if a tree is ill, we call a tree doctor. Trees are planted as memorials, signifying a sense of permanence or landmark in our past. Furthermore, planting trees is a community project that shows a commitment to the future of an area and contributes to the overall landscape (Dwyer 1994; Kaplan et al 1998). Trees demonstrate the importance of "everyday nature" as a significant contributor to the health and well-being of people who live in the city. It is not necessary to leave the city to truly experience the value of nature. Personifying trees shows 'the unique value of experiences of nature 'at the doorstep,' of trees and nature in everyday lives" (Dwyer 1994: 149).

\section{Social Functions}

Parks support a public life, which is the essential communication system and linkage of a city. Historically public spaces were areas where people went to meet various needs, including markets, places for sacred celebrations or sites for local rituals, and often represent the community or its culture. This is linked to the psychological functions previously 
discussed, where places have special meanings and create a sense of place. A healthy life has both public and private experiences. There are three important functions of public spaces. First, they allow for casual encounters with others who live and work in the area, where people can bind together giving their lives meaning and power. Second, parks and public spaces offer relief from stress through relaxation, entertainment and social interaction. And finally, these spaces have the potential to bring diverse groups of people together with the potential to learn form each other and enjoy the spaces under a supportive mutual respect.

However, even with the important social functions associated with parks, there has been a continued loss of public spaces due to various reasons. The sizes of cities are increasing, people are becoming more private and retreating into their homes, and the open public spaces that were once markets, playgrounds and plazas are being transformed into new uses, particularly private developments. Lack of public space makes residents feei isolated and less likely to offer mutual help and support.

Cities have been making efforts to reverse this trend. There has been renewed effort in creating new public spaces in already congested cities. The formation of neighborhood associations and the creation of community gardens, which involve the participation of locals in the improvements of neighborhoods, has strengthened public life and shown its value. Promoting public life around natural features, such as parks, gardens and tree-planting support the importance of these features in neighborhoods. People are attracted to them and they bring a sense of commitment to the area as well as pride in residents for the appearance of their streets. A new playground can greatly enrich the social life of a neighborhood (Carr et al 1992).

\section{Economic Functions}

Municipal governments have great control of parks and open spaces through creation and maintenance, which are, in turn, influenced by budgets and allocation of different types of funding from different sources, whether it is from local, state or federal sources. Cranz (1982) sites in his chronology of parks that budgets gradually got smaller through the years because of increased services provided by cities. Additionally, the exodus of the middle- 
class families also decreased the amount of revenues a city had to work with to maintain its services. Parks that are attractive and safe increase the desirability of a neighborhood, but a city needs a strong economic tax base to maintain facilities in the first place (Harnik 2000).

The distribution of municipal funds has becorne quite competitive and park advocates look to others for assistance from both public and private investors. Priorities of city officials determine the amount of commitment parks get. Other pressing urban issues include creation of affordable housing and availability and competition for land (Carr et al 1992). Spirm (1984) makes a suggestion and instead of acquiring new land for new parks, redesign existing parks with more natural landscapes to require less maintenance. A multi-functional park can contribute to less spending associated with flood control and stormwater treatment as well as energy consumption. The ecological functions associated with parks and open spaces mentioned above highlight these savings for cities.

In their 1999 report for The Trust for Public Land, Lerner and Poole discuss the economic benefits of parks and open spaces. Revitalizations of many downtown areas across the country are using parks, open space and quality of life to attract residents, businesses and economic activity, such as Boston, New York City, Santa Fe, and Burlington Vermont. They sight the flexibility businesses have in choosing a location for new operations and prefer areas with a high quality of life, which include an abundance of open space and recreational opportunities. Lerner and Poole argue that easy access to parks and open space is a measurement of community wealth and a way to attract businesses and residents as well as visitors. Cities want to keep the existing middle-class families and attract others, and parks play an important role. They make tremendous contributions to boosting the image of a city.

\section{Importance of Nature and Parks to Poor and Minority Communities}

As Cranz (1982) traces park history, recognition of social or economic classes or race and ethnicity increased in importance in each era. Creators of pleasure parks avoided such issues because they felt the park would neutralize economic differences and act as a place where classes could mingle; however parks were not designed with the poorer residents in mind. It was felt that their interaction with upper classes would inspire them to better their lives. Park 
designers further assumed that the location of pleasure parks did not have to be in poor areas because of improved transportation through parkways and street-cars. A major change occurred in the reform era, where park advocates rallied for more parks in poor and workingclass neighborhoods because they were the primary users of the facilities. This was especially evident when the middle and upper class families began to leave cities for the suburbs.

Cranz notes that park response to racial and ethnic issues had been sporadic, showing little attention to such groups as users of parks in their own right. Although documentation from parks departments do not mention segregation, Cranz references sources that indicate practices to maintain racial differences was common. During the Reform Era, annual reports from the parks departments did not refer to race, however, when there were photographs of African American children, they were accompanied by racial captions. Racial segregation was assumed, but park advocates opposed ethnic segregation. The park was seen as a place to assimilate immigrants into the American culture, which led certain parks being associated with a specific ethnic group. Cranz argues that this raised and heightened the issue of ethnicity for the average citizen. During WWI in Harlem, the African American community pressured city officials for facilities. After WWII there was a conscious effort to make parks non-prejudiced, but certain parks were still known as African American parks.

Throughout park history, Cranz argues that parks were used as a way to maintain the status quo. The park assimilated the immigrants into the dominant culture. It kept people occupied in the late 1930s during the Depression when a shortened workweek and unemployment gave people potentially destructive time on their hands. And when the civil rights movement charged young people and racial and ethnic groups to riot, the park was there to pacify them. After 1965, programming for parks began to change and accommodate racial and ethnic groups; however the white, middle-class administration knew little about the needs of the communities they were to serve. In the end of his book, Cranz determines that throughout history the park was a way to bring political values to the young, poor and ethnic groups, creating good citizenry, social consciousness, and sentiment of democracy. 
Today, nature and parks could play significant roles in the quality of life in poor areas of the city. In addition to the values and benefits previously discussed, there are specific roles parks play in a low-income neighborhood. Poorer neighborhoods rely on public spaces more than middle-class neighborhoods and use them for many more functions. Lower income city areas have a higher density than middle and upper income areas. Residents usually rent small apartments and have less private open space. This can be related to the notion that lower-income persons have less buying power and other alternatives do not exist for them (Carr et al 1992). These characteristics reinforce the need for public spaces, including parks, for recreation and socialization.

Parks also increase the economic vitality of an area. In Atlanta, the expansion of the Martin Luther King, Jr. National Historic Site has sparked revitalization of an African American neighborhood. Since, the 1980s, the Trust for Public Land has acquired historic homes and demolished a dilapidated factory to provide land for a park. The improved site has been a catalyst for reinvestment in the community. Crime has decreased, dozen's of homes have been built or restored, and the site's 500,000 annual visitors have bolstered neighborhood businesses (Lerner and Poole 1999).

\section{Environmental Justice}

If a neighborhood lacks a park or open space to receive its values and benefits, is it an environmental injustice? Based on the theories of environmental justice, yes. Lack of green and recreational resources has a detrimental impact on communities economically, environmentally and socially. Neighborhoods are undesirable, lowering property values and increasing pollution in the natural environment through neglect and lack of respect and responsibility. Although most environmental justice research focuses on the adverse environmental impacts of the placement of hazardous waste facilities and transportation and public works projects, there are few studies that look at access to green and recreational spaces in urban environments. The methodologies, techniques and conclusions of all these case studies are applicable to parks and open spaces. The following is a brief summary of research conducted under environmental justice that supports the theory of this study. 
The environmental justice movement is a combination of environmental, social and economic advocacy. Work towards environmental justice has increased over the past ten years. Camacho (1998) discusses the roots of the movement with the landmark study in 1987 by the United Church of Christ Commission for Racial Justice, which found that local land use decisions resulted in the disproportionate placement of hazardous waste facilities in poor and minority neighborhoods. These areas suffer disproportionately from adverse environmental impacts of our consumer society and regulatory system. Decisions are made with little or no involvement from the populations receiving the greatest negative effects. These populations consume the least and have no influence in the regulatory system. Increasingly, low-income groups, members of the working class and people of color are taking a more active role in local environmental issues. These groups have connected "environmental issues with those of racial and gender inequality, lack of heath care and social services, inadequate housing, poverty, and other economic barriers that have been the focus of the civil rights and the social justice movement" (Camacho, 1998: 1-2).

Results of environmental injustice studies have conflicting views as to the role of economics and racial and ethnic identity in the placement of hazardous waste facilities. There are studies that say economics play a greater role in the distribution of locally unwanted land uses (Tarrant and Cordell, 1999) while others conclude that racial and ethnic composition of an area will predict the locations of such sites (Stretesky and Hogan, 1998). Both of these studies examined areas with different demographics. The former looked at a more homogeneous area where as the latter studied more diverse communities and compared them to the state as a whole. Decisions that produce inequalities vary from place to place and should be looked at individually. However, there are some underlying forces that run common among cases.

Direct discrimination as a result of the decisions of policy makers against poor and minority communities is prohibited by federal, state and local policies and regulations, but these populations continue to be affected by adverse environmental impacts. Indirect discrimination may be an additional concept to aid conflicting research. Studies discuss several contextual factors that contribute to an environmental injustice beyond the direct 
discrimination of siting hazardous waste site in poor or minority neighborhoods. Social and economic processes to consider are the changes in land values, housing discrimination, migration trends, and changes in economic activities (Mitchell, Thomas and Cutter, 1999; Stretesky and Hogan, 1998). For example, Mitchell, et. al. found that initially, during the 1960s, Toxic Release Inventory (TRI) sites in South Carolina were not located in areas because of the population characteristics, however, over time, cost of land and migration caused the population to change around the sites and appear as an environmental injustice in 1990. In addition, their research analyzed incorporated areas, which expanded their landmass to include TRI sites many years later. Supportingly,.Stretesky and Hogan (1998) found an increase in the percentage of blacks living in Florida census tracts containing Superfund sites despite the fact that the overall black population in the state decreased from 1980 to 1990. They concluded that blacks in Florida had fewer choices in deciding where to live in 1990 than in 1980 due in part by discrimination in housing and employment.

Sometimes it takes more than demographics to understand environmental injustices. Social attitudes in the community also influence decision-makers. In their study of Pima County, Arizona, Clarke and Gerlak (1998) conducted interviews of political district leaders and their constituents regarding their perceptions of environmental inequalities and their presence in the county. They concluded that the white majority was too removed physically and ethnically to take seriously the health and safety concerns of the Latino populations. Health agency staff dismissed correlations between the contaminated water supply in the poorer and minority neighborhoods and the illnesses of the residents.

One tool that is seen as most valuable in research of environmental justice is the use of geographic information systems (GIS). It emphasizes the spatial relationships between minority and low-income communities with hazardous environmental impacts (Clark and Gerlak, 1998; Tarrant and Cordell, 1999; Mitchell, et. al., 1999; Forkenbrock and Schweitzer, 1999). As Clark and Gerlak (1998) point out, GIS displays the impacts of environmental hazards clearer and more accurately than pure statistical interpretations. Mapping helps to visualize the interaction of conflicts to all interest groups (Forkenbrock and Schweitzer, 1999). The geographic distribution of resources and the activities of 
municipalities along with socioeconomic data can indicate if policy makers and local regulation systems in the allocation of resources favor specific neighborhoods or communities.

Minimal research has focused on the social equity of access to green and recreational spaces. The study by Tarrant and Cordell (1999) focused on access to quality recreational opportunities by minority populations. However, their study was not performed in an urban area and the population was homogeneous. What is important about their research as it relates to this proposal is the mapping of the scarcity of environmental "goods" as opposed to "bads." This paper will support continued environmental justice studies in the direction of identifying lack of access to positive environmental impacts: 


\section{METHOD OF ANALYSIS}

To answer the research questions of whether low-income cities have less access to quality parks and open spaces than middle and upper income areas, a case study of Providence, Rhode Island is performed. Data and resources from the city, the State of Rhode Island and Providence Plan, a non-profit organization, are used to reach conclusions. The geography of the study is census blocks within the municipal boundaries of the city. Independent variables are indicators of social and economic characteristics of the area. Dependent variables are parks and opens spaces under the administration of the City of Providence.

\section{Methodology}

A case study of the Providence, Rhode Island is used to answer the questions posed in this study. The analysis is performed in three parts: GIS mapping, statistical analysis, and access and quality assessment.

\section{GIS Mapping}

The first component includes a geographic information system (GIS) is used to map the social and economic characteristics of blocks along with the locations of greens spaces and outdoor recreational opportunities. These maps provide a geographic snapshot of the city. They are also analyzed for geographic patterns between demographics and the locations of the parks and open spaces.

\section{Statistical Analysis}

The second component of the analysis incorporates the statistical test performed in the study by Tarrant and Cordell (1999). The authors compared the social and economic characteristics of census tracts within 1,500 meters of an outdoor recreation site with census tracts more than 1,500 meters from a site. Logit regression in SPSS was used, which predicts a dichotomous dependent variable (outdoor recreation site) from a set of independent variables (social and economic characteristics of census tracts). The model determines the probability that the independent variables can be used to determine the location of the dependent variable. In this study, census blocks are used and their proximity to a park or 
open space. A distance of one-eighth of a mile is modeled, because it was assumed that a neighborhood park should be within a 2 to 3 minute walk from a residence. Because the land area of Providence is so small (11,800 acres), almost the entire city is within one quarter of a mile of a park or open space.

\section{Access and Quality Assessment}

The final component of this study examines the quality of parks and open spaces in the city. Each park in the City of Providence was visited to examine opportunities to have contact with nature and their overall maintenance, which was coded for GIS application. To assess the quality of parks, a checklist was developed. Based on the Portland field assessment, there were four steps. The first step involved identifying if the problem occurred in the park or park feature. Areas addressed are paved surfaces, play equipment, irrigation, paths and the presence of natural features. Second, the extent or range of the problem was defined by one of five letter ratings described below:

- A - Problem does not occur in the park or feature, 4 points

- B - Problem occurs in less than one-third of the park or the particular feature, 3 points

- C - Problem occurs in one-third to two-thirds of the park or the particular feature, 2 points

- D - Widespread problem that is present throughout the park or the particular feature, 1 point

- NF - Feature is not found in park, no points

Step three required totaling the letter ratings for each feature by calculating the number of points for each letter received by each park. The total scores are compared to determine the median score, highest score and lowest score. The rankings were then grouped into quartiles and shown geographically. The final step was to make notes or comments of unusual circumstances.

The ranked parks were also examined for relationships with social and economic data, specifically, if deteriorated parks and parks with little access to nature were more likely to be 
found in poor and minority areas. The same regression model used in the statistical analysis of park size is applied.

\section{Data and Collection}

Data is available from a variety of sources, including released data from the 2000 US Census. Independent variables for social and economic characteristics used in the GIS application and regression model analysis are:

- Population count

- Race and ethnicity: non-white, non-Hispanic white, Hispanic

- Housing tenure: rental, owner-occupied

- Single parent-headed households with children under 18; female-headed household with children under 18 and no husband present

- Size of household

- Children under age 18

Providence Plan provided this data based on the 2000 US Census. Dependent variables include open space and outdoor recreational opportunities. These sites included those managed by the city, such as designated parks, playgrounds, basketball courts, baseball and multi-use fields, and tot lots. Additional open spaces that are part of the analysis were the State House lawn and Swan Point Cemetery. These areas are not municipally maintained but are used by the public for active and passive recreation. Providence Plan and the City of Providence also provided GIS data for the dependent variables. 


\section{ANALYSIS AND FINDINGS}

The following demographic profile is compiled from 2000 US Census data synthesized by Providence Plan. The discussion summarizes the overall findings, accompanied by maps that show details of census blocks.

\section{City Snapshot}

\section{Physical Environment}

Providence is a small urban environment with dense residential areas combined mixed uses, commercial and industrial areas, institutions and developed recreational space (Map 1). Water features within the city include rivers and ponds. There are few wooded areas. The Providence River is a working waterfront with oil storage and various industrial and commercial activities. The Providence River opens into Narragansett Bay just south of the city.

The total land area of the city is approximately 11,800 acres. There are over 100 parks and open spaces under the administration of the city, which includes playground, schools, recreation centers, and indoor and outdoor swimming pools (Map 2). In this study, schools without playgrounds or fields and recreation centers without outdoor facilities are not included in the analysis. When the area of each park is calculated, building footprints, parking, and so forth are not subtracted. For example, the entire lot that houses the Davey Lopes Recreation Center, Pool and Playground totals approximately 93,000 square feet and that number is used instead of just the portion where the playground is located. Swan Point Cemetery, a private cemetery, and the State House Lawn are added to the list, so a total of 136 parks and open spaces are analyzed, encompassing approximately 1,200 acres. These areas constitute an estimated 10 percent of the city's total land area, or about 7.3 acres of parks and open space per 1,000 residents (population 173,618). National standards recommend 6 to 10 acres per 1,000 residents. 


\section{Map 1: Land Uses, Providence, RI, 1998}

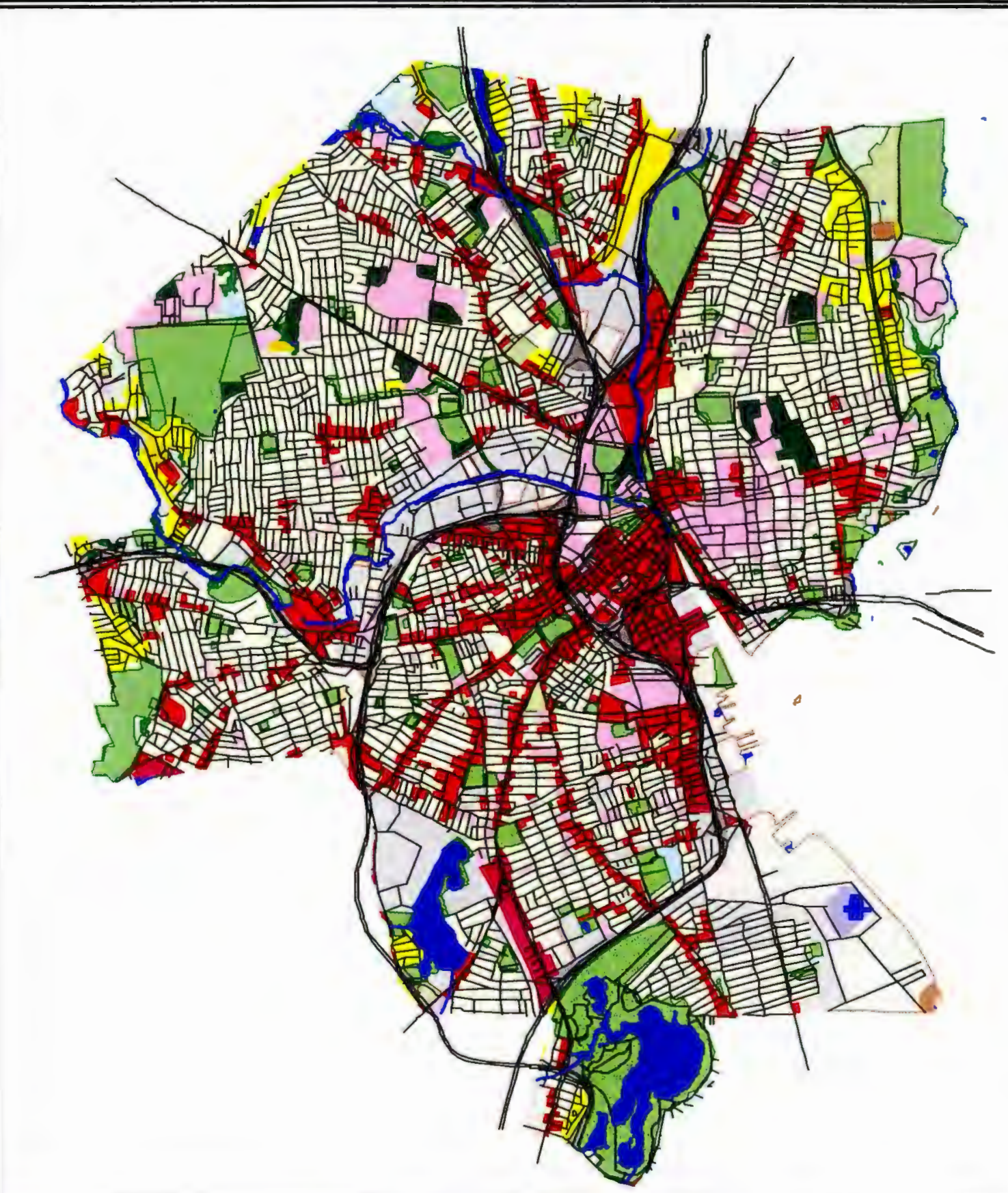

Water Features Land Uses

Res: High Density

Res: Med-High Den

Res: Med Density

Commercial

Industrial

Roads

Railroads

Water and Sewer $\wedge$ Roads

City Parks and Open Spaca

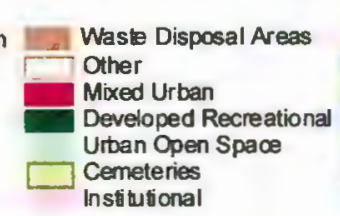

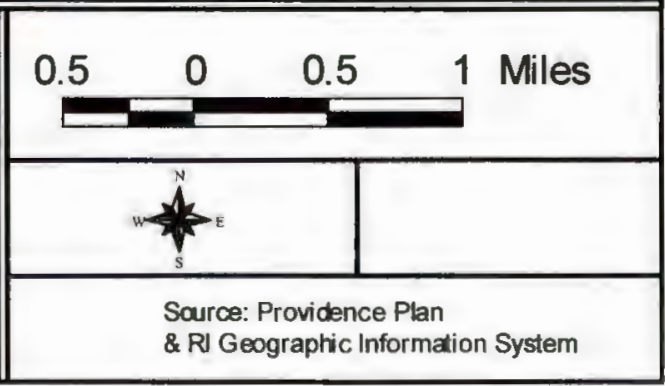




\section{Map 2: City Parks and Open Space, Providence, RI, 2000}

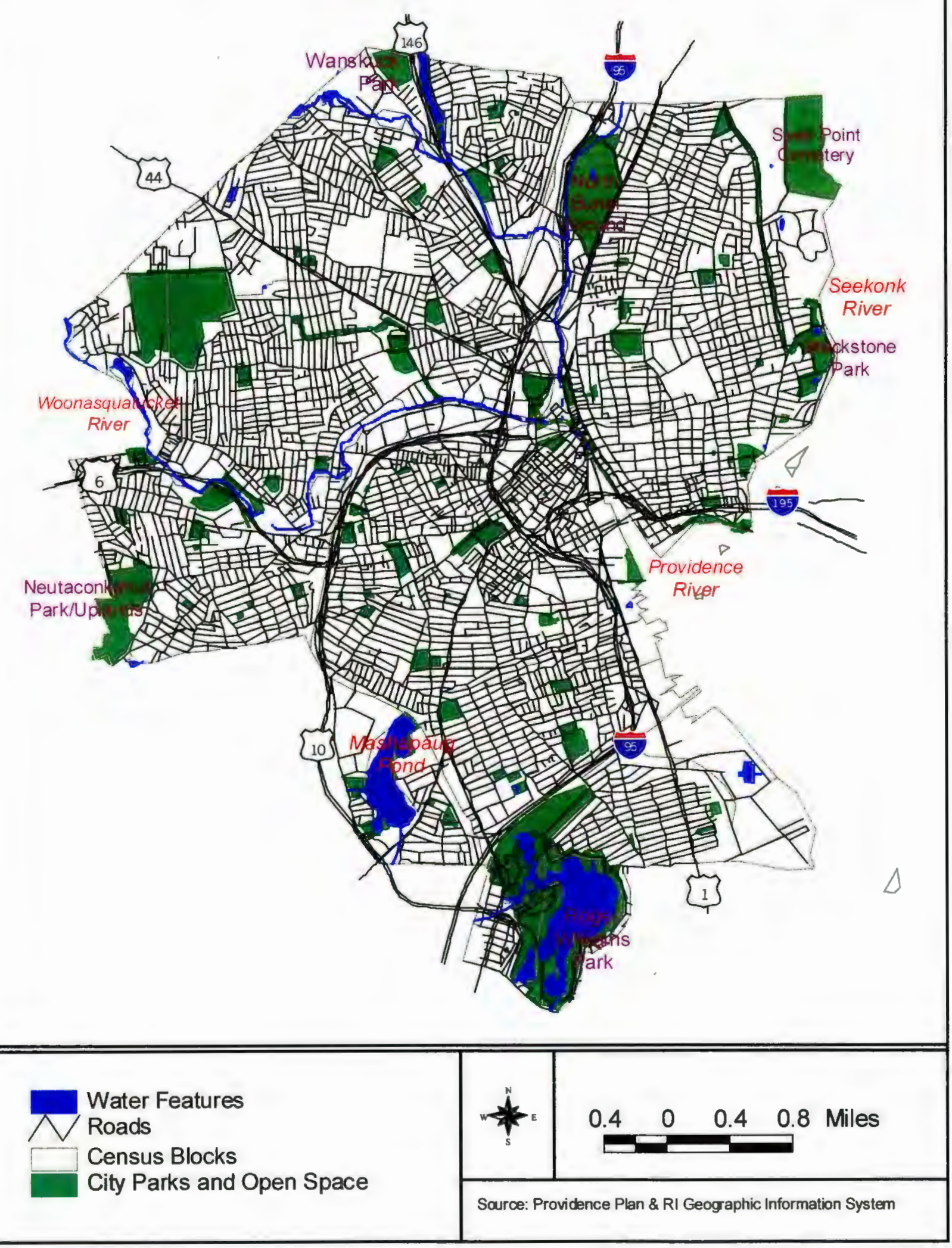


Compared to other cities, Providence is a small city with a population density of 14.7 persons per acre. Harnik (2000) reports on the park resources of central cities of the largest metropolitan areas in the country (Table 1). Of course Providence does not compare in land area or population size, but the ratio of parks per 1,000 residents is interesting. For example, of high-density central cities that have 7 acres of parks and open spaces per 1,000 residents like Providence are Baltimore (13.1 persons per acre), Philadelphia (17.1 persons per acre), and New York (37.3 persons per acre). Boston, with 18 persons per acre, has 8.7 acres of parks and open space per 1,000 residents. Medium density cities such as Portland, Oregon (6 persons per acre) and Pittsburgh (9.8 persons per acre), acres of parks and open space per 1,000 residents are calculated to be 26.2 and 7.8 , respectively. Providence seems to be doing well overall in providing park space compared to other areas around the country; however, it is important to remember that this study includes some structures in its parks and open space calculation. 
Table 1. Central cities of the largest metropolitan areas in US, ranked population density and comparing acres of parks and open spaces per 1,000 residents.

\begin{tabular}{|c|c|c|c|c|c|}
\hline City & $\begin{array}{r}\text { Area } \\
\text { (acres) }\end{array}$ & $\begin{array}{r}\text { Population } \\
\text { (1990) }\end{array}$ & $\begin{array}{r}\text { Total acreage of } \\
\text { parks \& open spaces } \\
\text { within city }\end{array}$ & $\begin{array}{r}\text { Persons per } \\
\text { acre }\end{array}$ & $\begin{array}{r}\text { Acres of parks } \& \\
\text { open space per } \\
1,000 \text { residents }\end{array}$ \\
\hline \multicolumn{6}{|c|}{ High-density Population } \\
\hline New York & 197,696 & $7,381,000$ & 52,938 & 37.3 & 7.2 \\
\hline San Francisco & 29,888 & 735,000 & 7,594 & 24.6 & 10.3 \\
\hline Chicago & 145,408 & $2,722,000$ & 11,629 & 18.7 & 4.3 \\
\hline Boston & 30,976 & 558,000 & 4,865 & 18.0 & 8.7 \\
\hline Philadelphia & 86,464 & $1,478,000$ & 10,685 & 17.1 & 72 \\
\hline Miami & 22,784 & 365,000 & 1,329 & 16.0 & 3.6 \\
\hline Baltimore & 51,712 & 675,000 & 5,091 & 13.1 & 7.5 \\
\hline Los Angeles & 300,352 & $3,554,000$ & 30,121 & 11.8 & 8.5 \\
\hline \multicolumn{6}{|c|}{ Medium-density Population } \\
\hline Detroit & 88,768 & $1,000,000$ & 5,890 & 11.3 & 5.9 \\
\hline Minneapolis & 35,156 & 359,000 & 5,694 & 10.2 & 16.0 \\
\hline Cleveland & 49,280 & 498,000 & 2,887 & 10.1 & 5.8 \\
\hline Pittsburgh & 35,584 & 350,000 & 2,735 & 9.8 & 7.8 \\
\hline Seattle & 53,696 & 525,000 & 6,194 & 9.8 & 11.8 \\
\hline St. Louis & 39,616 & 352,000 & 3,385 & 8.9 & 9.6 \\
\hline Cincinnati & 49,408 & 346,000 & 7,391 & 7.0 & 21.4 \\
\hline Portland, OR & 79,808 & 481,000 & 12,591 & 6.0 & 26.2 \\
\hline \multicolumn{6}{|c|}{ Low-densify Population } \\
\hline San Diego & 307,360 & $1,171,000$ & 36,501 & 5.6 & 31.5 \\
\hline Denver & 98,112 & 497,000 & 5,643 & 5.1 & 11.4 \\
\hline Houston & 345,536 & $1,744,000$ & 21,790 & 5.0 & 12.5 \\
\hline Dallas & 218,880 & $1,053,000$ & 21,828 & 4.8 & 21.3 \\
\hline Atlanta & 84,352 & 402,000 & 3,147 & 4.8 & 7.8 \\
\hline Phoenix & 268,736 & $1,159,000$ & 36,501 & 4.3 & 31.5 \\
\hline Tampa & 69,568 & 286,000 & 3,090 & 4.1 & 10.8 \\
\hline Indianapolis & 231,488 & 747,000 & 13,239 & 3.2 & 17.7 \\
\hline Kansas City, MO & 199,360 & 447,000 & 13,329 & 2.2 & 30.2 \\
\hline
\end{tabular}

Inside City Parks "Table 3. City Population Density (Persons Per Acre)" and "Table 5. Parks and Open Space per 1,000 residents" (2000) 


\section{Demographics}

The following discussion describes Providence based on the social and economic variables used in this study. Key factors that are being analyzed are the percentages of minority populations, children under the age of 18 , household composition and housing tenure. The hypothesis is that these variables will indicate accessibility to quality parks and open space. The demographics of an area should influence the development and maintenance of functional and usable parks.

\section{Citywide}

The 2000 US Census shows many changes in the City of Providence since 1990. It became the second largest city in New England with a population of 173,618. As Figure 1 shows, a majority of the city's population is "minority." The non-Hispanic white population accounts for less than half of the city's total population. Fifty-four percent of city's residents describe themselves as Hispanic or a race other than white (Maps 3). The Hispanic population increased more than 100 percent since 1990 to nearly one third of the population. Figure 2 shows the breakdown of city's Hispanic population (Maps 4 and 5). More than 75 percent of the city's population under the age of 18 is "minority" and almost 50 percent is Hispanic, shown in Figure 3. Children under 18 years make up nearly one quarter (26\%) of the city's total population (Map 6). Children are an important aspect of this study since they are a primary user group of parks and open spaces. Development of recreational spaces must consider the location of this population. The needs of the growing Hispanic population must also be a part of park development. 


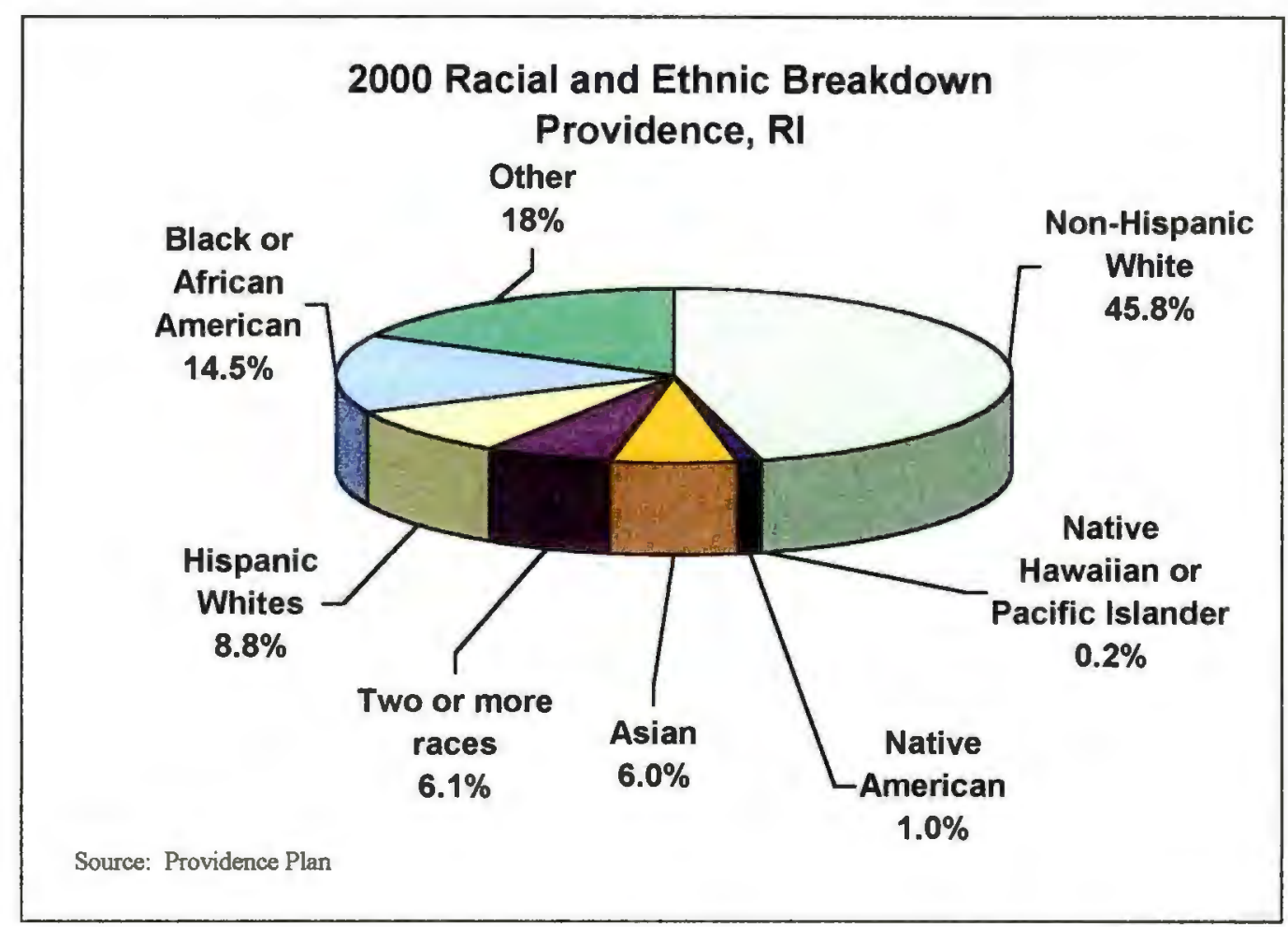

Figure 1. Race and ethnicity breakdown from the 2000 Census for Providence, RI.

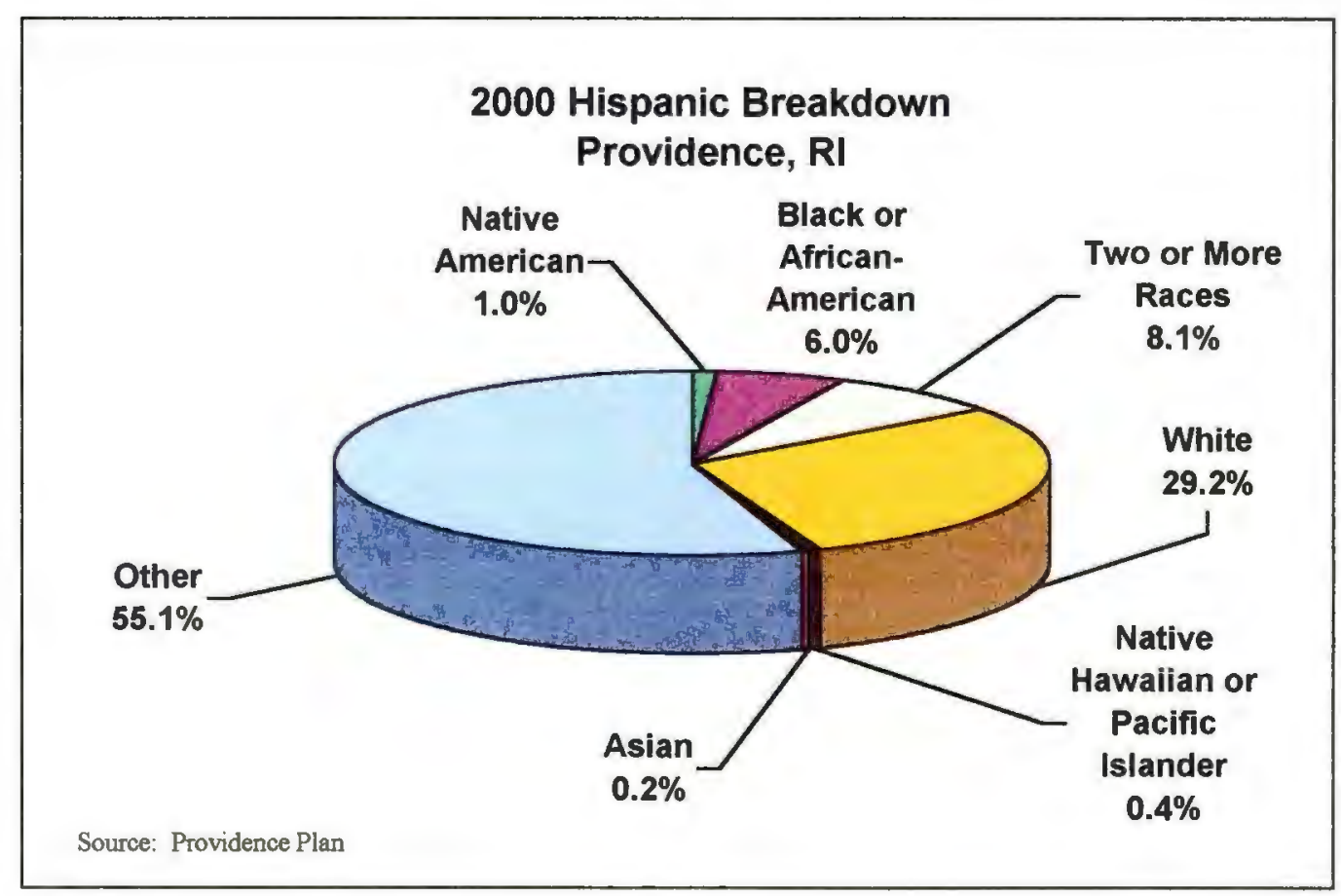

Figure 2. Hispanic population breakdown from the 2000 Census for Providence, RI. 


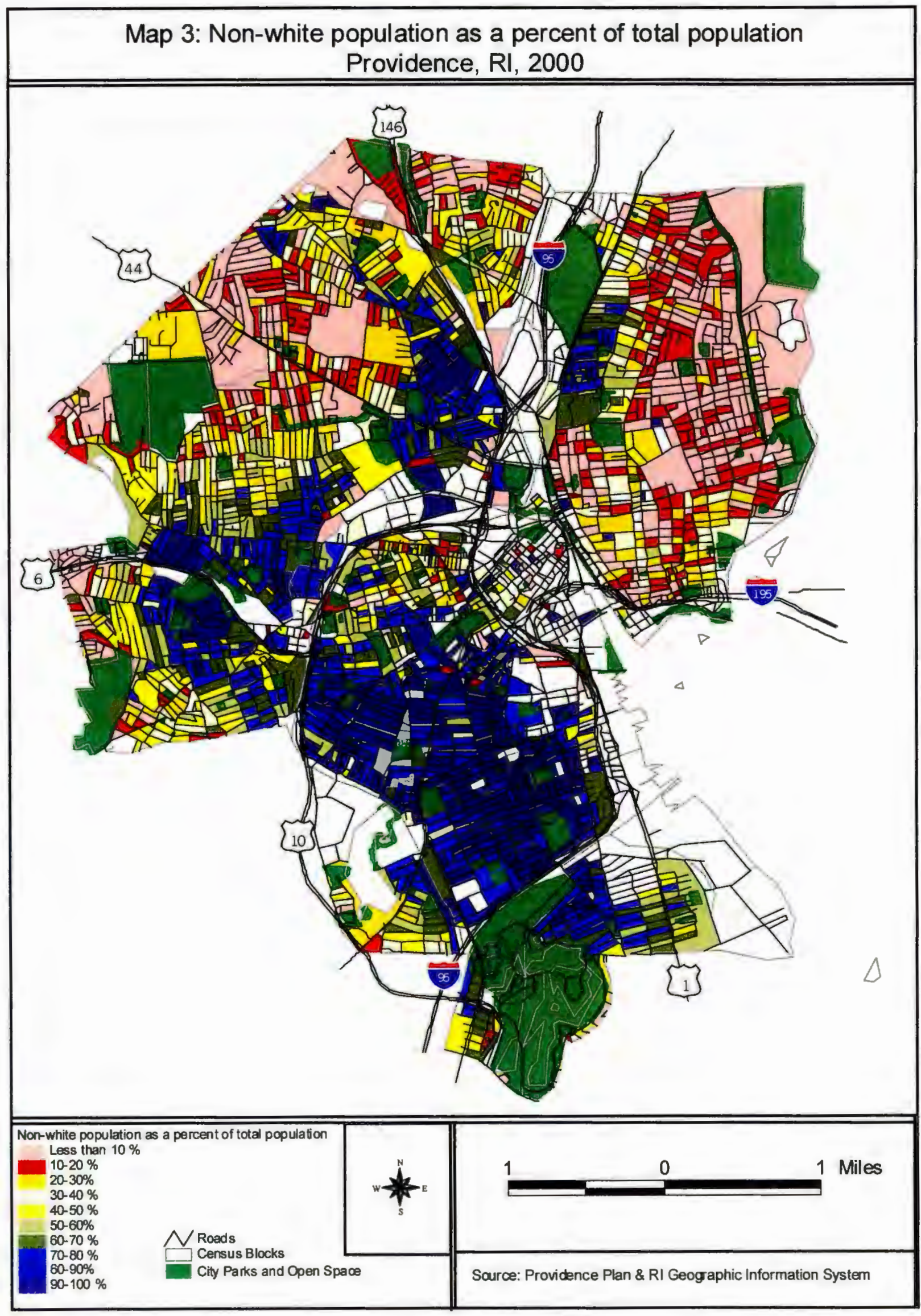


Map 4: Non-Hispanic White Population as a Percent of Total Population Providence, RI, 2000

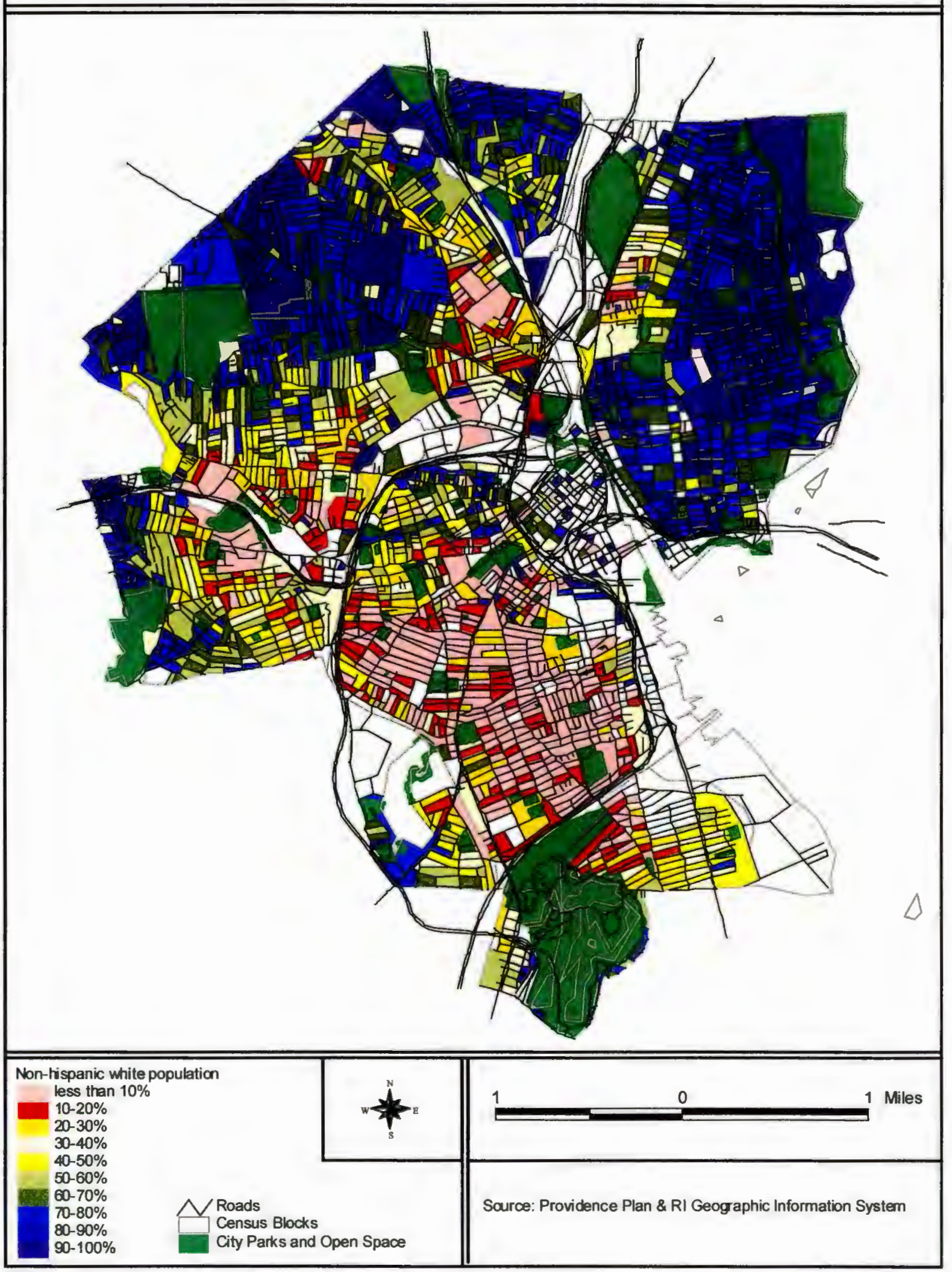


Map 5: Non-White Hispanic Population as a Percent of Total Population Providence, RI, 2000

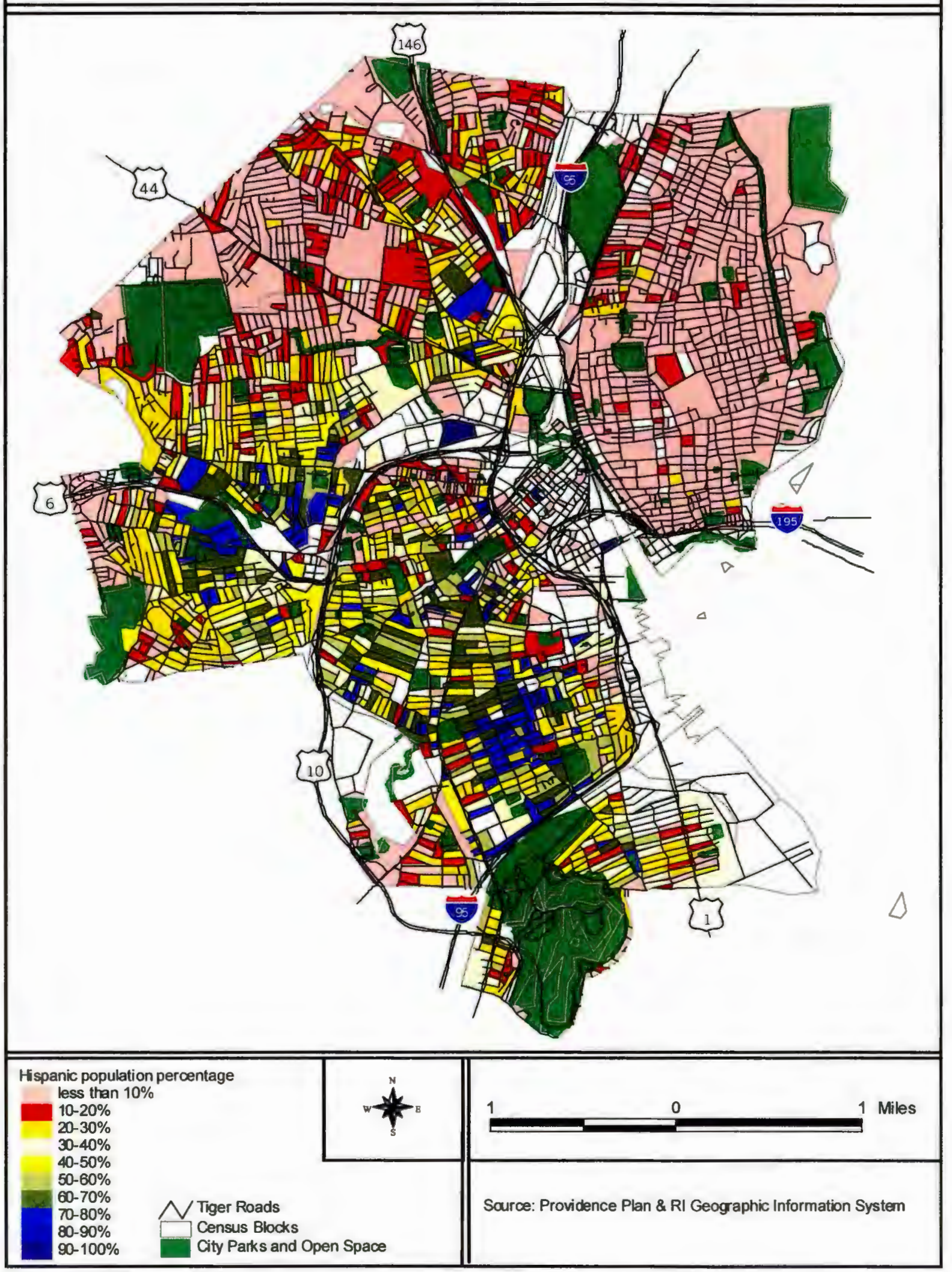


Map 6: Population Under 18 Years as a Percent of the Total Population Providence, RI, 2000

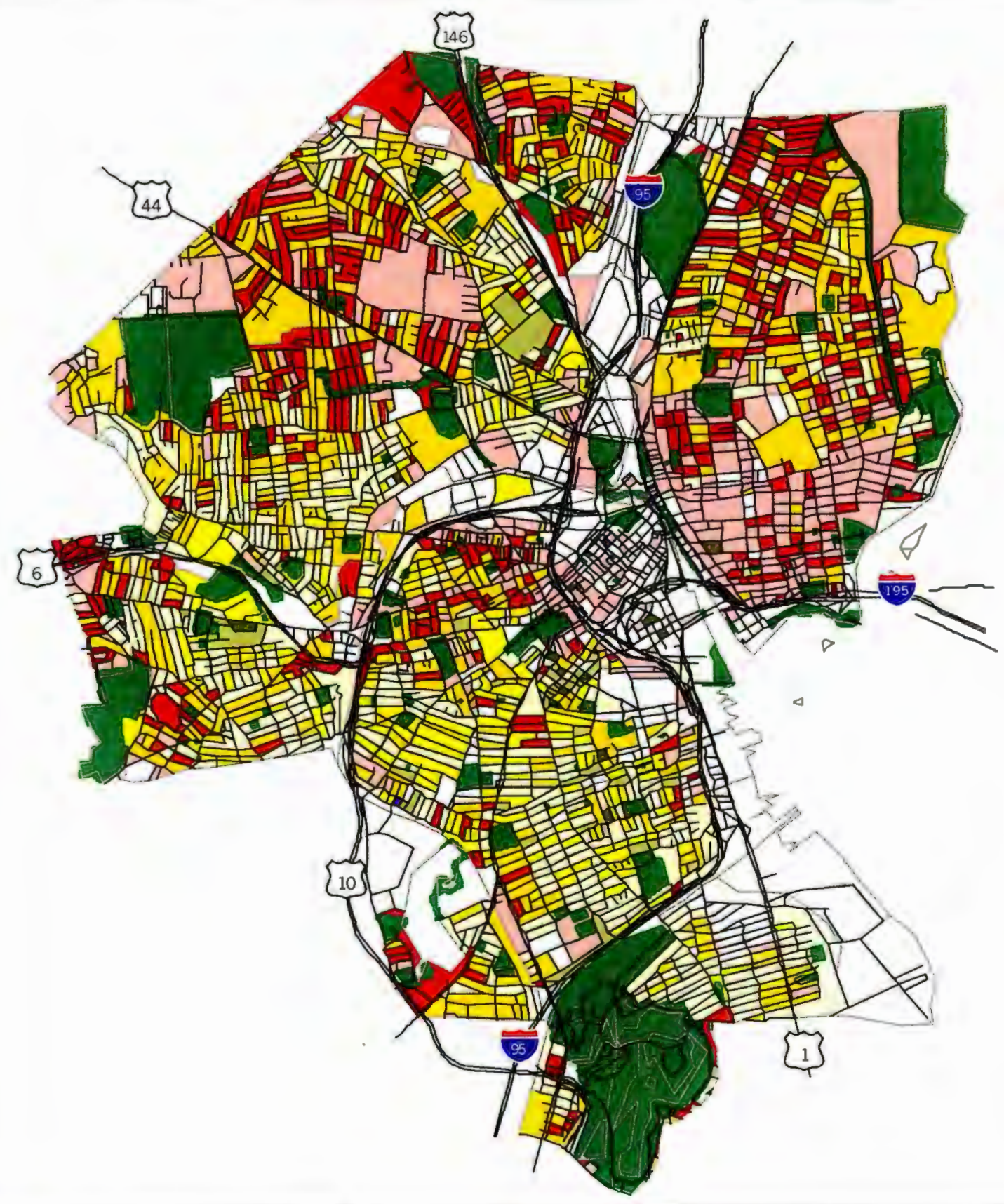

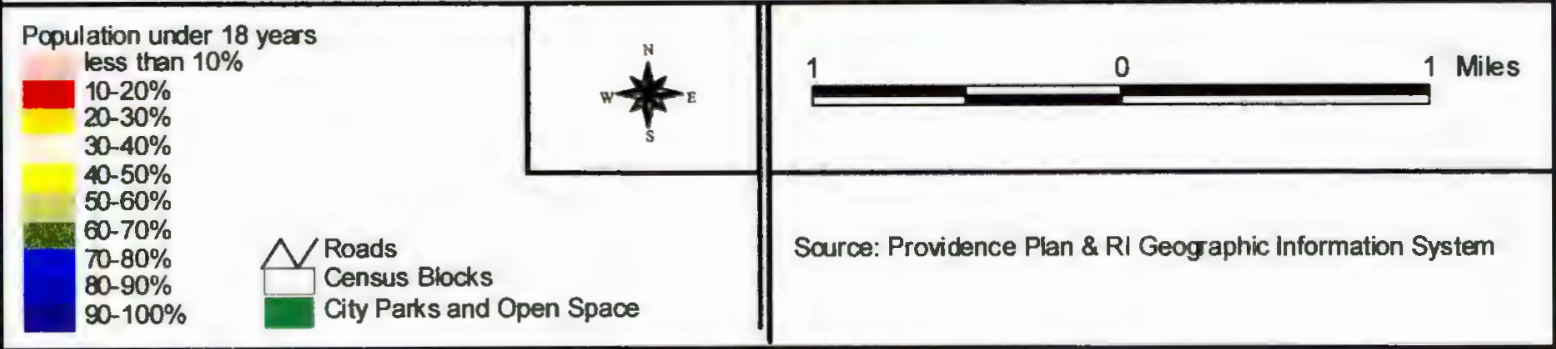




\section{Racial and Ethnic Breakdown \\ Population under age 18 \\ Providence, RI}

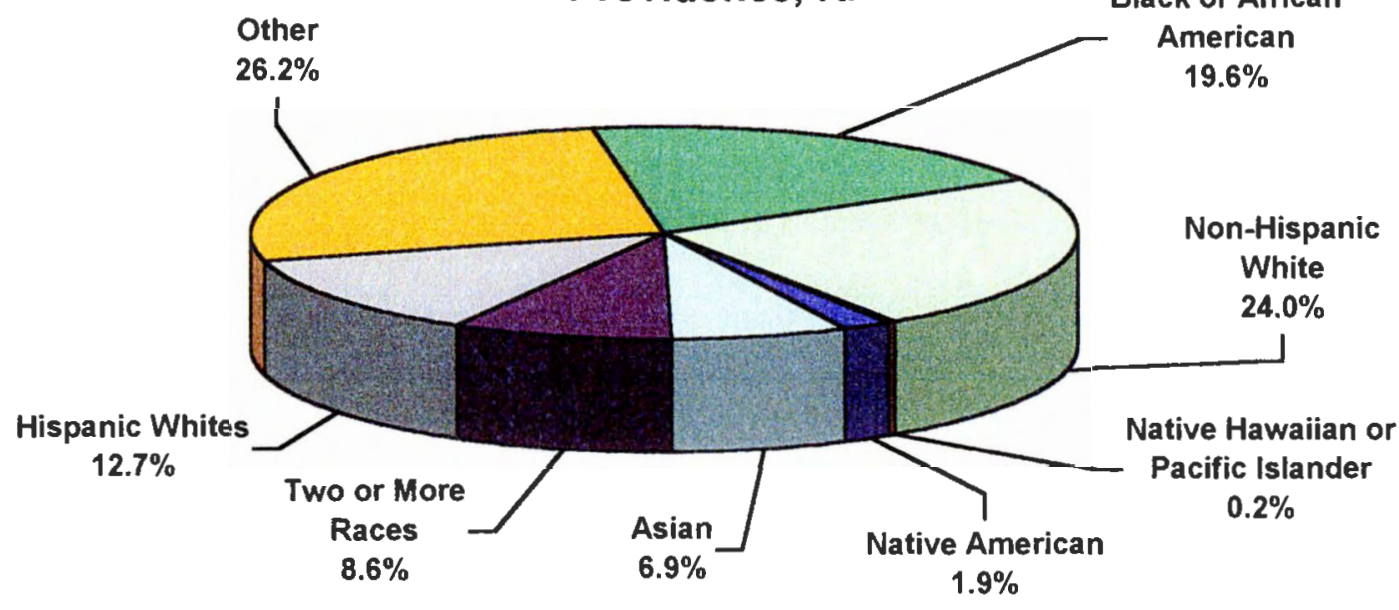

Source: Providence Plan

Figure 3. Race and ethnic breakdown for population under 18 from 2000 Census for Providence, RI

The 2000 census indicates that 91.8 percent of the 67,915 housing units in Providence were occupied. Of those occupied, 34.6 percent are owner-occupied units and 65.4 percent were rental units. Having a majority of rental units infers most of those living within these census blocks have less private space and rely more on public open space. There are 62,389 total households in the city. Of that total, 35.5 percent are households with persons under the age of 18 .

At the time this paper was written, the US Census had not released economic data such as median income, poverty rates or employment status. Therefore, indicators of economic status in an urban area are used collectively to obtain a snapshot: average household size, single-family households with children under age 18, female-headed household with no husband and children present, and Hispanic population. I assume that these variables would identify lower-income areas of the city. There are over 11,000 households $(18.5 \%)$ with single parents and children under age 18 (Map 7). Approximately 15 percent of total households in the city are female-headed with children under the age of 18 and no husband present (Map 8). Household sizes identify dense areas, such as the western and southern 
portions of the city (Map 9 and 10). Based on the data presented, the lower income minority areas are found in the western and southern portions of the city. It is anticipated that these areas will have fewer, lower quality parks and open spaces.

Census blocks are the unit of analysis for this study. According to Providence Plan, the city contains 2,789 blocks, of which, 2,143 are populated. Using geographic information system (GIS), blocks are divided into three categories for comparison: those with parks or open space, those within 660 feet of a park or open space and those more than 660 feet of a park or open space. 
Map 7: Single-parent Households with Children Under Age 18 as a Percent of Total Households

Providence, RI, 2000

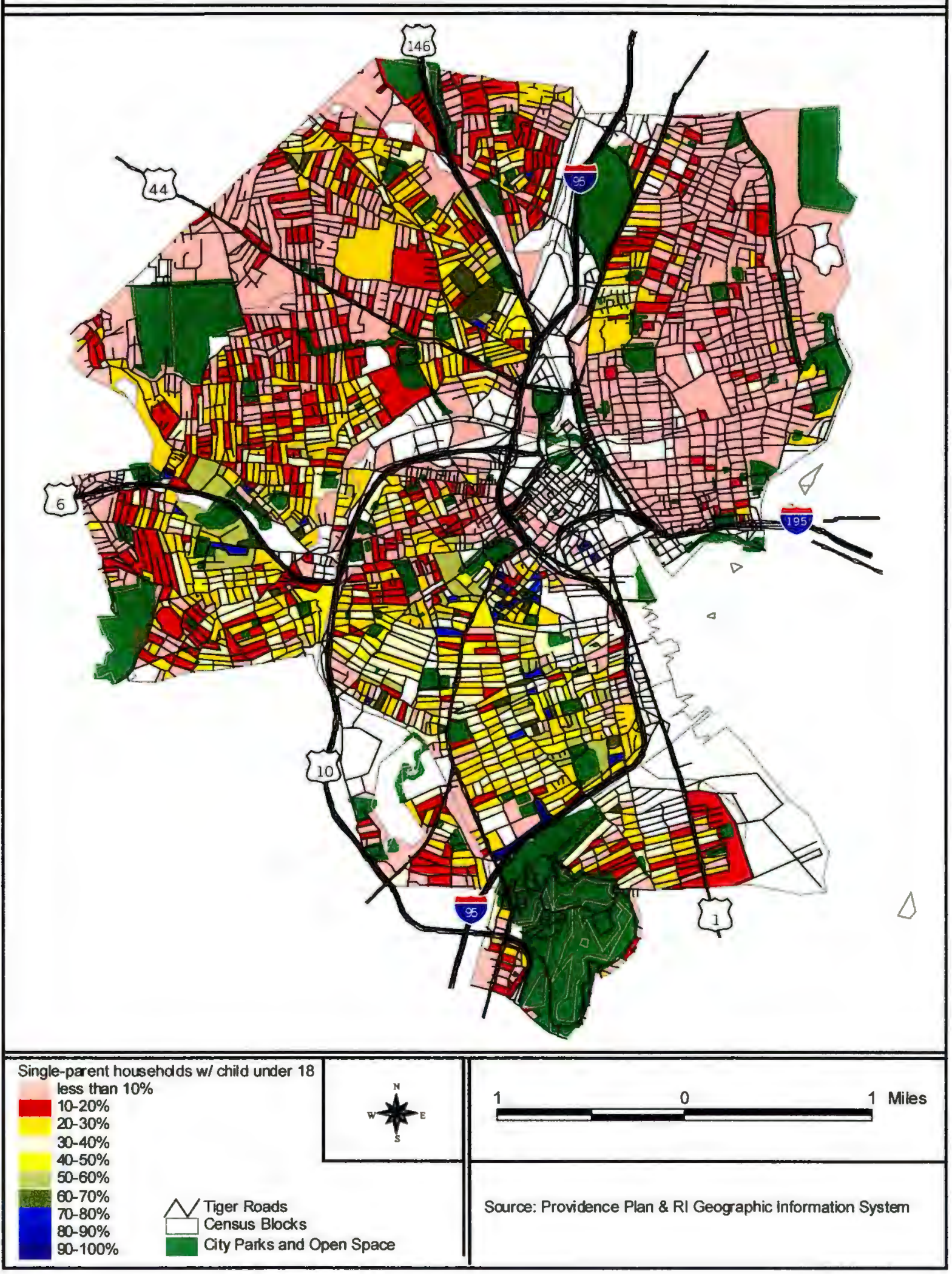


Map 8: Female-headed Households with children under 18 and no husband present as a percent of total households, Providence, RI, 2000

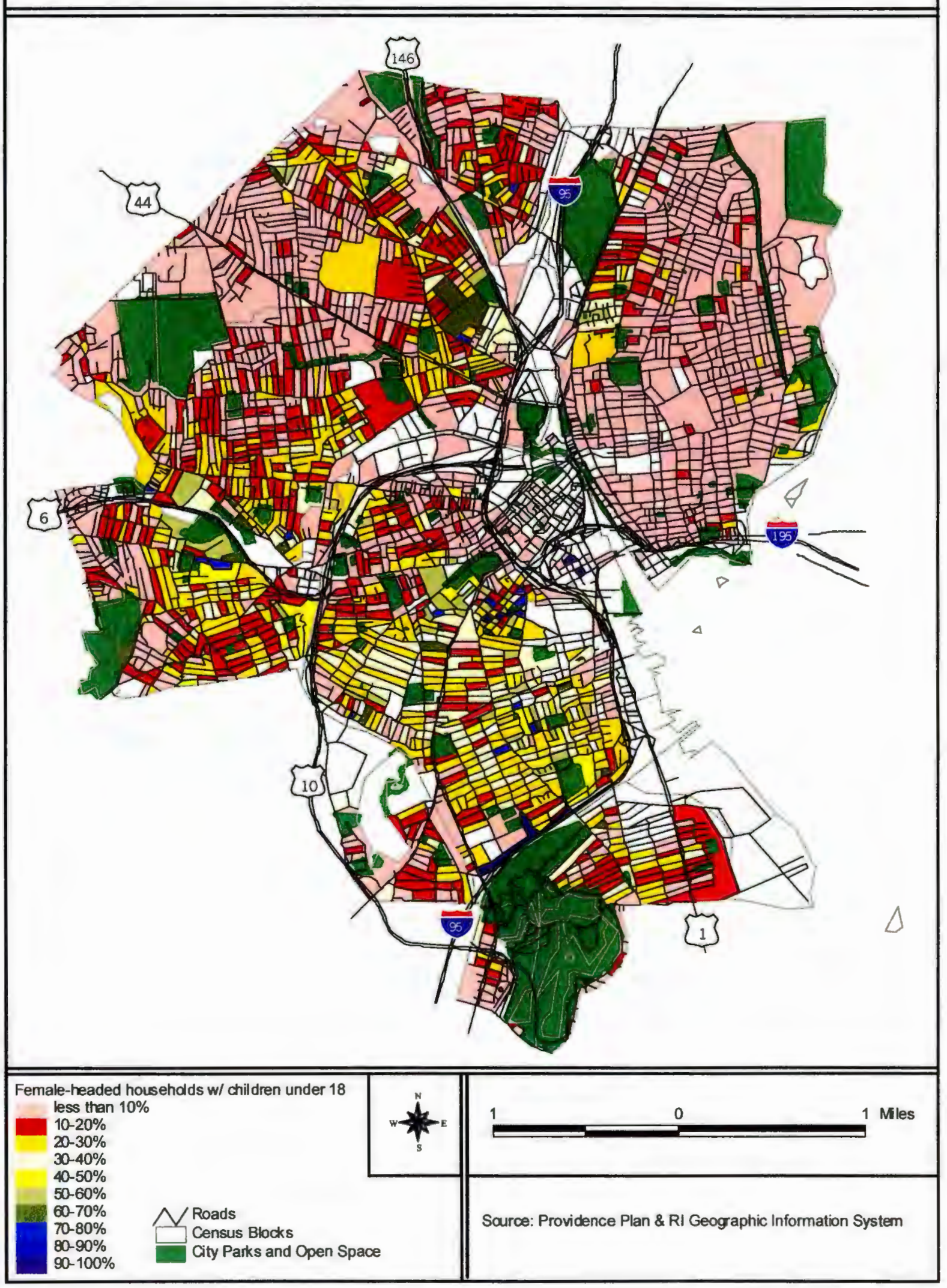


Map 9: Average households size for non-Hispanic white population Providence, RI, 2000

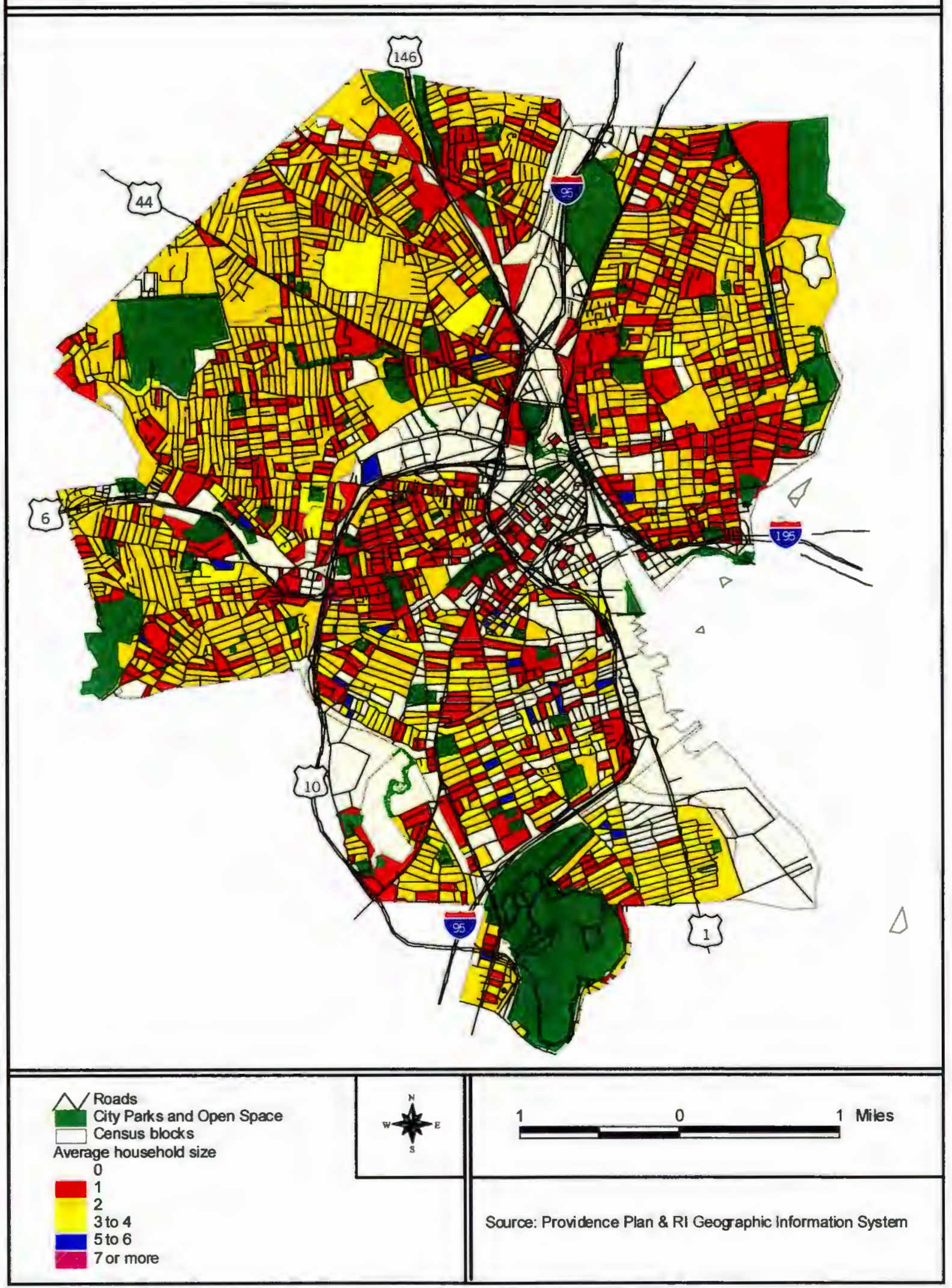




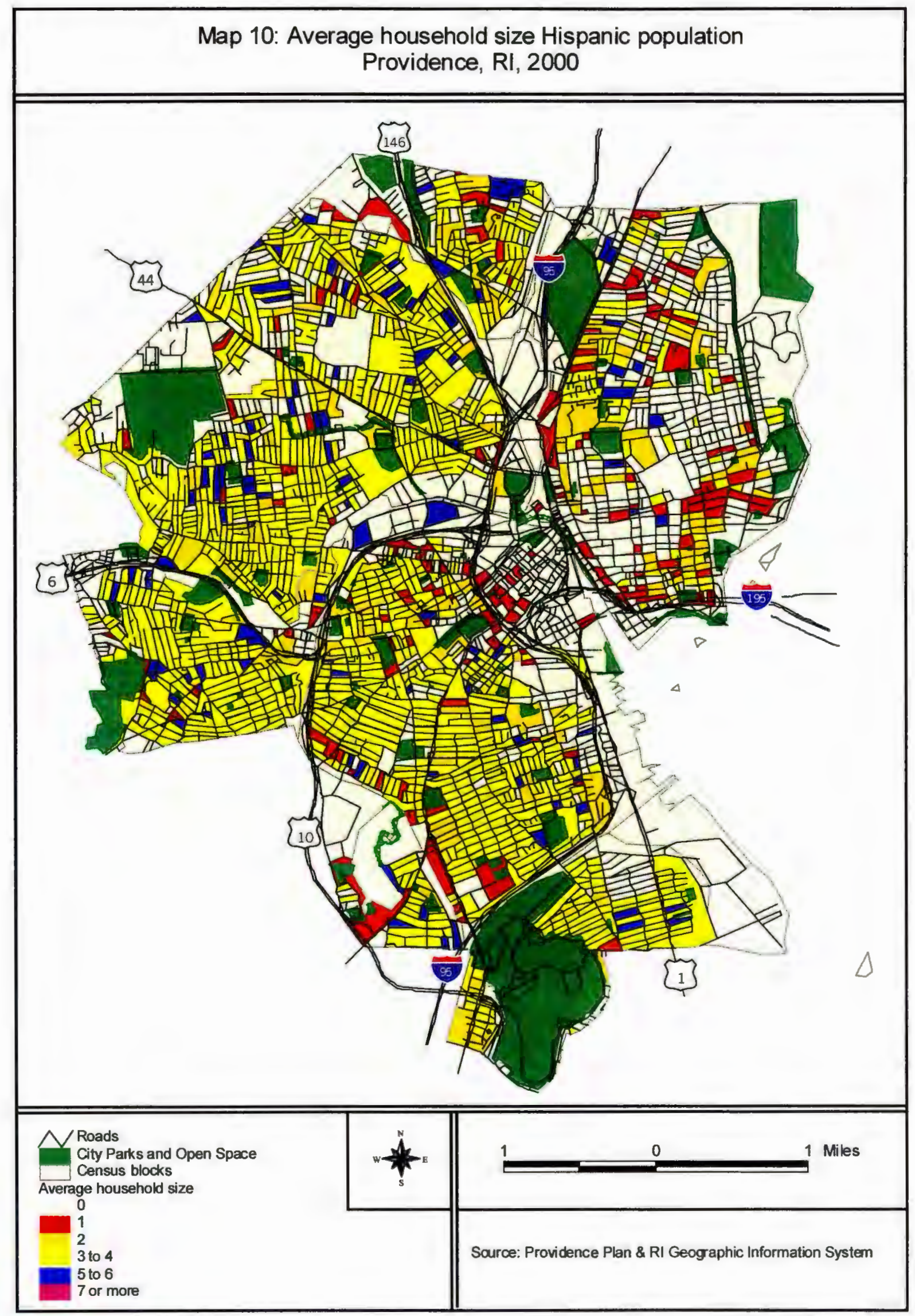




\section{Census Blocks with Parks or Open Space}

There are 457 blocks that contained a park or open space (Map 11). It should be noted that there are few parks and open spaces identified in the map that are not aligned exactly with the coordinating census block and a small portion of the park may be located across the street. Although the blocks across the street are incorporated into the following summary, it is not significant in that the park is very close. Table 2 shows the demographics of this grouping of census blocks. These blocks contain about 15 percent of the city's total residents as well as children under age 18 (Map 12). The percentages of the other demographic subjects are similar (Maps 13 through 15). The ratio of non-white and non-Hispanic populations reflect that of the city, where the minority is the majority. Most of the occupied housing in this grouping of census blocks is rental (64.6\%). Twenty percent of the total households are headed by single parents with children under age 18. Female-headed households with children under age 18 and no husband present comprise 18 percent of total households.

Table 2. Census blocks with parks: Selected demographic subjects.

\begin{tabular}{|l|c|c|c|}
\hline Subject & Count & $\begin{array}{c}\text { As a percent of } \\
\text { grouping total }\end{array}$ & $\begin{array}{c}\text { As a percent of } \\
\text { City total }\end{array}$ \\
\hline Total population & 28,564 & - & 16.5 \\
\hline Population under 18 years old & 7,816 & 25.8 & 15.6 \\
\hline Race/Ethnicity & & & \\
\hline Hispanic population & 8,820 & 30.5 & 16.1 \\
\hline Non-Hispanic white population & 12,446 & 47 & 16.3 \\
\hline Non-white population & 16118 & 53 & 15.5 \\
\hline & & & \\
\hline Household Composition & & & 16.6 \\
\hline Total households & 10,356 & - & 18.6 \\
\hline $\begin{array}{l}\text { Single-parent households with children under } \\
\text { age 18 }\end{array}$ & 2,147 & 20.7 & 19.1 \\
\hline $\begin{array}{l}\text { Female-headed households, no husband present } \\
\text { with children under 18 }\end{array}$ & 1,873 & 18.0 & \\
\hline & & & \\
\hline Housing Temure & & & 16.6 \\
\hline Occupied units & 10,356 & 91.9 & 16.4 \\
\hline Vacant housing units & 909 & 8.07 & 17.0 \\
\hline Owner-occupied housing units & 3,666 & 35.4 & 16.4 \\
\hline Rental housing units & 6,690 & 64.6 & \\
\hline
\end{tabular}

Source: Providence Plan 


\section{Map 11: Census blocks with a park or open space Providence, RI, 2000}

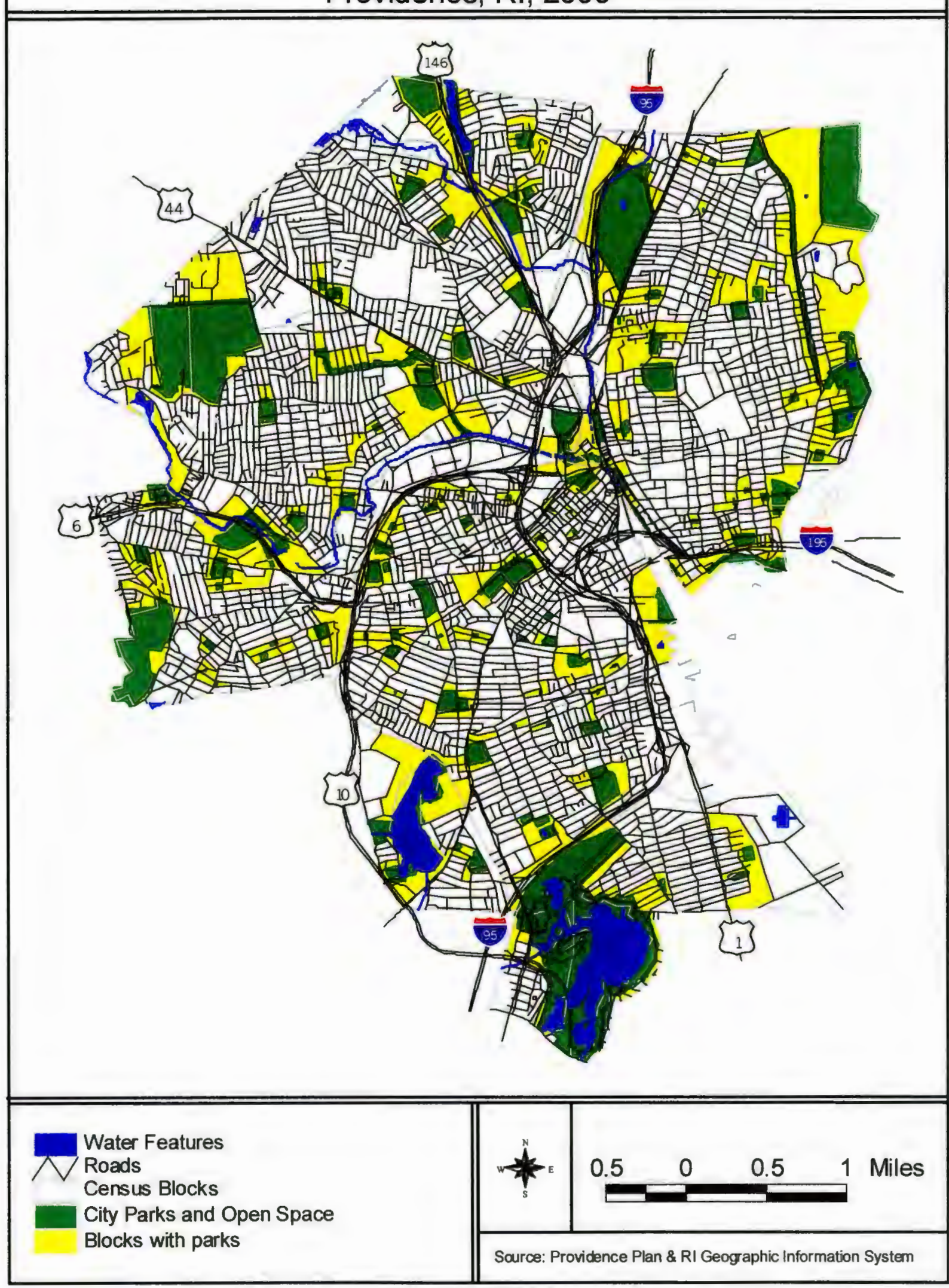




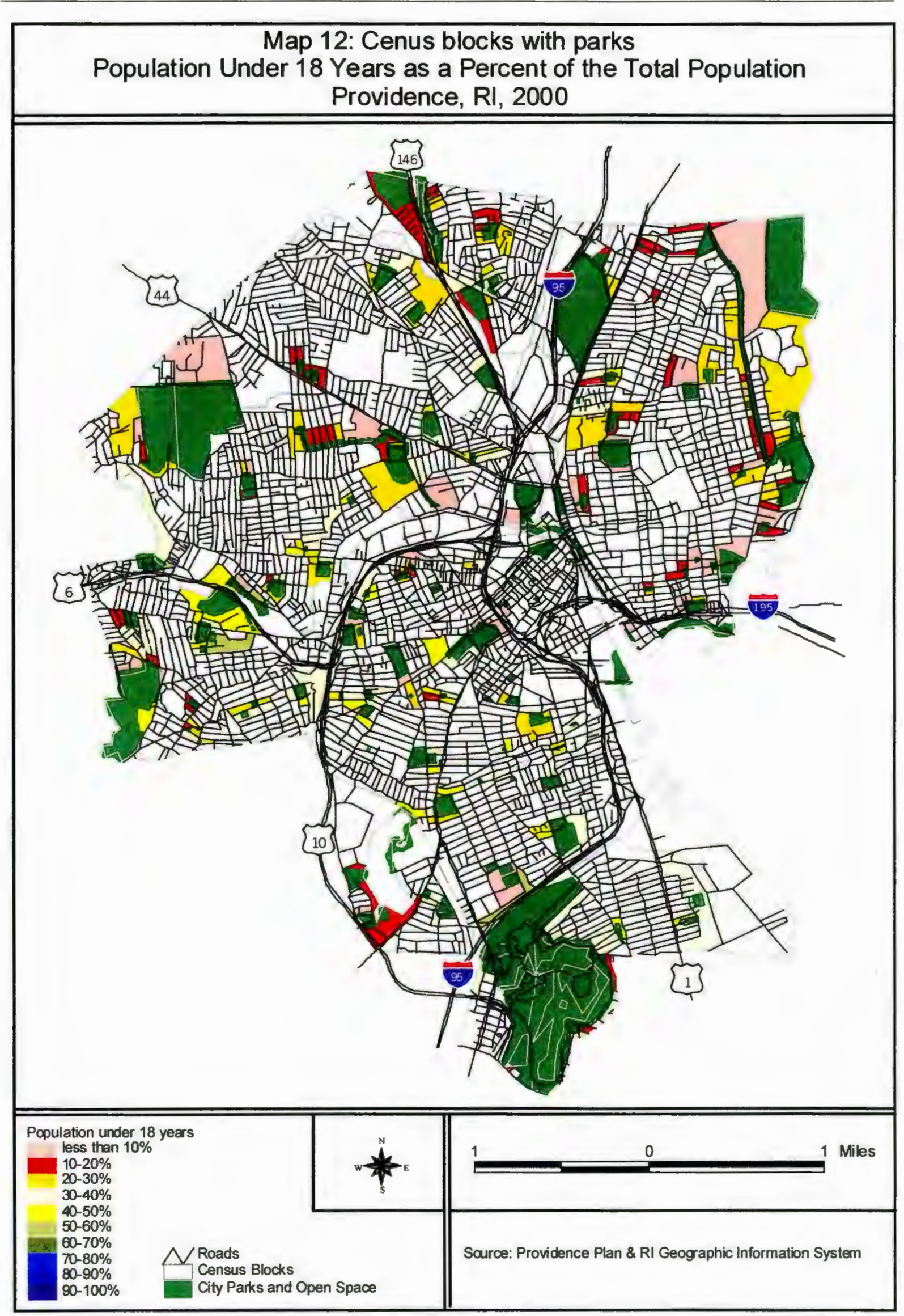




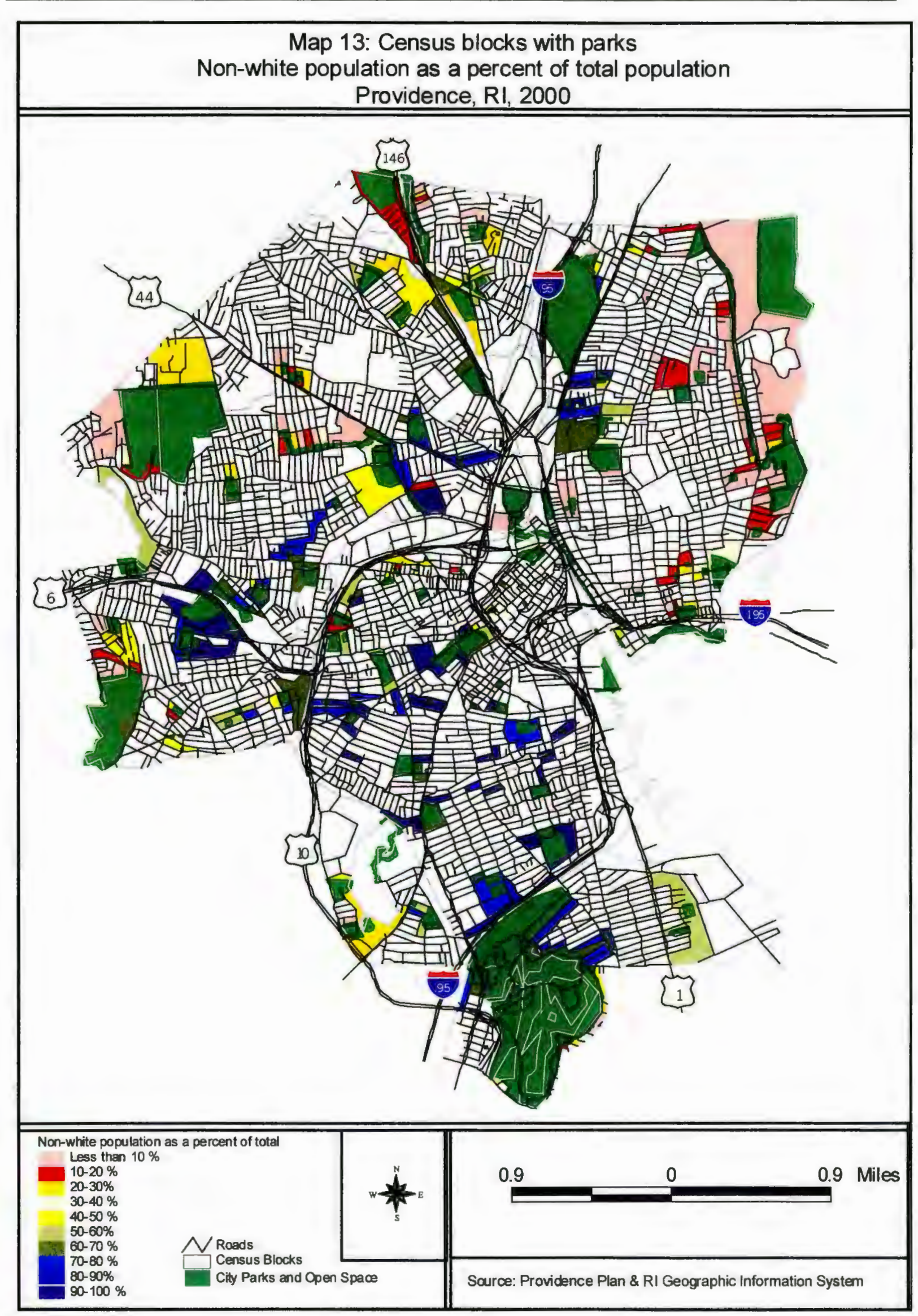




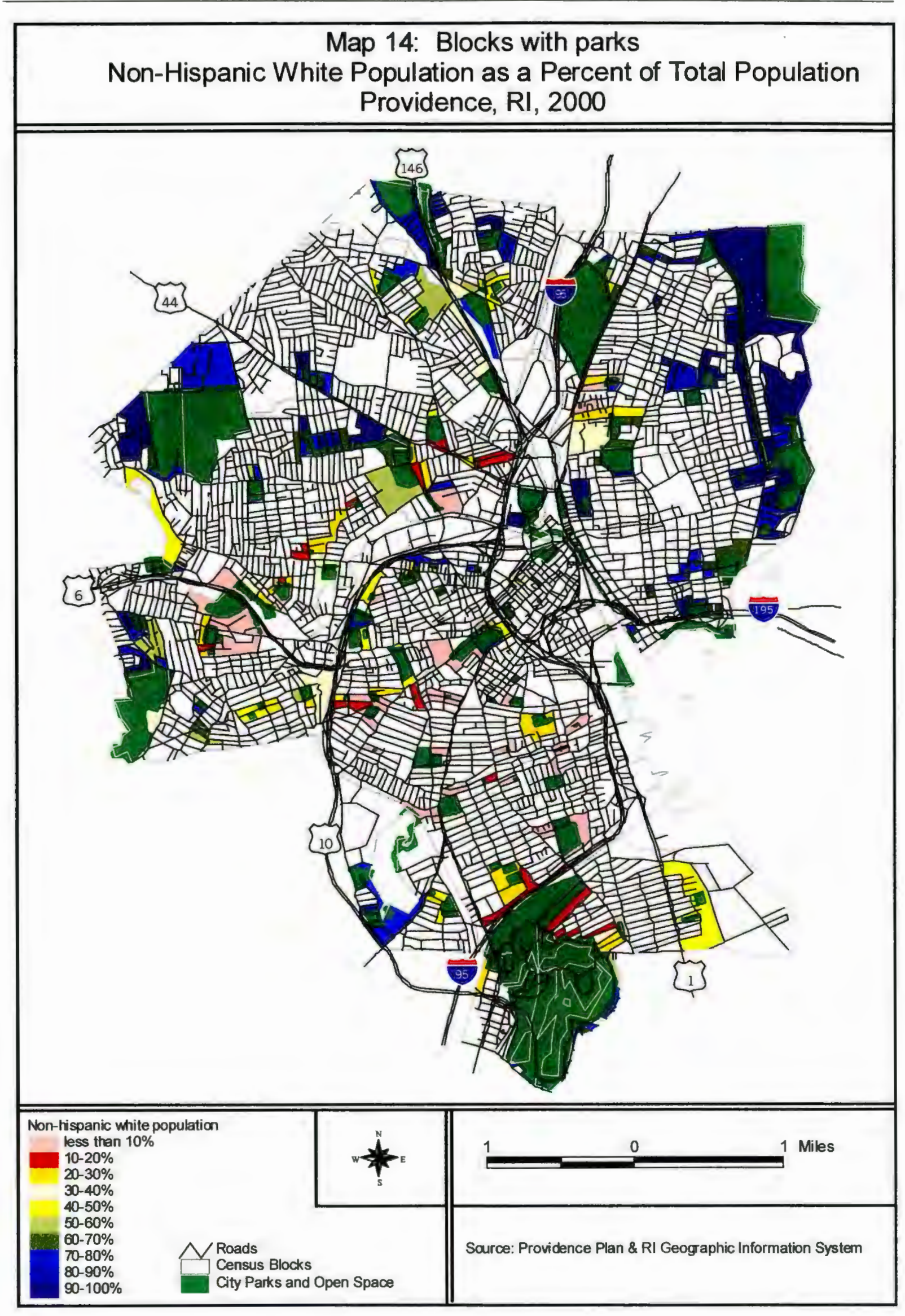




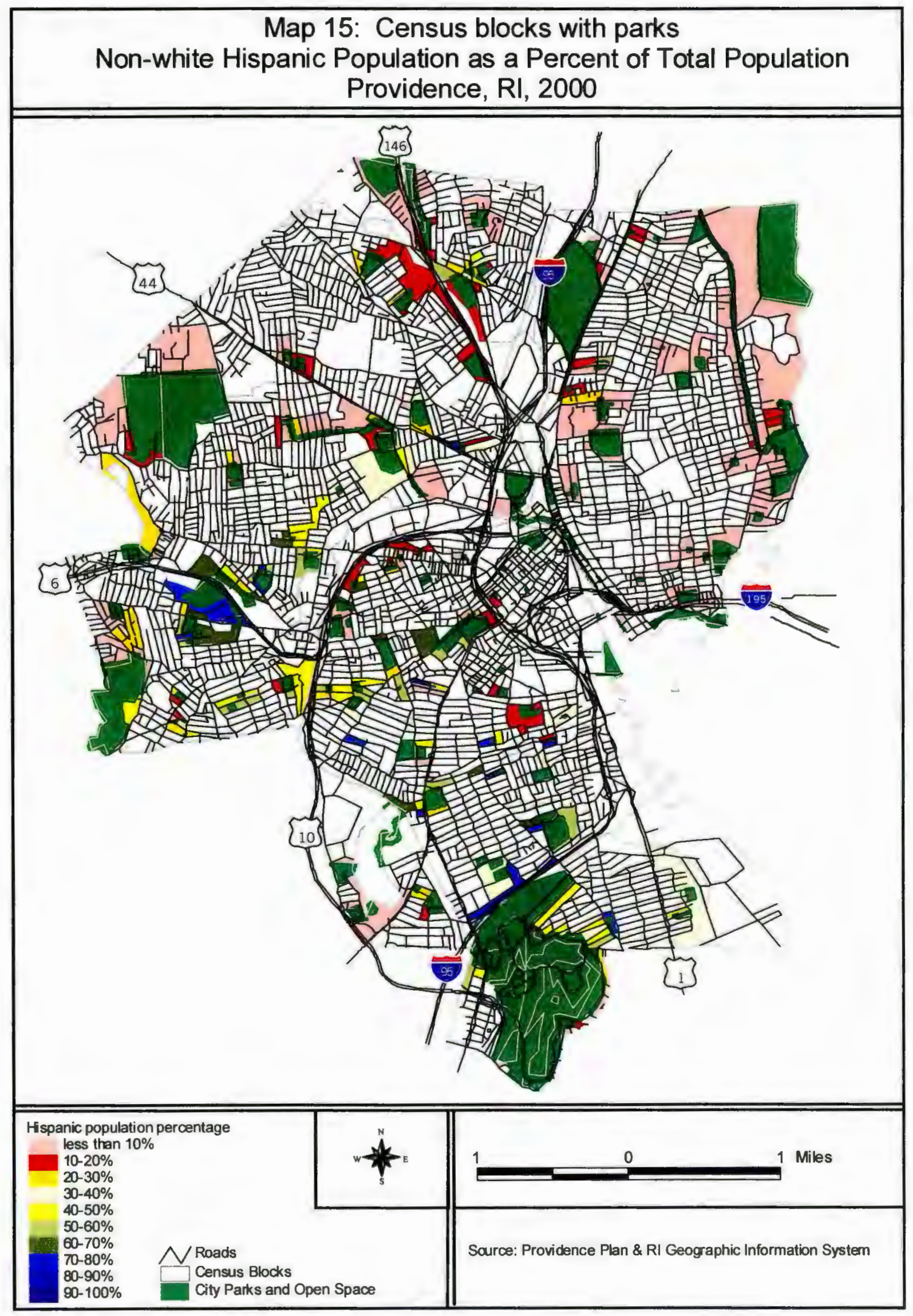


Census blocks within 660 feet of a park or open space

The next group of census blocks is those within 660 feet (1/8 of a mile) of a park or open space (Map 16). This distance is selected based on a 2 to 3 minute walk to a park or open space, indicating a neighborhood place. GIS captured those blocks that are within the distance from the perimeter of the park or open space. There are some limitations to this strategy. Blocks are selected even though one side was within 660 feet and the far side is not.

Table 2 summarizes the demographics of this group of census blocks, which includes the previous group of census blocks with parks. This area contains a majority of the city's population (80 percent) as well as most of its occupied housing stock (80.4\%). These blocks have high percentages of the city's total for each subject. This is related to the fact that it contains a large portion of the city's total land area. As seen in the census blocks with parks, approximately one quarter of the groupings population is under age 18 and a majority was non-white. Single parents head 19.2 percent of total households with children under age 18; a majority being headed by females with no husband present.

Table 3. Census blocks within 660 feet of a park or open space: Selected demographic subjects.

\begin{tabular}{|c|c|c|c|}
\hline Subject & Count & $\begin{array}{l}\text { As a percent of } \\
\text { grouping total }\end{array}$ & $\begin{array}{l}\text { As a percent of } \\
\text { City total }\end{array}$ \\
\hline Total population & 139,823 & - & 80.5 \\
\hline Population under 18 years old & 37,260 & 26.7 & 82.3 \\
\hline \multicolumn{4}{|l|}{ Race/Ethnicity } \\
\hline Hispanic population & 44,068 & 31.5 & 84.5 \\
\hline Non-Hispanic white population & 60,299 & 43.1 & 75.8 \\
\hline Non-white population & 79,524 & 56.9 & 84 \\
\hline \multicolumn{4}{|l|}{ Household Composition } \\
\hline Total households & 50,177 & - & 80.4 \\
\hline $\begin{array}{l}\text { Single-family households with children under } \\
\text { age } 18\end{array}$ & 9,645 & 19.2 & 83.4 \\
\hline $\begin{array}{l}\text { Female-headed households, no husband present } \\
\text { with children under } 18\end{array}$ & 1,873 & 17.4 & 19.1 \\
\hline \multicolumn{4}{|l|}{ Housing Temure } \\
\hline Occupied housing units & 50,177 & 91.7 & 80.4 \\
\hline Vacant housing units & 4,534 & 8.3 & 82.0 \\
\hline Owner-occupied housing units & 16,389 & 32.7 & 75.9 \\
\hline Rental housing units & 33,788 & 67.3 & 82.8 \\
\hline
\end{tabular}




\section{Map 16: Census blocks within 660 feet of a park or open space Providence, RI 2000}

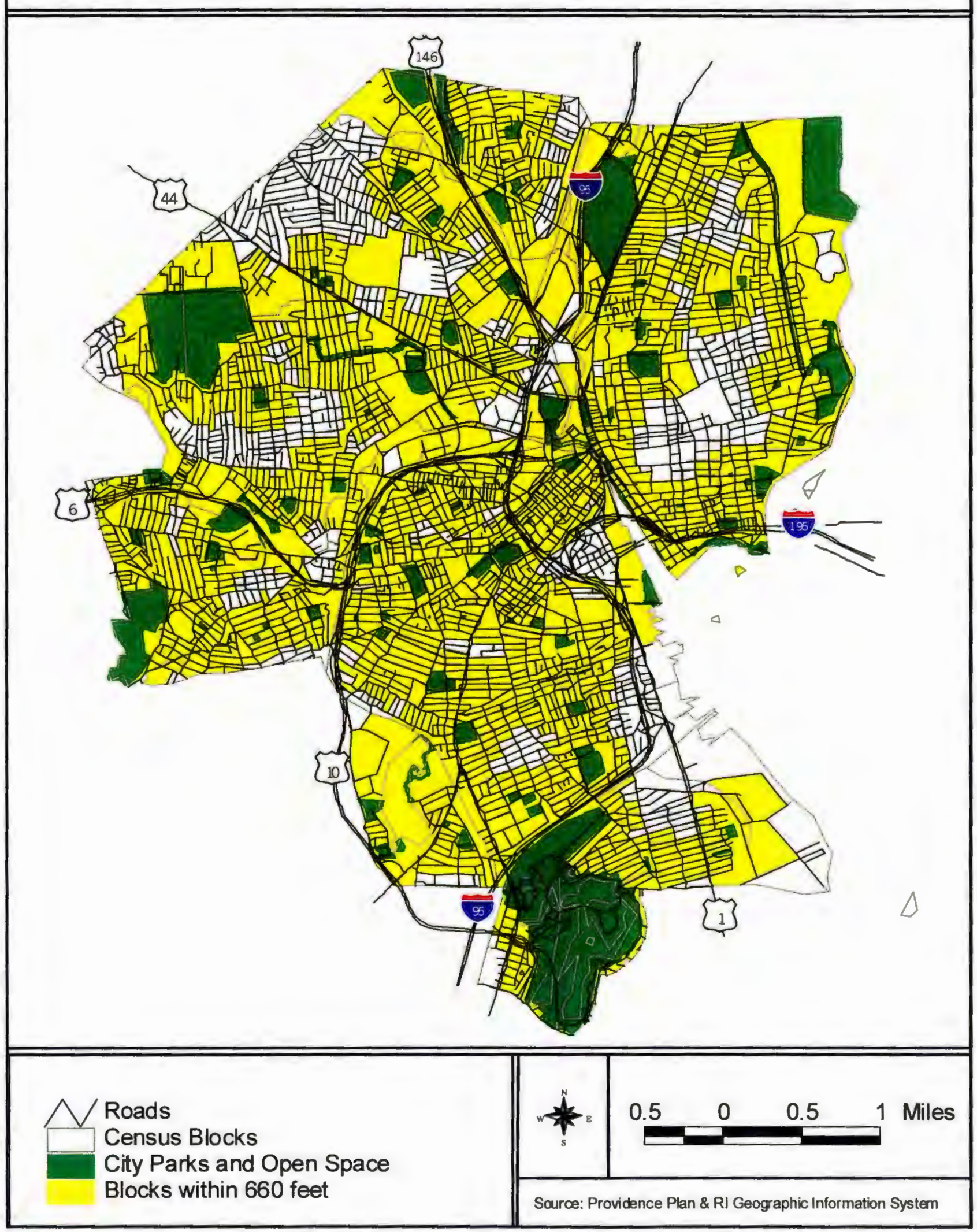


Census blocks more than 660 feet from a park or open space

The census blocks not identified in the previous discussion are classified as those more than 660 feet from a park or open space, totaling 672 blocks (Map17). Table 3 lists demographics for this group. These census blocks contain 19.6 percent of the city's total population. The characteristics of this group closely resemble those of census blocks with parks, but with one difference. The proportion of non-Hispanic white is greater than the non-white population (Maps 18 through 21). This area contains nearly one quarter of the city's total population of non-Hispanic whites, which constitutes more than half of its population (56.7\%). The same housing characteristics are seen in this grouping, where most of the units are occupied and rented. Single parents households with children under 18 are 15.8 of the total, with 13.1 percent headed by females with no husband present (Maps 22 and 23). Based on the hypothesis of this study, I assumed the census blocks further from a park or open space would have a higher percentage of non-white populations, single family households with children and female headed households with no husband present. I would also expect a lower percentage of non-Hispanic whites.

Table 4. Census blocks more than 660 feet from a park or open space: Selected demographic subjects.

\begin{tabular}{|l|c|c|c|}
\hline Subject & Count & $\begin{array}{c}\text { As a percent of } \\
\text { grouping total }\end{array}$ & $\begin{array}{c}\text { As a percent of } \\
\text { City total }\end{array}$ \\
\hline Total population & 33795 & - & 19.6 \\
\hline Population under 18 years old & 8017 & 23.7 & 17.8 \\
\hline Race/Ethnicity & & & \\
\hline Hispanic population & 8078 & 23.9 & 15.6 \\
\hline Non-Hispanic white population & 19152 & 56.7 & 24.3 \\
\hline Non-white population & 14643 & 43.3 & 15.6 \\
\hline & & & \\
\hline Household Composition & & & 19.6 \\
\hline Total households & 12,212 & - & 16.5 \\
\hline $\begin{array}{l}\text { Single-parent households with children under } \\
\text { age 18 }\end{array}$ & 1,910 & 15.6 & 16.2 \\
\hline $\begin{array}{l}\text { Female-headed households, no husband present, } \\
\text { with children under 18 }\end{array}$ & 1,590 & 13.0 & \\
\hline & & & \\
\hline Housing Temure & & & 19.6 \\
\hline Occupied housing units & 12,212 & 92.5 & 24.0 \\
\hline Vacant housing units & 992 & 7.5 & 17.2 \\
\hline Owner-occupied housing units & 5,199 & 42.6 & \\
\hline Rental housing units & 7,013 & 57.4 & \\
\hline Sounce Provid & & & \\
\hline
\end{tabular}

Source: Providence Plan 
Map 17: Census blocks more than 660 feet from a park or open space Providence, RI 2000

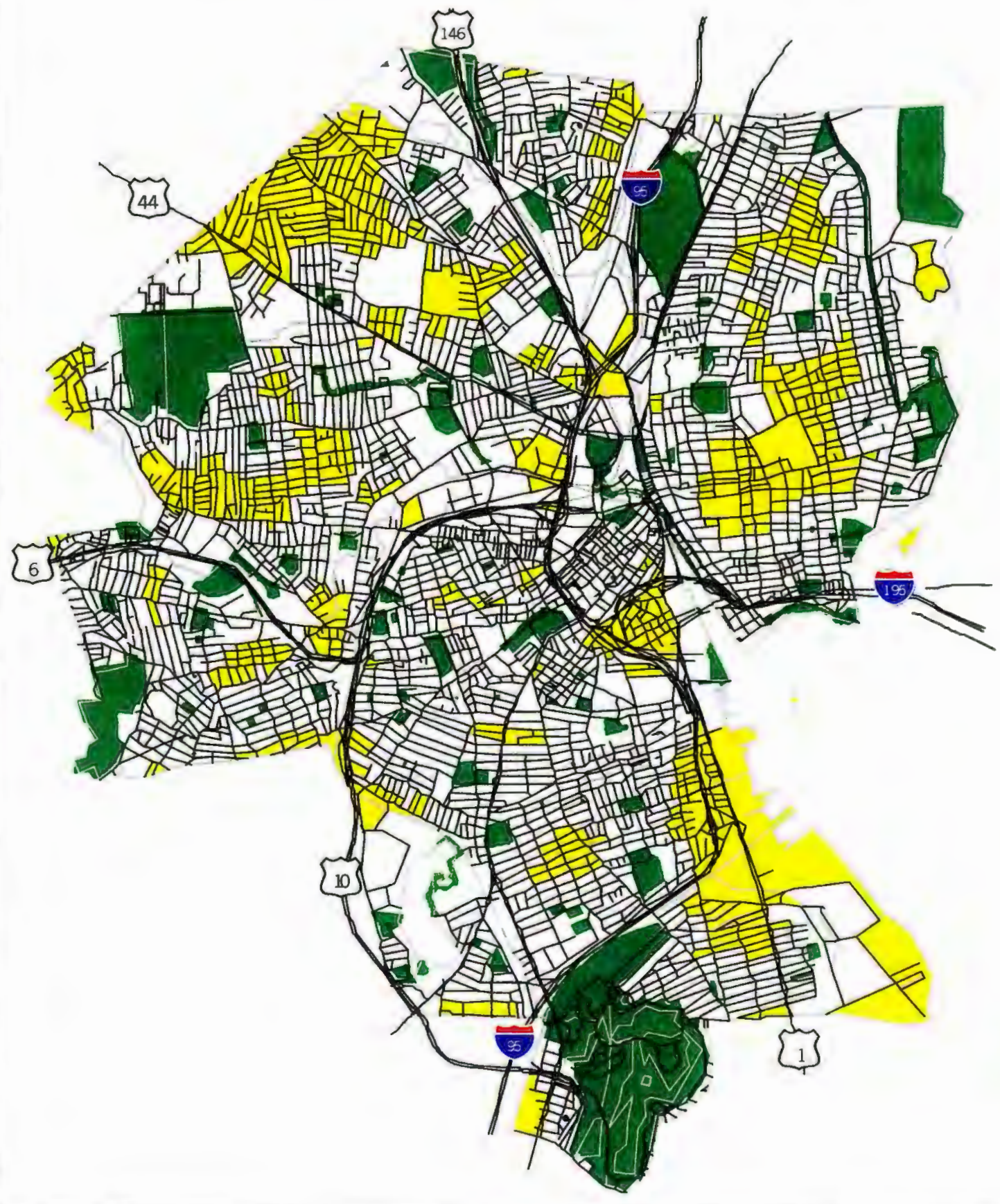

$\triangle$ Roads

Census Blocks

City Parks and Open Space

Census Blocks

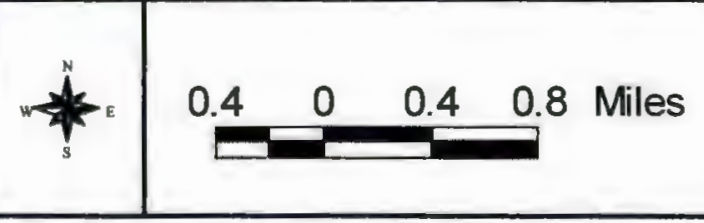

Source: Providence Plan \& RI Geographic Information System 
Map 18: Census Blocks More than 660 feet from a park or open space Population under 18 years, Providence, RI, 2000

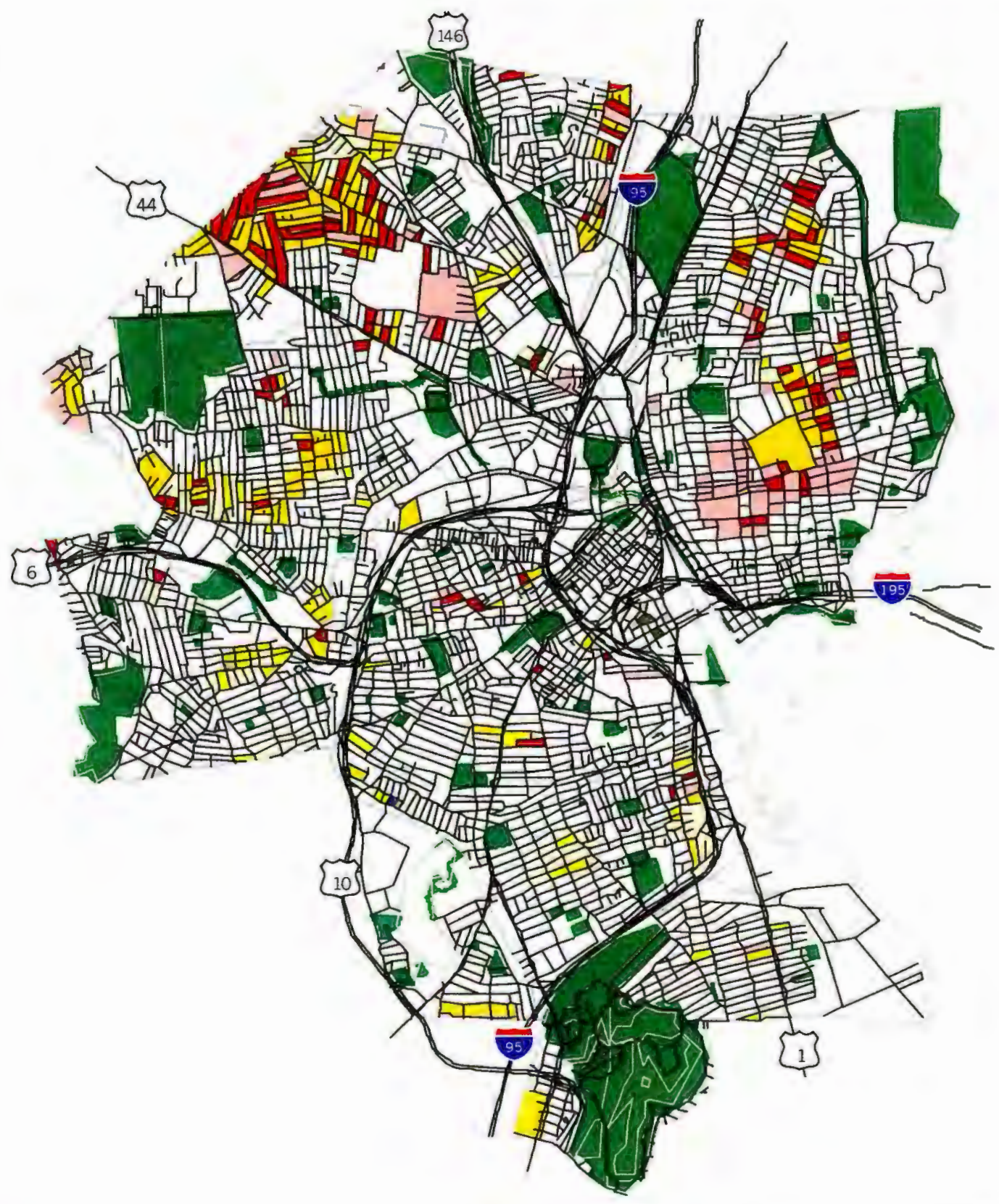

Under 18 years population as a percent of total less then $10 \%$

$10-20 \%$

20-30\%

$30-40 \%$

$40-50 \%$

$50-60 \%$

$60-70 \%$

$70-80 \%$

$80-90 \%$

$\bigwedge$ Roads

$90-100 \%$

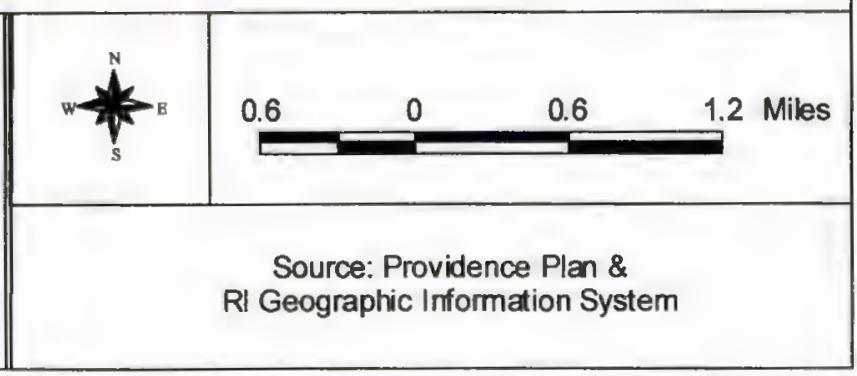




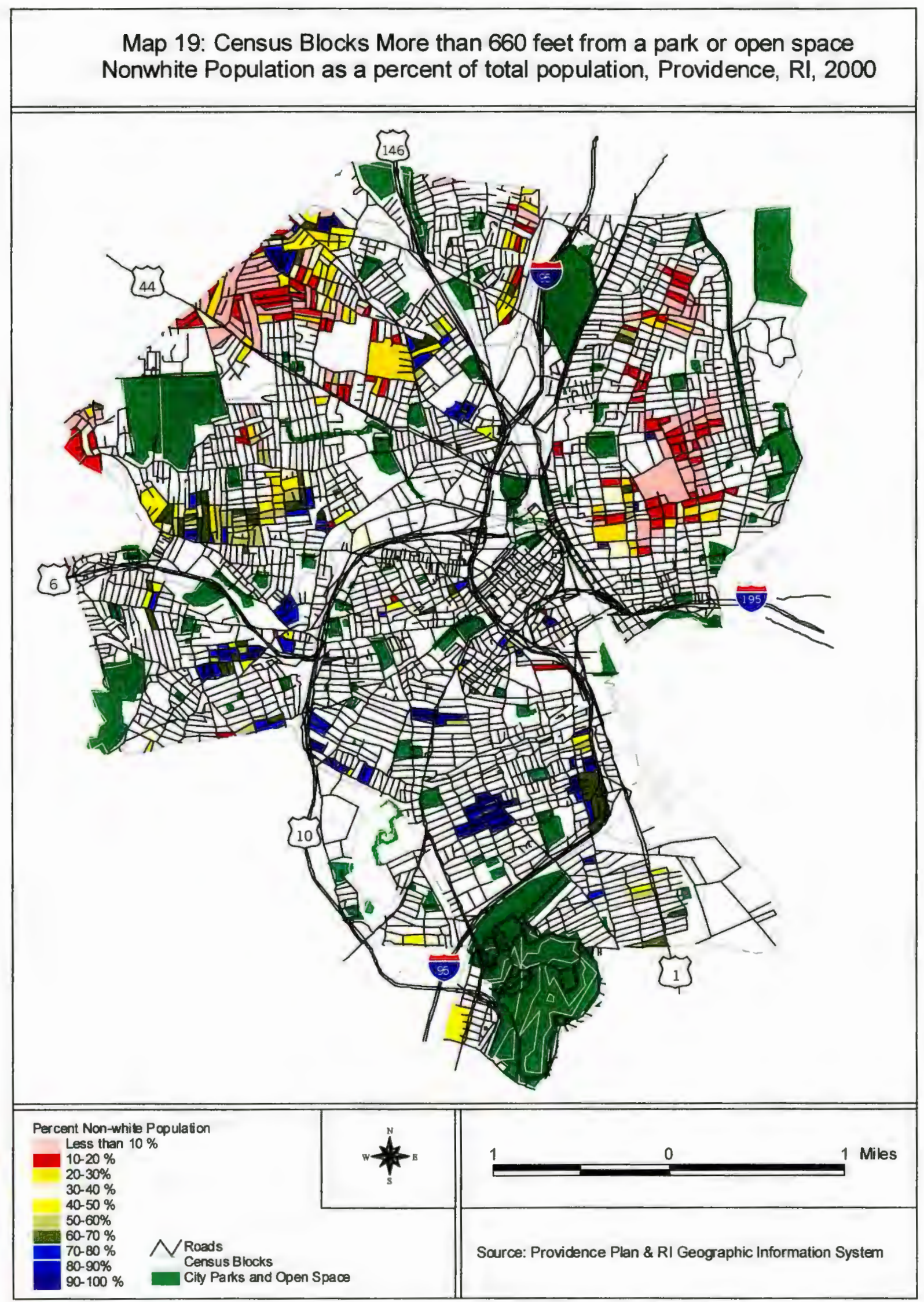




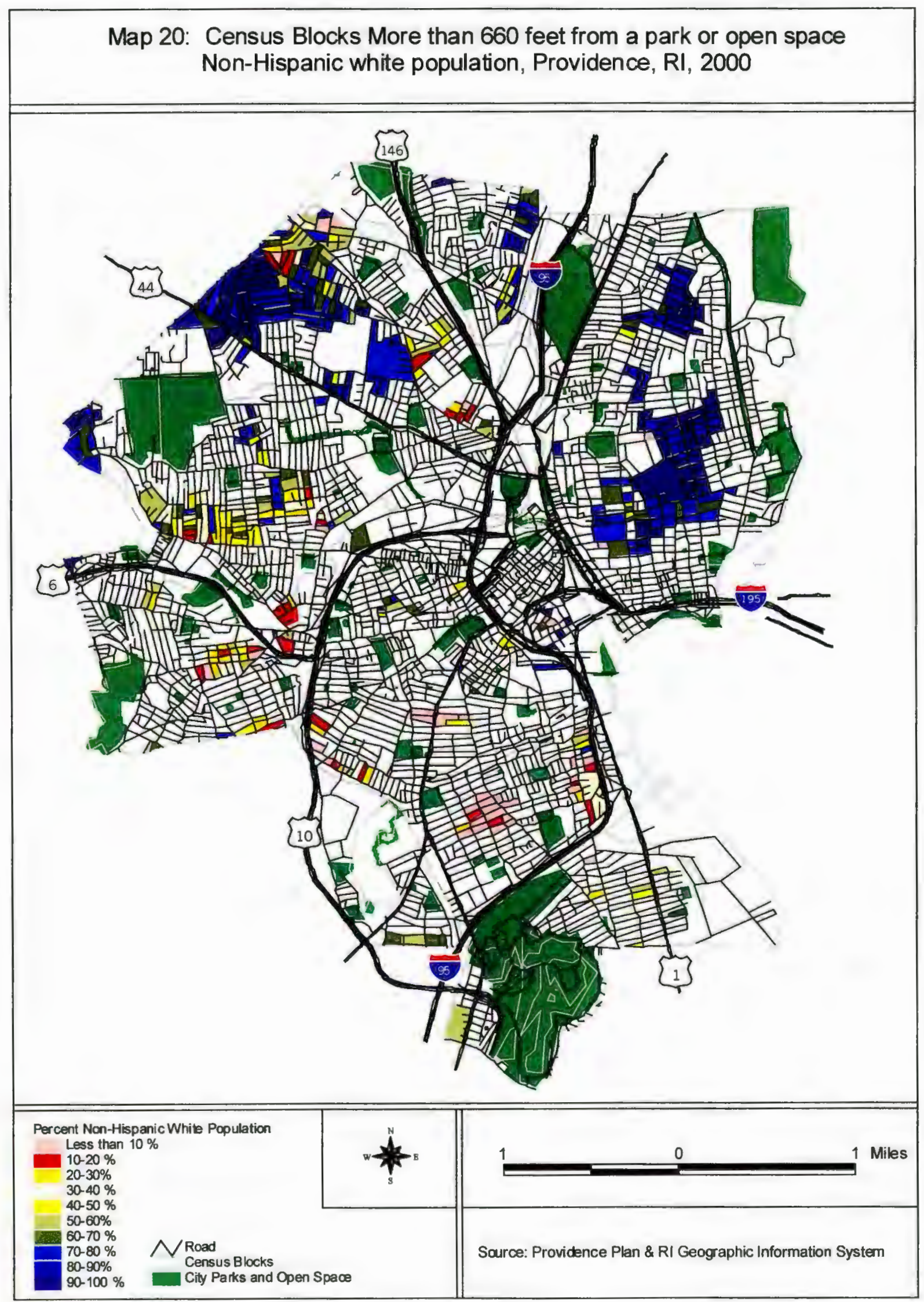




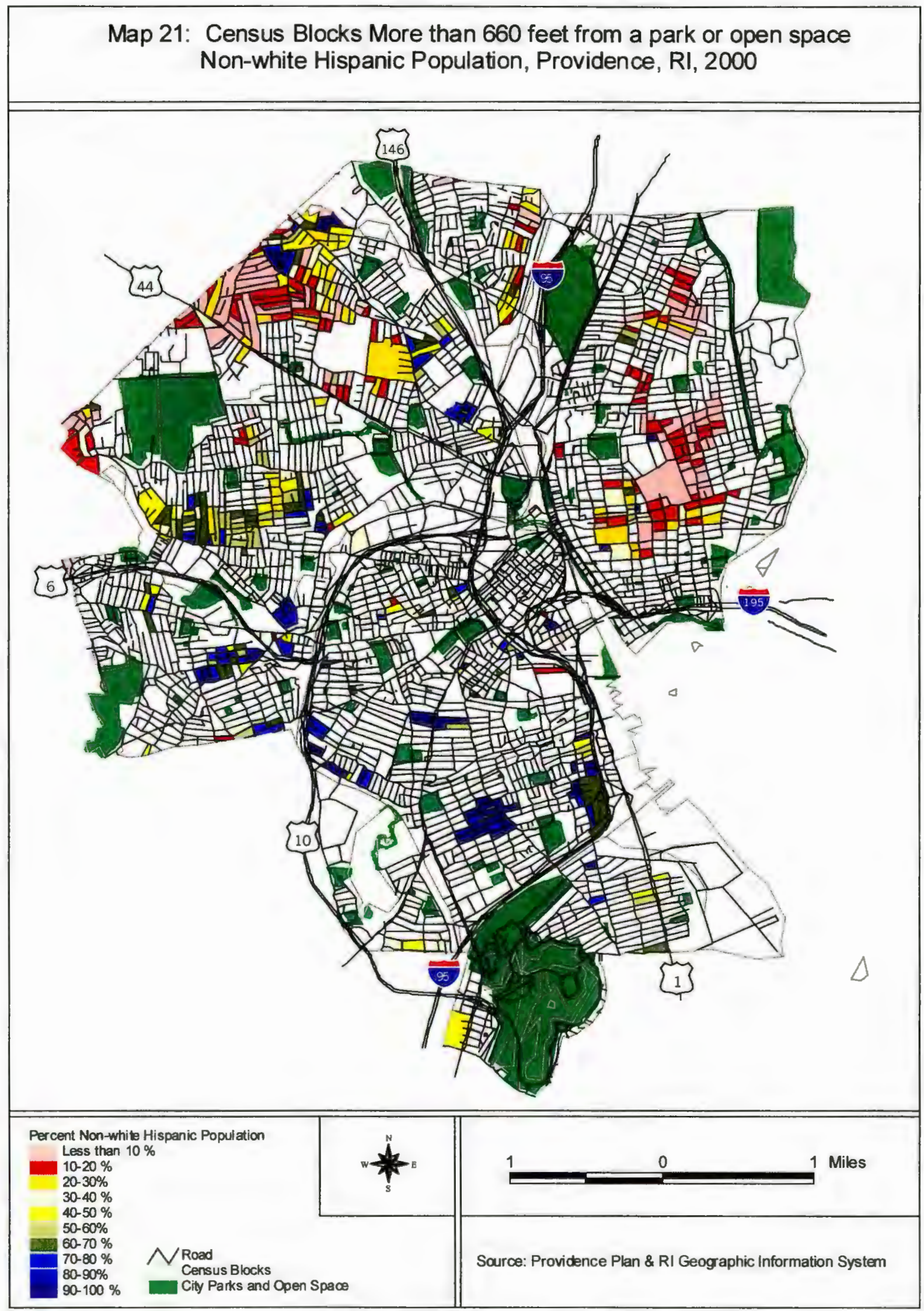


Map 22: Census Blocks More than 660 feet from a park or open space Single-parent households as a percent of total households, Providence, RI, 2000

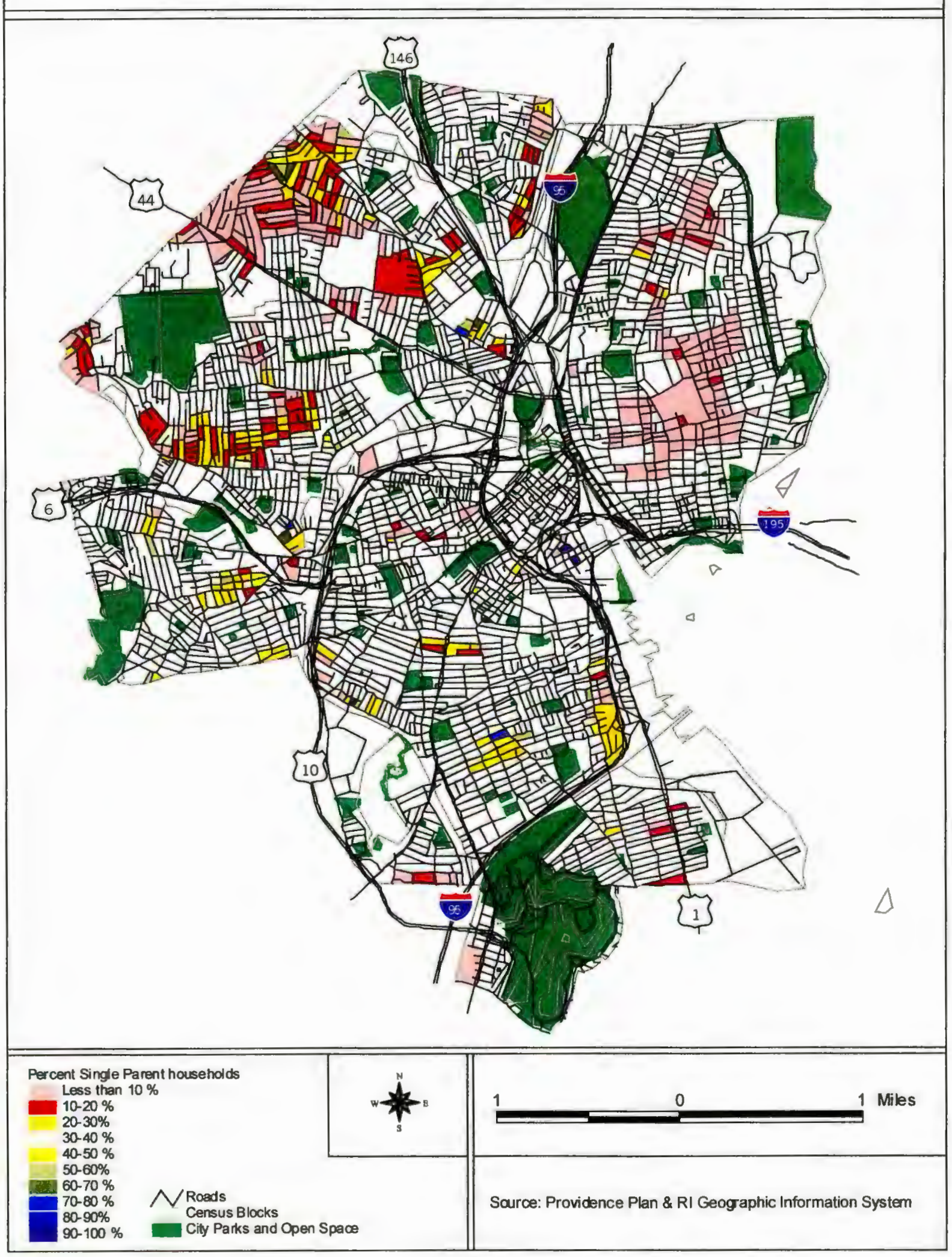




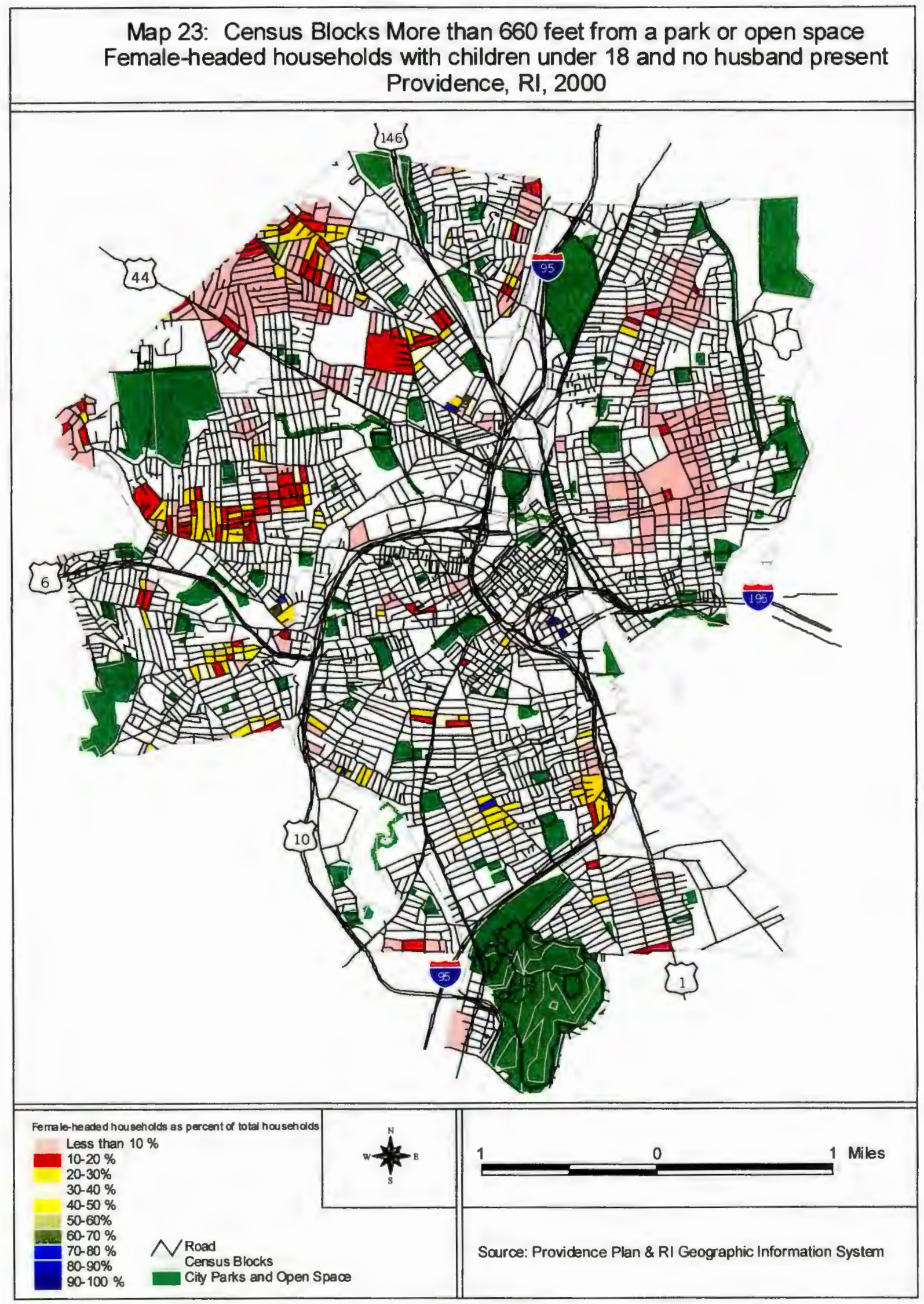




\section{Statistical Analysis}

The statistical analysis of this study replicates the regression test performed by Tarrant and Cordell (1999). A regression model is used to predict the values of a dependent variable from a set of independent variables (Norusis 2000). In this study, the size of a park or open space (dependent variable) is evaluated based on its relationship between several independent variables, which includes the following percentages: population under age 18, rental housing units, vacant housing units, Hispanic population, non-Hispanic white population, and average household size for Hispanic and white populations. The hypothesis is that these independent variables will predict the size of a park, where areas with more rental and vacant housing along with a larger percentage of Hispanic population would have smaller parks and open spaces. According to Norusis, the relationship between the independent variables and the dependent variable must be linear in order to be significant. Linearity shows a positive or negative correlation between the variables and allows us to summarize the relationship. As the independent variable increases, the dependent variable will decrease for a negative relationship and increase for a positive relationship. In this study, I would expect non-white population, non-white Hispanic population, or household sizes of Hispanic populations to increase as the size of parks and open spaces decrease.

The first step is to plot the values of two variables, each independent variable with park size to examine the nature of their relationship. The result will be either a pattern, usually clustered around a straight line, or plots scattered randomly. If a pattern exists, the relationship is linear and the regression model can be run with the data to determine the significance of the relationship.

When each independent variable is plotted with the size of park or open space within each census block, not one scatterplot shows a linear relationship. For example, Figures 4 through 6 show the percentage of non-Hispanic white populations to park or open space size for all census blocks that contain parks or open space. Figure 4 is difficult to read because of the irregularly large parks that skew the graph. Figure 5 shows parks or open space less than 100,000 square feet. The distribution of the variables is clearer. In this scatterplot, although most are still clustered along the $\mathrm{x}$-axis, the amount of parks and open spaces with larger 
sizes is significant. However, a pattern still did not exist. Figure 6 shows parks or open space less than 50,000 square feet and a pattern still is not visible. Looking at parks and open space smaller than 50,000 square feet would loose a significant portion of facilities.

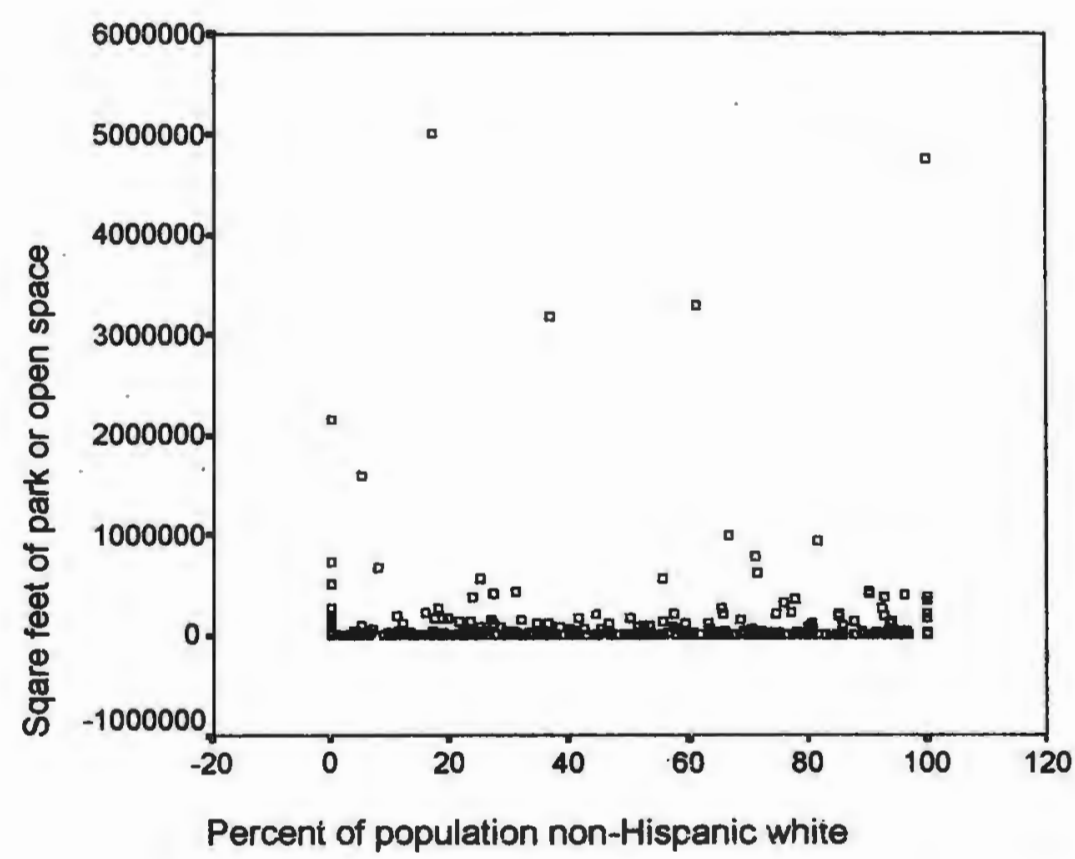

Figure 4. Census blocks with parks or open space: Percent of non-Hispanic white by square feet of park or open space. 


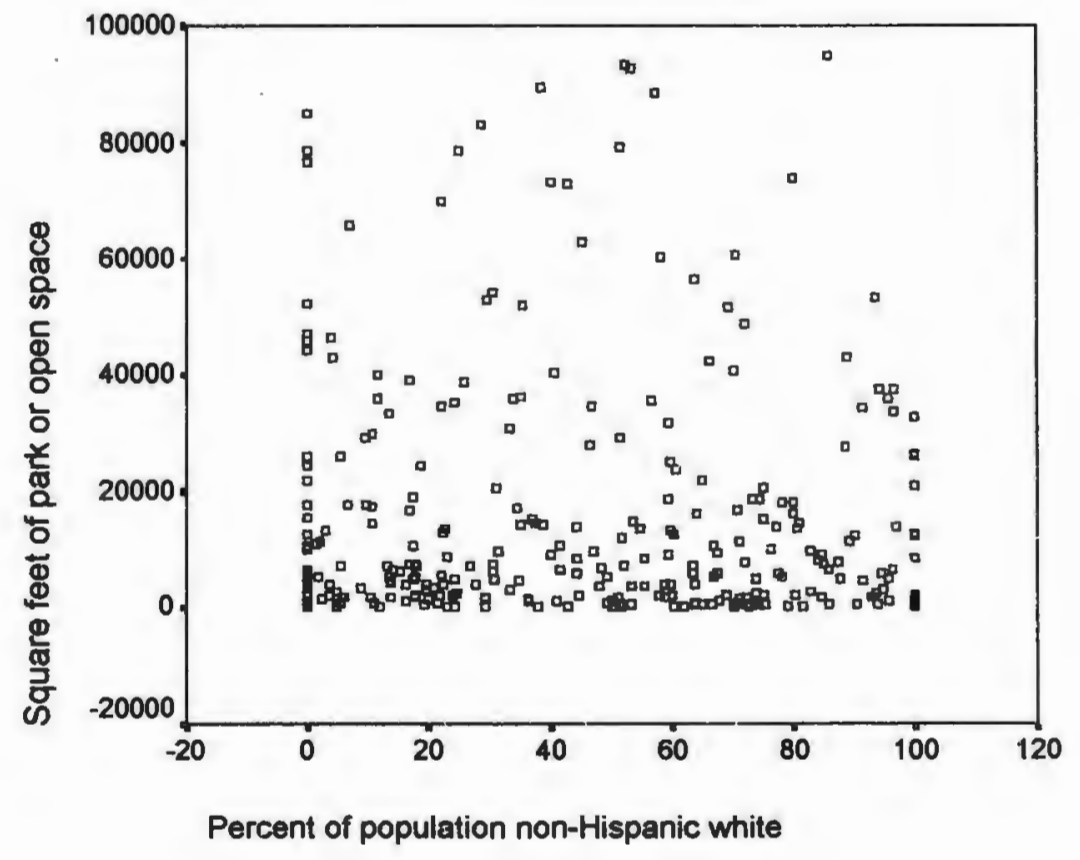

Figure 5. Census blocks with parks or open space: Percent of population non-Hispanic white by square feet of park or open space less than 100,000 square feet.

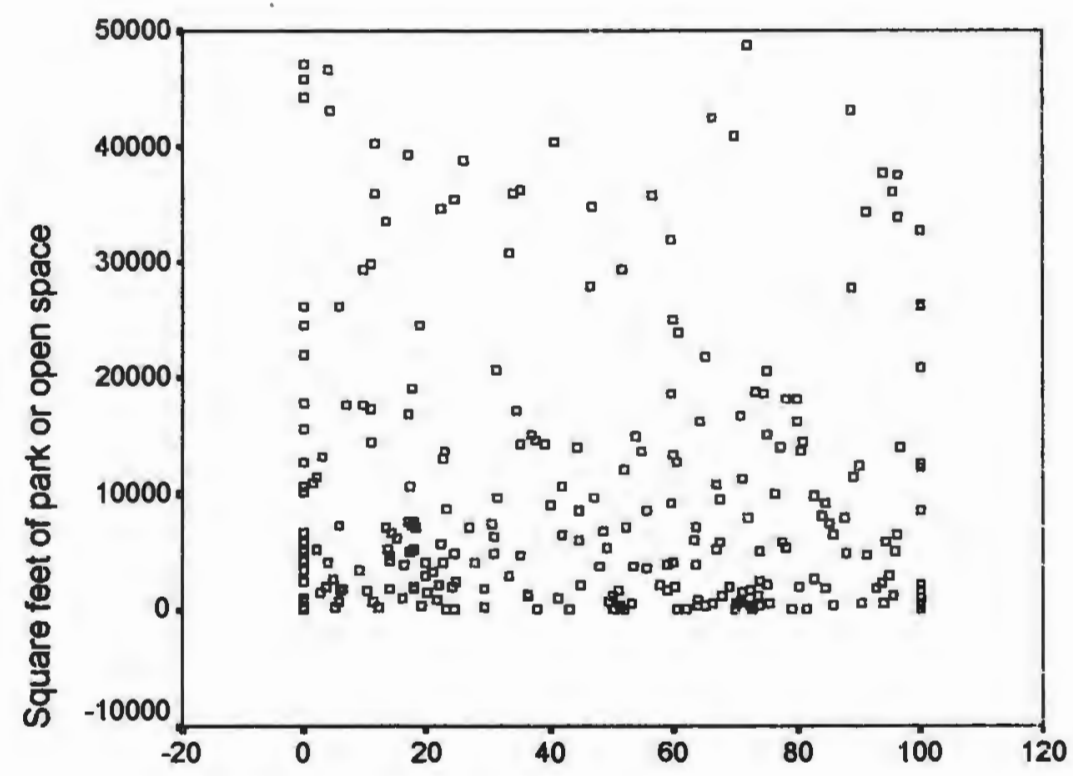

Percent of population non-Hispanic white

Figure 6. Census blocks with a park or open space: Percent of population non-Hispanic white by parks or open space less than $\mathbf{5 0 , 0 0 0}$ square feet. 
Even though the variables do not show a linear relationship, the regression model is still applied for verification. Table 5 shows the model summary. R-square tells us how well the model fit. Only 4.6 percent of the observed variability of park and open space size is "explained" by the independent variables. The R-value shows the correlation between the observed values of park and open space size and the predicted value based on the regression model. As the R-value gets closer to zero, the relationship between the variables is not linear (Norusis 2000). The R-value in Table 5, .215, supports the conclusions from the scatterplots that there is not a linear relationship between these variables. Therefore, the hypothesis is rejected.

Table 5. Linear Regression Model Summary for Census Blocks with Parks or Open Space.

\begin{tabular}{|c|c|c|c|c|}
\hline Model & R & R Square & Adjusted R Square & Std. Error of the Estimate \\
\hline 1 & .215 & .046 & .022 & 469861.03 \\
\hline
\end{tabular}

a Predictors: (Constant), UND18PER, \%RENT_HU_\%VAC_HU_AHS_WHT, AHS_HIS, \%HISP, $\%$ NHWHTE

\section{Access and Quality Assessment of Parks and Open Space}

\section{Access to Parks and Open Space}

As previously discussed, more than 80 percent of the city's population lives within 660 feet, a two to three minute walk, of a park or open space. Let's focus on the census blocks more than 660 feet. Table 4 summaries the demographics of this population. It contains nearly one quarter of the non-Hispanic white population and 15 percent of both the non-white populations and non-white Hispanic (Maps 19 and 21).

Seven major clusters of census blocks stand out with scattered blocks throughout the city. Clusters in the eastern and northern parts of the city are mostly non-Hispanic white and have lower percentages children under age 18 (less than $30 \%$ ) than areas to the south and west (Map 18). The low percentage of children is attributed to the increased college students and households of unrelated individuals that dominated these neighborhoods. Clusters in the western and southern parts of the city are predominantly non-white with children under age 18 , accounting for more than 40 percent of the population in most census blocks. According to Table 4, the overall population of census blocks more than 660 feet of a park or open 
space is almost equally divided between non-white and non-Hispanic white populations; but geographically, they are separated.

\section{Quality Assessment of Parks and Open Space}

Another way to see a relationship between area demographics and parks and open space is to look at the quality of the parks and open spaces. The second part of the hypothesis is that parks and open spaces in lower income minority areas would have a lesser quality than middle and upper income areas with fewer minority populations. The analysis of quality of parks and open space is done in two parts. The first part involves a site visit to each park or open space in order to evaluate its quality based on a ranking system. The second part consists of a statistical analysis based on the rankings from site visits.

\section{Site Visits}

Each park and open space in Providence was visited during the day between 9 am and $4 \mathrm{pm}$. It was observed that most playgrounds have new equipment, walkways are free of cracks and depressions, and play areas are protected from traffic by fences or landscaping. It did not seem necessary to rank these items since most would receive a high rating. Therefore, cleanliness, aspects of security/safety and opportunities to interact with nature in some fashion are features ranked.

A slightly different approach is used than the one discussed in Chapter IV to assess parks and open space. Each aspect observed is ranked in a specific way. For cleanliness, litter, graffiti and glass are ranked in the following fashion:

- A - not an issue;

- $\mathrm{B}$ - issue in one third of park;

- $\mathrm{C}$ - issue in two thirds of park; and

- D - widespread issue in park.

For security and safety features, ranking is done the following way:

- A - lockable gate present but area was open to the public;

- C - gate was lock to prohibit admittance; and 
- D - inappropriate activities at the park appeared to prohibit appropriate use of the park or open space.

- $B$ is omitted because a locked gate during the day prohibits access during peak user hours and deserves fewer points.

And finally, natural features were ranked in the following manner:

- A-opportunities existed to observe or interact with natural features;

- B-landscaping or grassy area was present but periodically altered through maintenance;

- C-roughly half of the natural feature was polluted with litter, glass or graffiti;

- D-severe problem with pollution in the natural feature or no access existed; and

- NF-no feature existed at park.

Each rank received specific points: As -4 points, Bs -3 points, Cs -2 points, Ds -1 point, and NFs - no points. For each park, a total score was calculated. See Appendix for full rankings.

There are several limitations associated with this ranking system. First, it has some level of subjectivity. My opinion of the cleanliness of a park may not be the same as another person, even when using an estimation of how much of a park space is covered with litter, glass or graffiti. Second, the park and open space elements assessed are limited. Items such as detailed safety issues, functionality, and usage are important issues in parks and they are not addressed to the greatest extent in this study. Additionally, comparing a ball field to a totlot or wooded area with no play equipment is difficult to summarize. Different people use these spaces for different purposes. Finally, the focus of this study is to look for natural features, in particular those that are not polluted and offer opportunities to observe natural systems. These types of areas are not common in Providence. With that, there is compatibility in that a single person applying the same standard for each site did the assessment.

\section{Rankings}

Map 24 shows the distribution of parks and open spaces and their scores. The highest score is a 19 and six parks and open spaces received it: Daniel Avenue Playground, Franciscan 
Park, Gladys Potter Park, Roger Williams Park, Triggs Memorial Golf Course and Wanskuck Park. All of these areas have landscaping or vegetation that is maintained in some fashion, such as mowing grassy areas. I observed no problems with litter, graffiti, glass, safety or security or polluted natural features.

These parks are clustered diverse areas (Map 25 through 26). Roger Williams Park and Franciscan Park are both located in areas dominated by non-white populations. Daniel Avenue Playground and Triggs Memorial Golf Course are in the most diverse neighborhoods, where the non-white population is around 50 percent. Wanskuck Park and Gladys Potter Park are in areas with the smallest proportions of non-white populations (less than 20 percent).

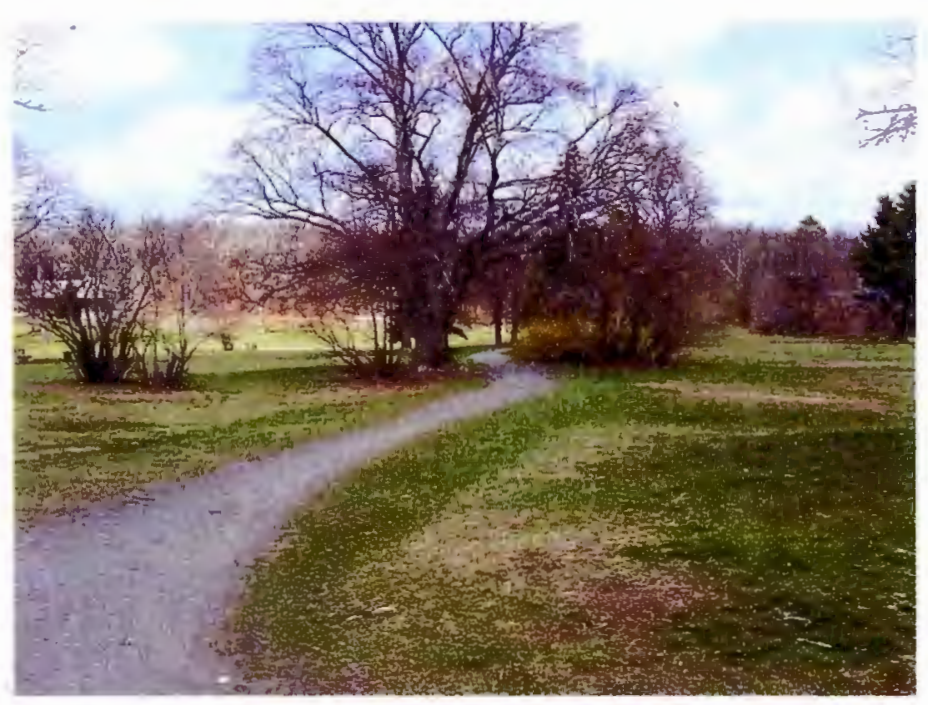

Wanskuck Park 

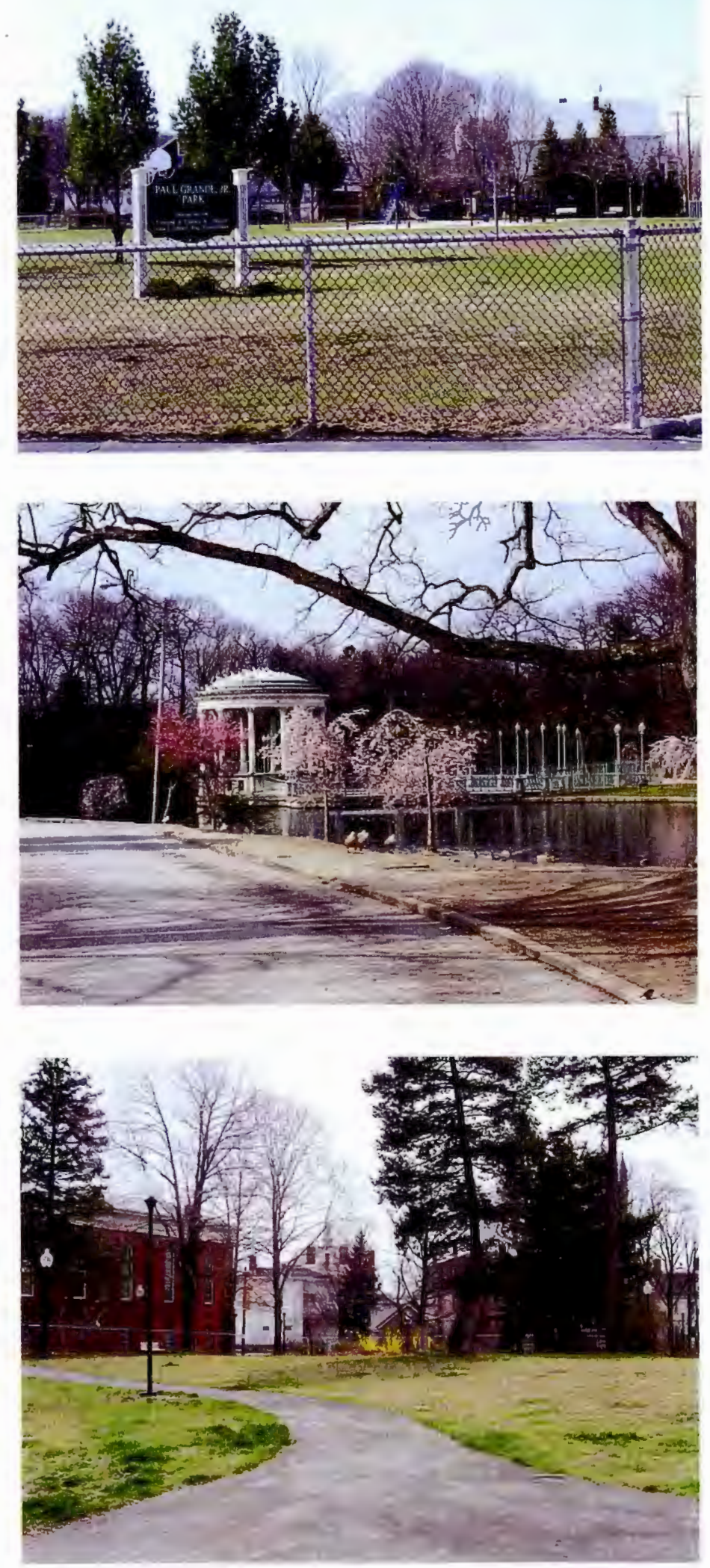

Daniel Avenue Playground

Roger Williams Park

Franciscan Park 
Map 24: Park and Open Space Ranking - Providence, RI, 2000

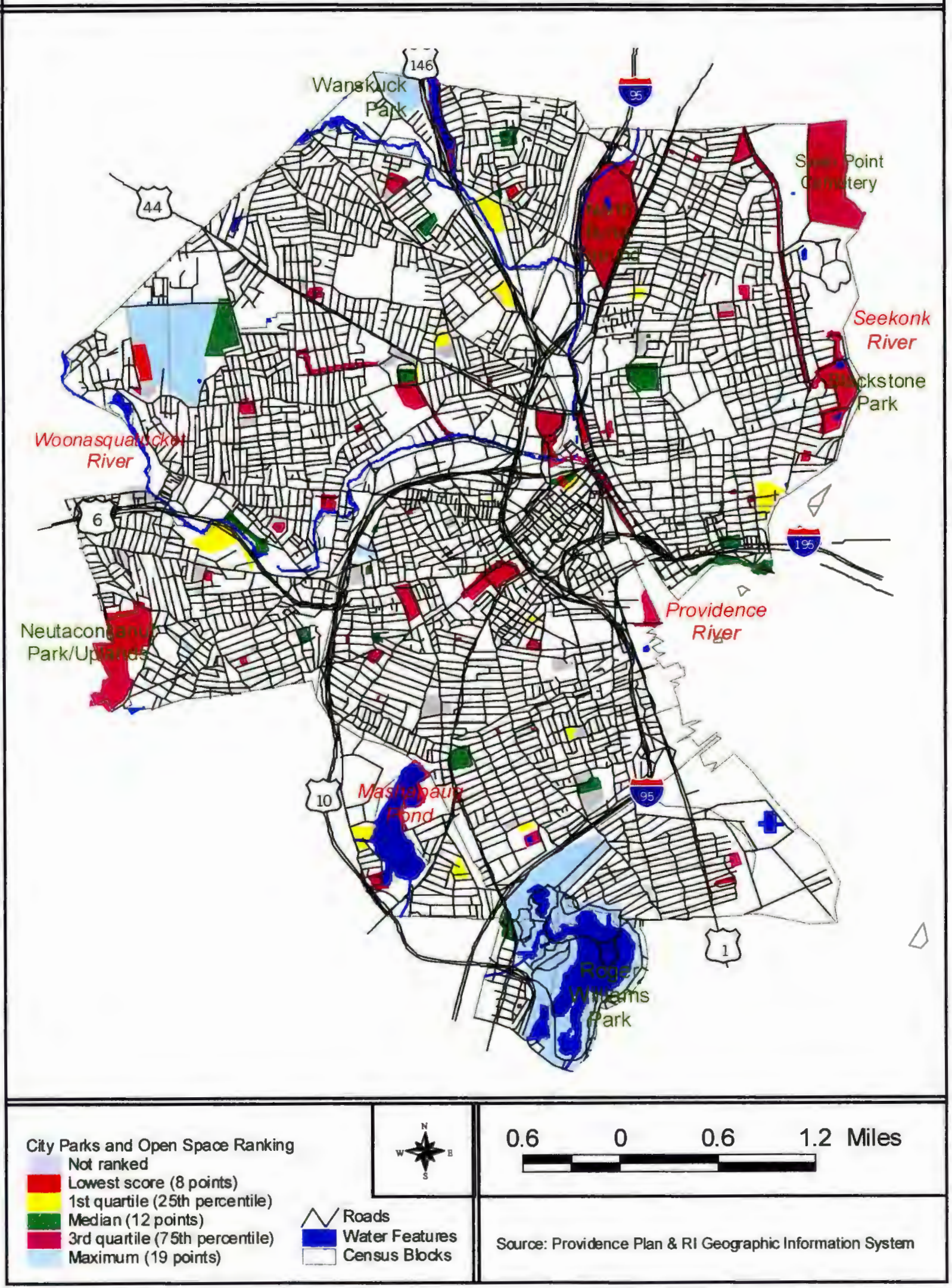




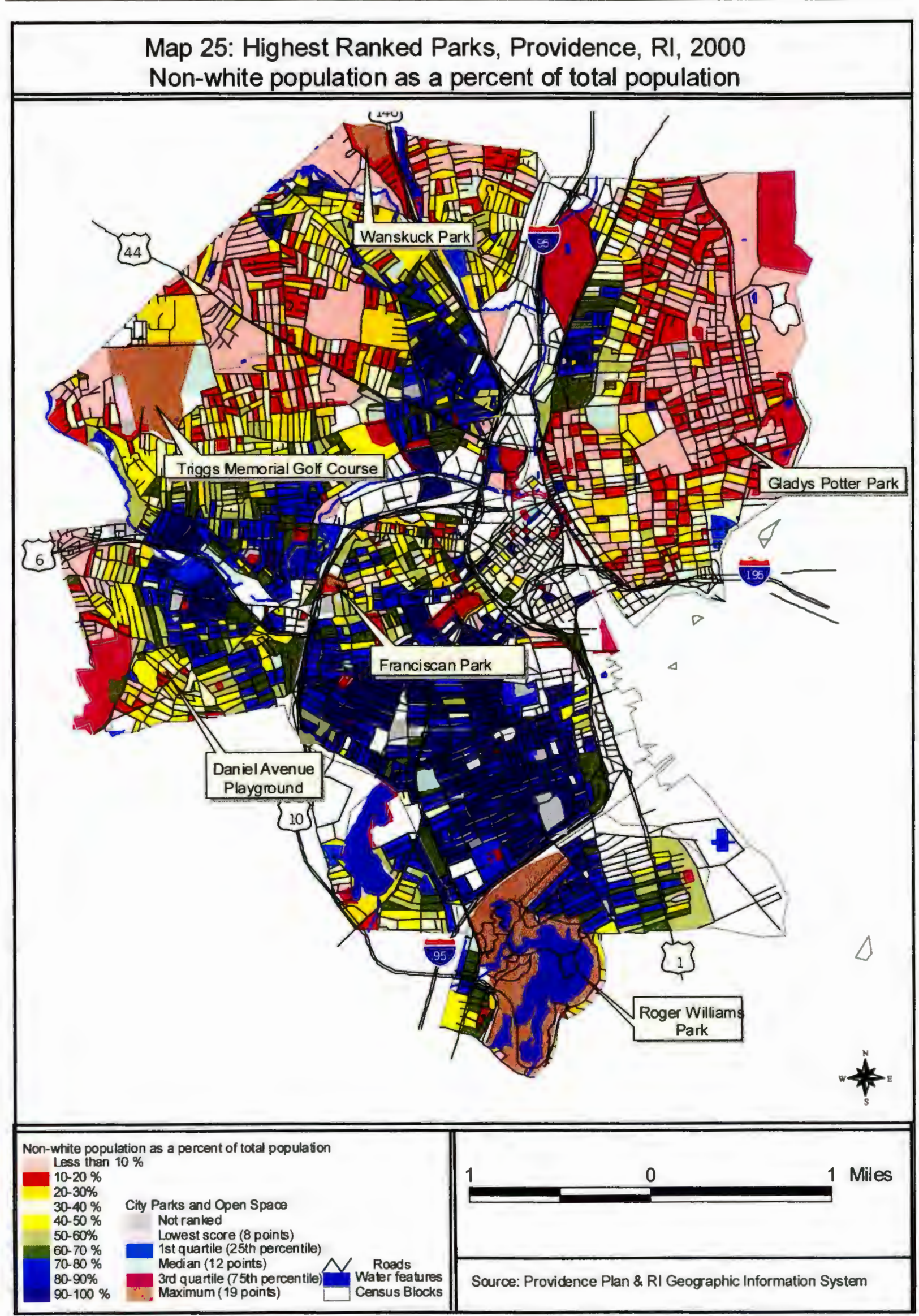


Map 26: Highest Ranking Parks, Providence, RI, 2000

Female-headed Households with children under 18 and no husband present as a percent of total households

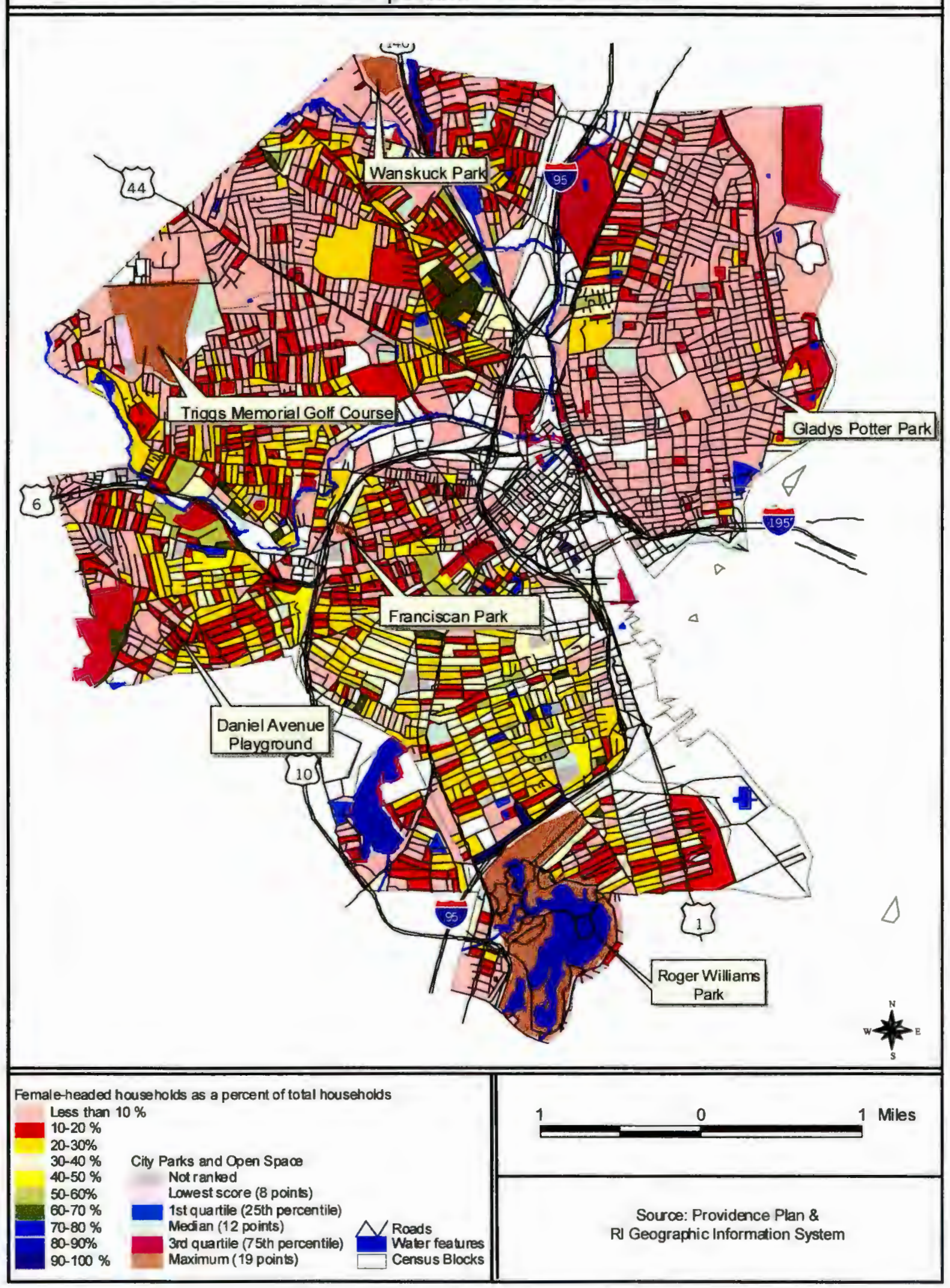




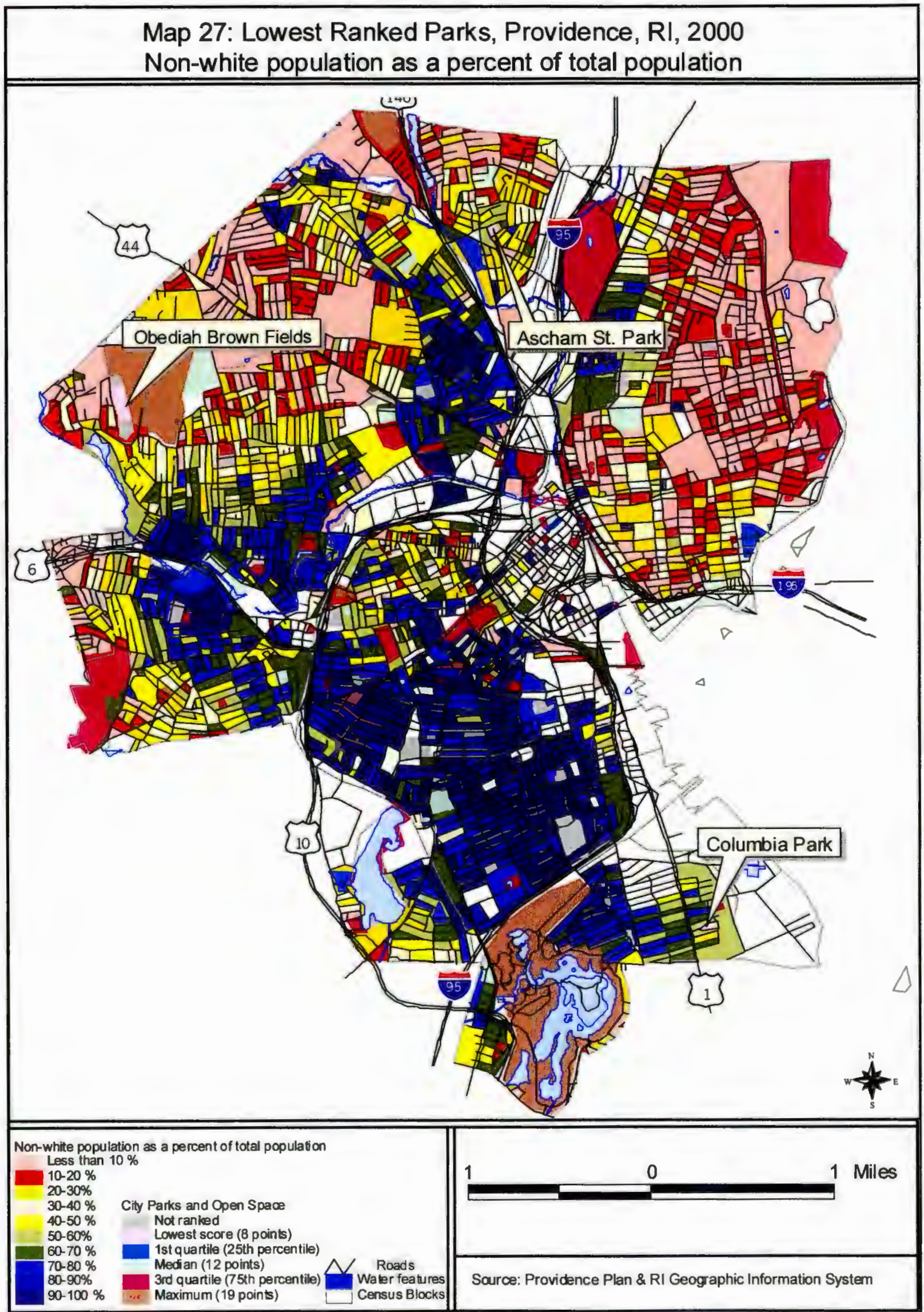


The lowest rating, 8, is given to three areas: Ascham Street Park, Columbia Park and Obediah Brown Fields. Ascham Street Park and Columbia Park both have graffiti that contributes to its low score. Ascham Street Park has a wall at one end of the park where most of the graffiti is located. This area also seems to be blocked from "eyes on the street" and a place where safety may be an issue. Carr et. al. (1992) refer to visible access or visibility as being important in order for people to feel free to enter a space. The question they ask is "Can potential users easily see into the space from outside, so that they know that it is a public space where they can enter safely and will be welcome?" (144). Activities against the wall at Ascham Street Park are not visible from the street above it. Finally, Obediah Brown Fields are littered with trash and glass in the parking lot.

These parks are also not concentrated in low-income minority areas. About half of the population near Ascham Street Park is non-white (Map 27). Columbia Park is within a census block with a non-white population between 50 and 70 percent of the total and less than 20 percent of the households have children under 18 and are headed by females with no husband present (Map 28). Obediah Fields is located next to one of the highest-ranking parks, Triggs Memorial Golf Course. The census block populations adjacent to the fields are less than half non-white and less than 10 percent are female-headed households with children under age 18 and no husband present. These parks are located adjacent to census blocks with a mix of minority and non-Hispanic white populations. 
Map 28: Lowest Ranking Parks, Providence, RI, 2000

Female-headed Households with children under 18 and no husband present as a percent of total households

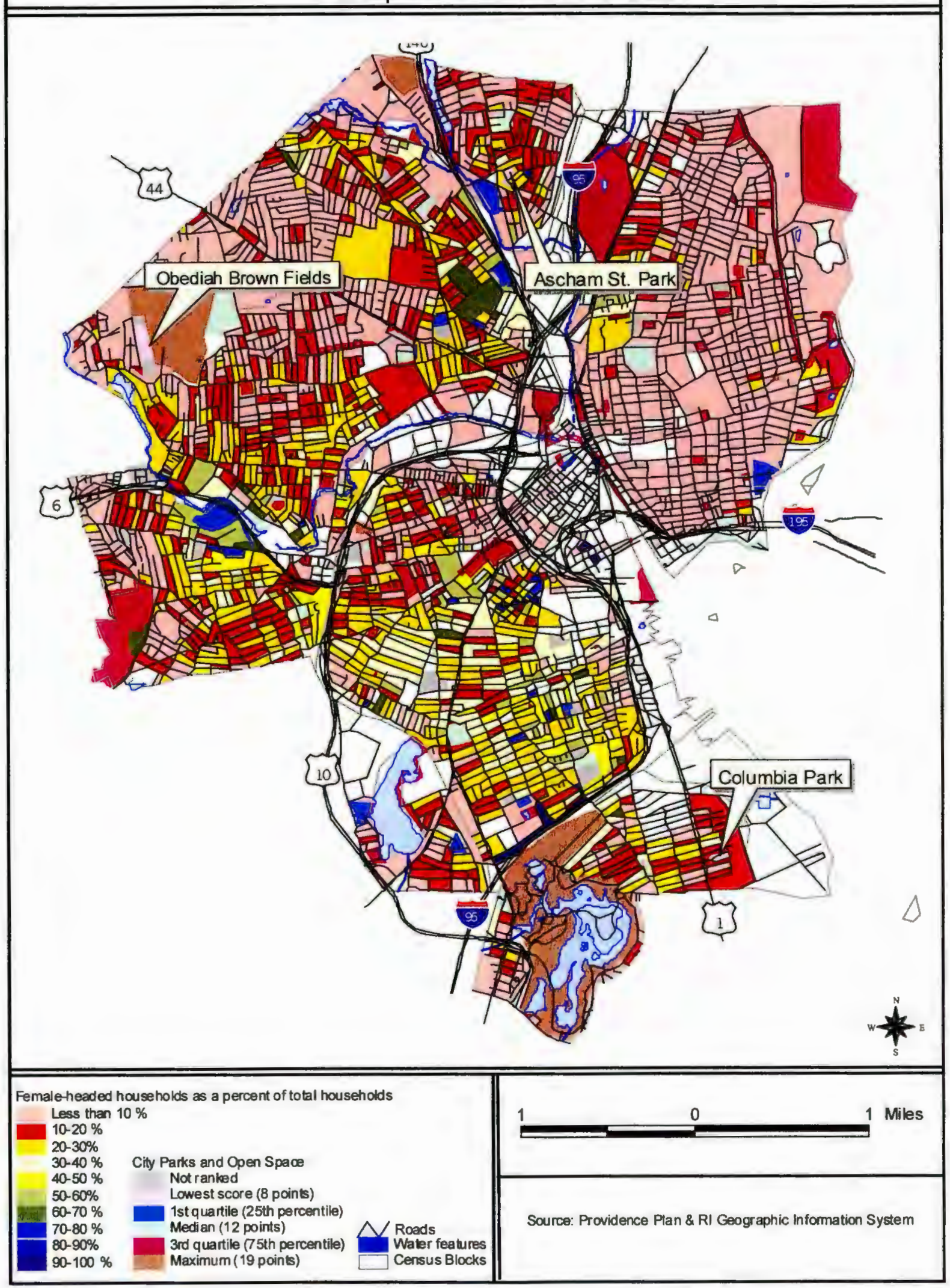



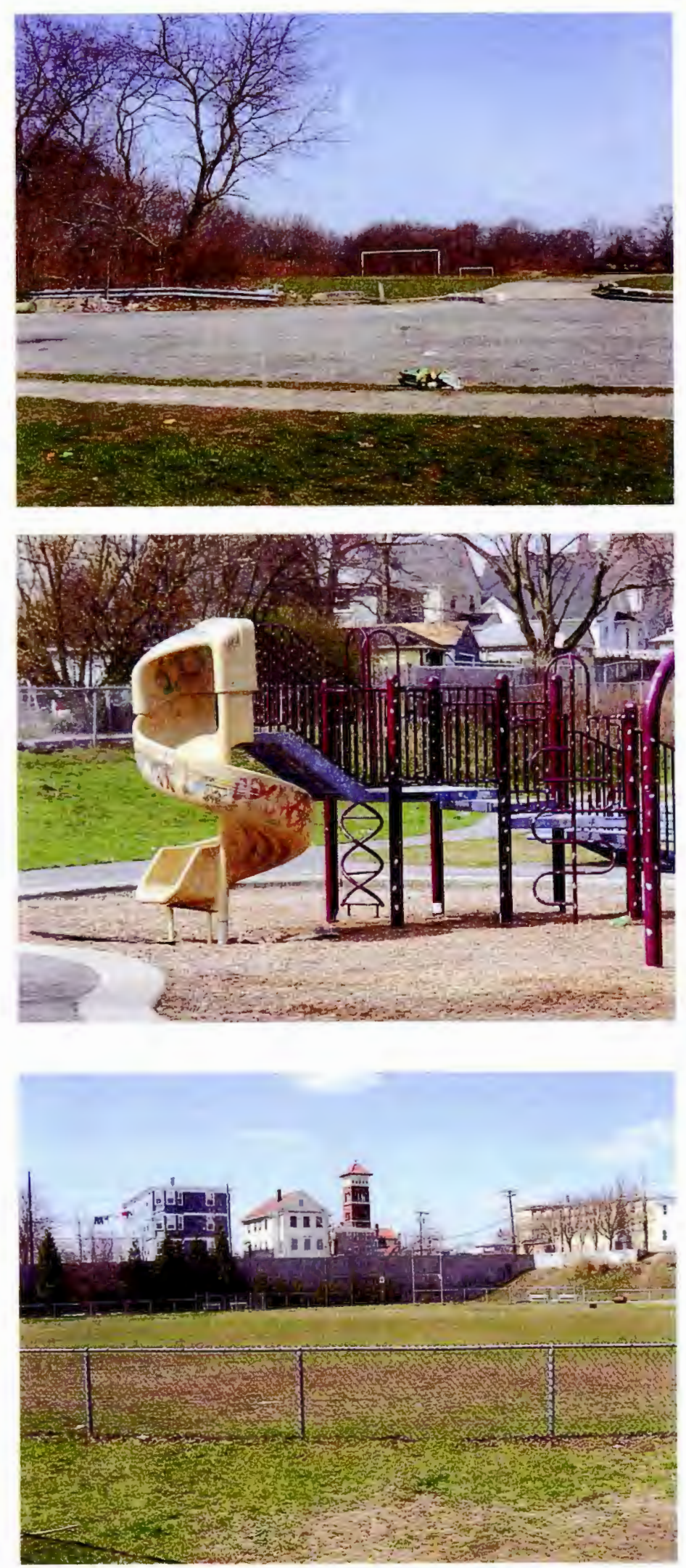

Obediah Brown Fields

Columbia Park

Ascham Street Park 
The median score is 12 , received by 38 parks. The second most received score is 15 . The major difference between these two groups is the present of natural features. Most with a score of 12 do not have a natural feature, or that feature is polluted. These parks are distributed throughout the city.

Within the city as a whole, there are a number of areas with opportunities to interact with nature. Areas specifically identified as places to interact with or observe natural features are the following:

- Blackstone Park/Seekonk River and natural wooded area

- Neutaconkanut Park and Uplands/natural wooded area

- Canada Pond Management Area

- Murphy-Trainer Park/Mashapaug Pond and natural wooded area

- Point Street Landing/Providence River

- Donigian Memorial Park/Woonasquatucket River

- Riverwalk/Providence River

- Waterplace Park/Woonasquatucket River

- Corliss Landing/Providence River

- Riverside Mills Park/Woonasquatucket River

Not all these areas receive an " $\mathrm{A}$ " rating for natural features. Pollution and graffiti are seen in many of them, which lowers the rating, such as at Mashapaug Pond, Providence River and Woonasquatucket River.

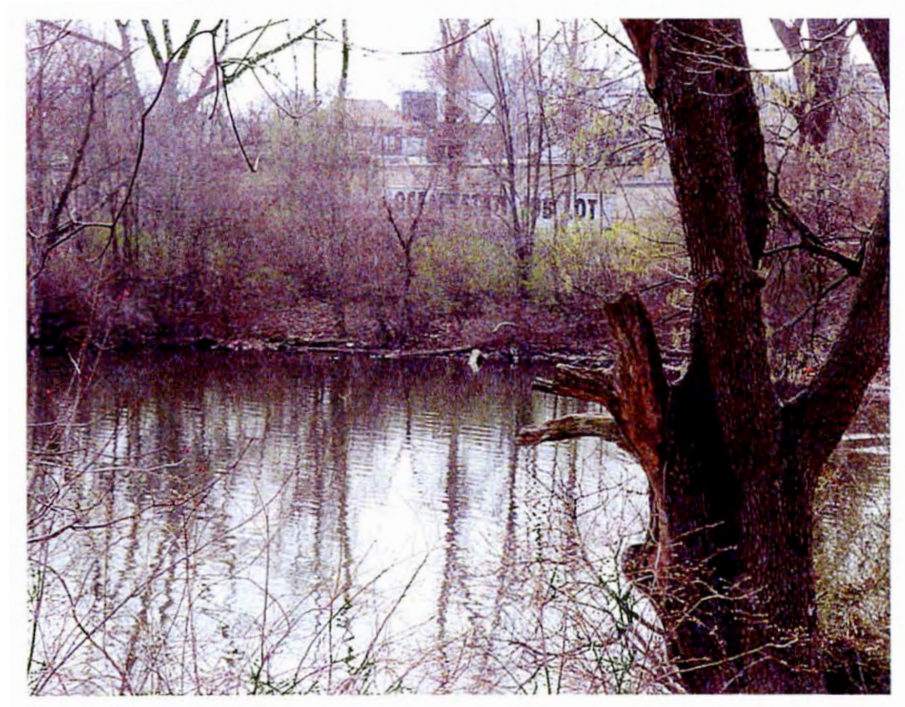

Mashapaug Pond at Murphy-Trainer Park 

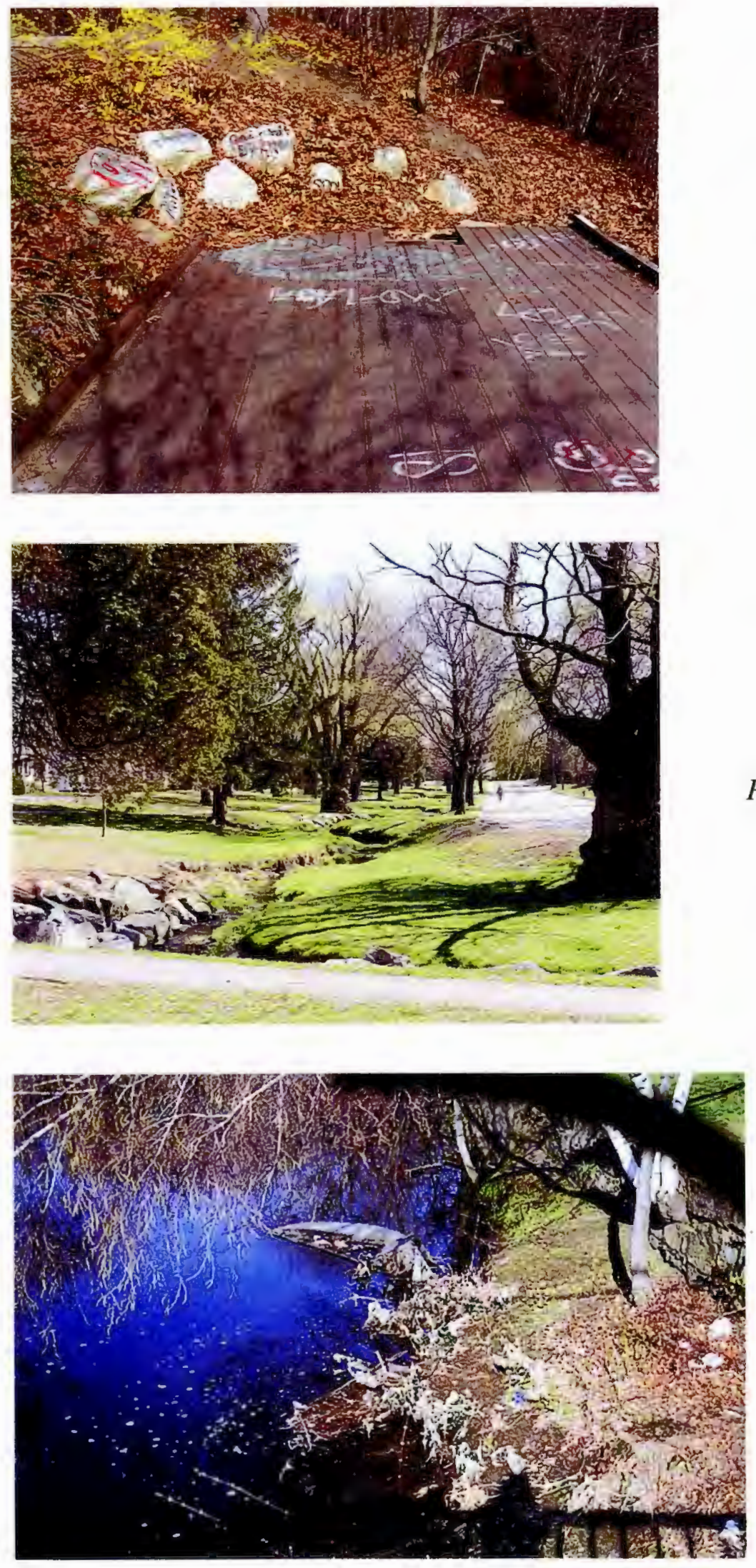

Graffiti at Murphy-Trainer Park along Mashapaug Pond

Pleasant Valley Parkway

Woonasquatucket River at Donigian Memorial Park 

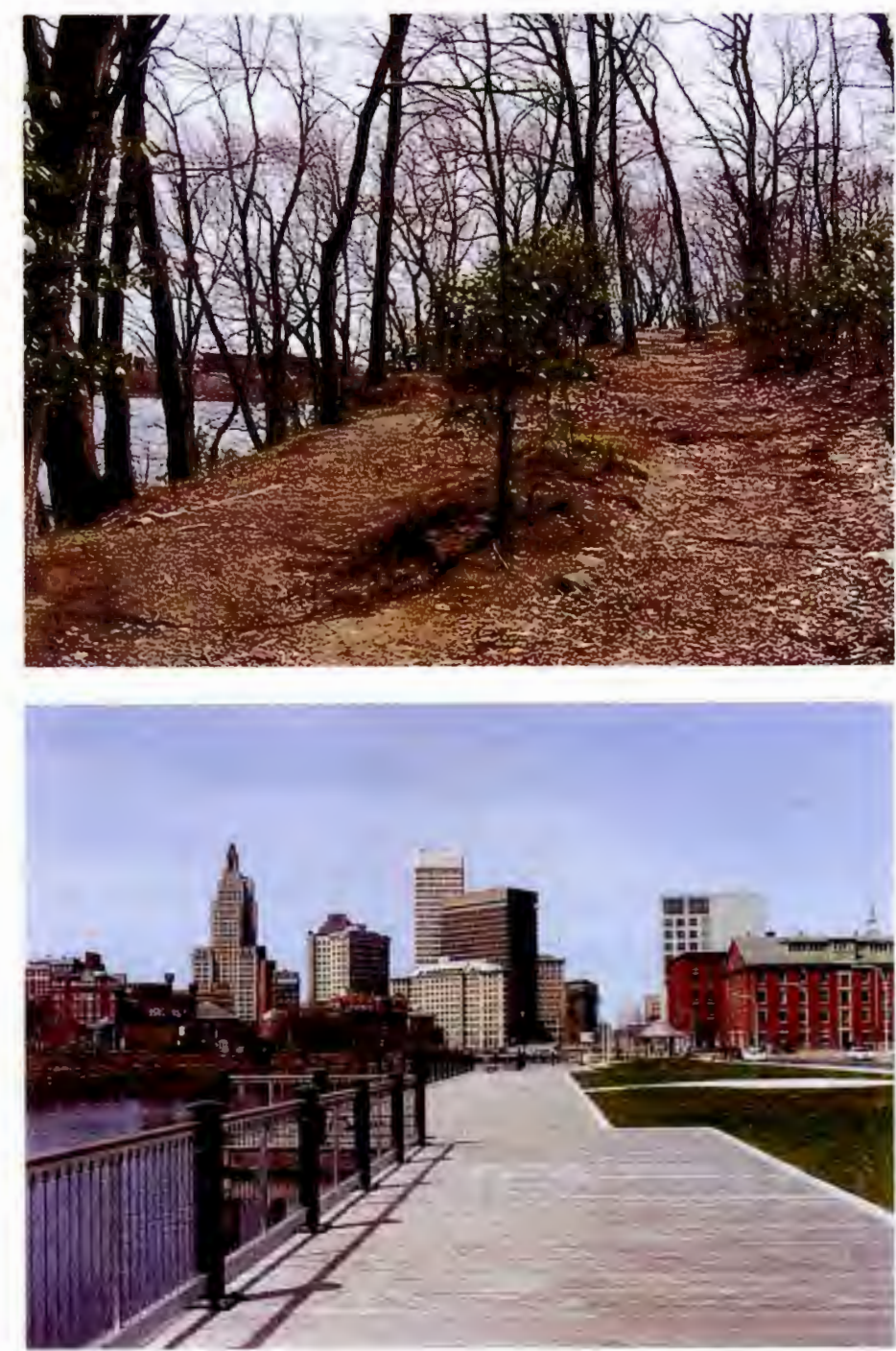

Blackstone Park

\section{Riverwalk}

Natural features also exist along the Woonasquatucket Greenway. The Greenway extends from Waterplace Park at Capital Center along the Woonasquatucket River through the neighborhoods of Valley, Olneyville, Hartford and Manton (Figure 7). The Greenway Plan identified open space along Route 6 that has been inaccessible. Because it was secluded, the area was able to develop naturally to produce a rich diversity of native plants and wildlife. With the Greenway project, these areas will become opportunities for interaction with natural systems (Providence Plan 1997). 


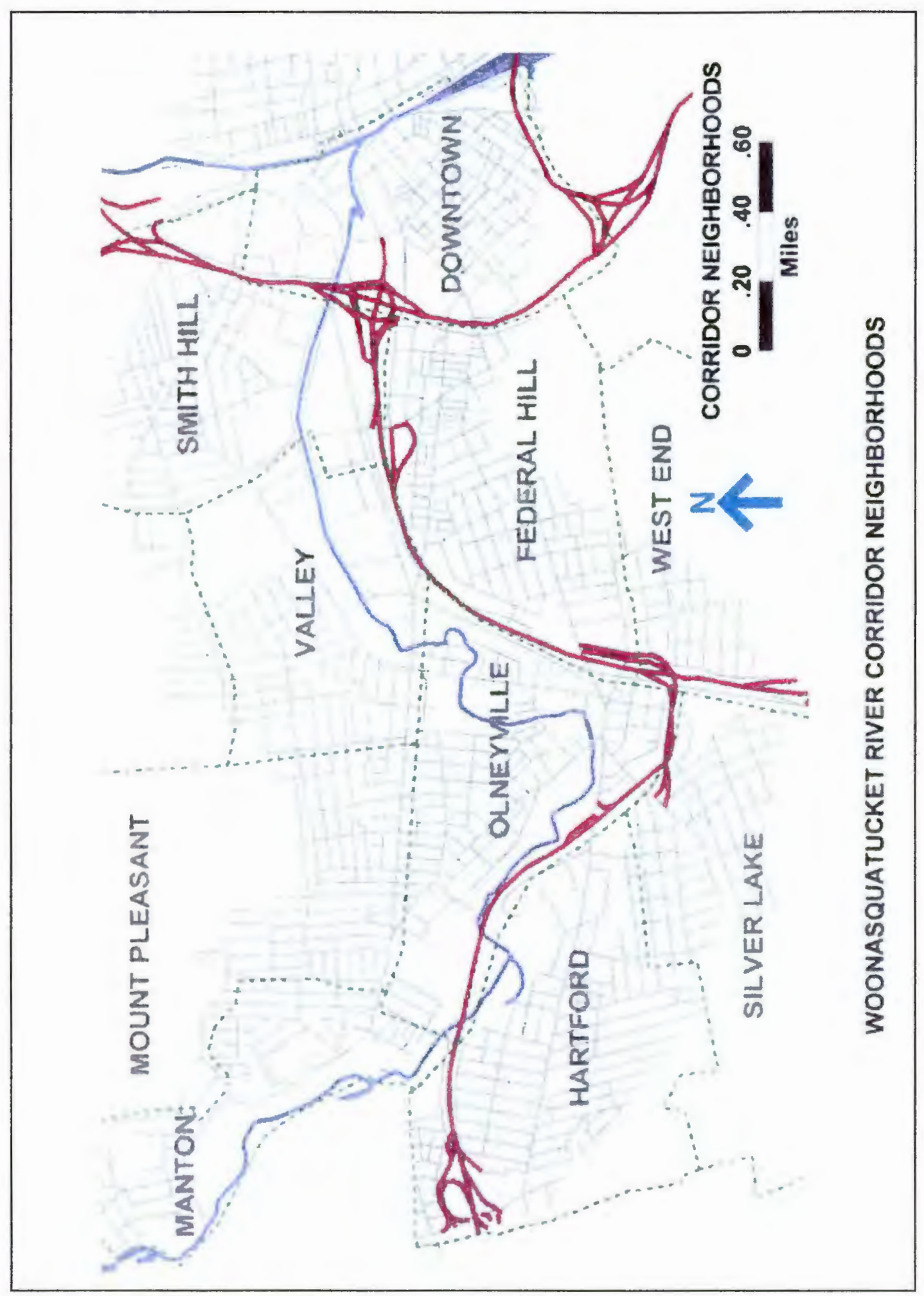

Figure 7. Neighborhoods of Woonasquatucket Greenway (Source: Woonasquatucket Greenway Plan) 


\section{Statistical Analysis of Rankings}

To examine the relationship between the ranking score of a park or open space with the demographics of its census block, a regression model is applied. The model is used to determine if the number of non-whites, vacant housing, children under age 18 , single parents with children under age 18 and female-headed households with children under age 18 and no husband present (independent variables) could predict a score below the median of 12 . Table 6 shows the model summary. R-square tells us that 35 percent of the observed variability in the scoring of parks is "explained" by the independent variables listed. The independent variables are one portion of the reason why these parks score lower than 12 . The remaining 65 percent is not explained.

Table 6. Linear regression model summary for parks and open spaces ranked below the median score of 12.

\begin{tabular}{|c|c|c|c|c|}
\hline Model & R & R Square & Adjusted R Square & Std. Error of the Estimate \\
\hline 1 & .591 & .350 & .106 & 1.00 \\
\hline
\end{tabular}
a Predictors: (Constant), NONWHITE, VAC_HU_HISPANIC_UNDER18, SINGPAR_FHHNH

The results of the analysis should not be taken alone. They should be combined with the visual quality assessment. Although throughout the city, socioeconomic factors do not explain why a park may receive a low score; however, examining individual neighborhoods may reveal a greater correlation. For example, the lowest ranking parks were not specifically located within area with high minority populations or large proportions of households headed by females and no husband present (an indicator of a low-income area). But, high-ranking parks are also not located in these areas. By looking at the social, economic and political context of the neighborhoods, the 65 percent that explaius the lower scores may be identified. 


\section{CONCLUSIONS \& RECOMMENDATIONS}

These conclusions take the analysis and findings discussed in the previous chapter and determine what they mean about the parks and open spaces in the City of Providence. Recommendations are an attempt to strengthen weaknesses within the study and identify additional areas of research.

\section{Conclusions}

\section{City Snapshot}

Table 7 summarizes the three categories of census blocks used in this study based on the proportions within each group. The blocks more than 660 feet from a park or open space have a slightly lower percentage of children under age 18. This group of census blocks also has the smallest proportion of Hispanic and non-white population. There are also lower percentages of vacant housing units and units that are rented.

Table 7. Summary of Census block categories for the proportions within each grouping

\begin{tabular}{|l|c|c|c|}
\hline Subject & With Parks (\%) & $\begin{array}{c}\text { Within 660 feet } \\
(\%)\end{array}$ & $\begin{array}{c}\text { More than 660 } \\
\text { feet (\%) }\end{array}$ \\
\hline Population under 18 years old & 25.8 & 26.7 & 23.7 \\
\hline Race/Ethnicity & & & \\
\hline Hispanic population & & 31.5 & 23.9 \\
\hline Non-Hispanic white population & 30.5 & 43.1 & 56.7 \\
\hline Non-white population & 53 & 56.9 & 43.3 \\
\hline & & & \\
\hline Household Composition & & & 12,212 \\
\hline Total households & 10,356 & 50,177 & 15.6 \\
\hline $\begin{array}{l}\text { Single-parent households with children under } \\
\text { age 18 }\end{array}$ & 20.7 & 19.2 & 13.0 \\
\hline $\begin{array}{l}\text { Female-headed households, no husband present, } \\
\text { with children under 18 }\end{array}$ & 18.0 & 17.4 & \\
\hline & & & \\
\hline Housing Temure & & 91.7 & 92.5 \\
\hline Occupied housing units & 91.9 & 8.3 & 7.5 \\
\hline Vacant housing units & 35.4 & 32.7 & 42.6 \\
\hline Owner-occupied housing units & 64.6 & 67.3 & 57.4 \\
\hline Rental housing units & & & \\
\hline
\end{tabular}

Source: Providence Plan

These findings are the opposite of what was anticipated. Census blocks more than 660 feet from a park or open space were expected to have a higher percentage of Hispanic and non- 
white populations, single-family households with children under 18 , female-headed households with children under 18 and no husband present, and rental housing. Results are linked to the increased Hispanic population citywide and the 7.3 acres of parks and open spaces per 1,000 residents ratio.

\section{Statistical Analysis}

The hypothesis that areas with higher minority, lower income populations would have smaller parks than those with middle and upper incomes and less minorities is rejected based on the regression model. There are two reasons why the hypothesis is rejected. First, the relationship between the dependent and independent variables is not linear. Second, the demographic characteristics of census blocks with parks are the opposite of the proposed hypothesis. These findings may also be the result of the changing demographics of the city as a whole, where most of the population refers to themselves as Hispanic or a race other than white. Additionally, areas of the city with higher incomes have little need for parks because of the increased private space. It is concluded that the distribution of minority populations would have little affect on the size of parks and open spaces in the City of Providence.

\section{Access and Quality Assessment of Parks and Open Space}

Based on the physical size of Providence and its population, the city met the national standard of 6 to 10 acres of park per 1,000 persons at 7.3 acres, with more proposed and in the process of development, including Riverside Mills and Pleasant Street Park. Although geographically the distribution of parks and open space appears to be equitable, the quality of the resources comes into question.

Roger Williams Park and Triggs Memorial Golf Course both received the highest score in the ranking system of this study. Even though they ranked high, their accessibility is quite low. Roger Williams Park is the largest in the city. It is well maintained with many features including a zoo, Japanese garden, botanical greenhouses, casino, children's playground and pastoral landscapes. Only one area of the city as direct access to this park, most residents have to drive to get there. Interstate 95 also runs along the western side of the park, acting as a barrier. It is assumed that a large portion of the Parks Department's budget goes to the 
maintenance of the park to keep it clean and functional. Triggs Memorial Golf Course is just that, a golf course. A private company maintains it and only those who golf use it. Therefore, it's usability and accessibility is limited to a small user group.

As previously mentioned, most playgrounds have new equipment as a result of a bond issued for park improvements. The city's parks also provide a variety of recreational activities, the most common being ball and soccer fields, playground equipment, walking paths and basketball courts. Several have parking lots or ample street parking, as well as being within walking distance from several neighborhoods.

The biggest factor that distinguished parks is the cleanliness categories of the evaluation. Parks between Broad Street and Eddy Street have the most litter, which accumulates along chain-link fences that surround the parks (Map 29 and 30). They are in areas dominated by non-white populations and female-headed households with children under 18 and no husband present, an indicator of low-income areas. Mr. Robert McMahon, Deputy Director of the Providence Parks Department indicated in a telephone conversation that certain parks are vandalized continuously and it is difficult for his staff to maintain them. His assumption is that a more transient population would have less investment in a park than a stable neighborhood. I would take from his comment that a poorer neighborhood would take less responsibility in a park's appearance. I do not completely agree with this comment. To some degree, actions of residents surrounding the park and its users will affect its cleanliness. Kaplan et. al. (1998) discuss the importance of providing local residents the opportunities to participate in park maintenance and clean up. Being involved in volunteer programs gives participants the sense of accomplishment, joy in learning new things, pride in contributing to the appearance of their neighborhood, and feeling environmental degradation is an issue that can be tackled and overcome. These programs need significant organization, guidance and leadership to be successful. Perhaps if the city cannot keep up with the maintenance of neighborhood parks, instituting a volunteer program with area residents may help. 
Map 29: Parks and Open Spaces

Between Elmwood Avenue, Broad Street and Eddy Street

Non-white population as a percent of total population

Providence, RI, 2000

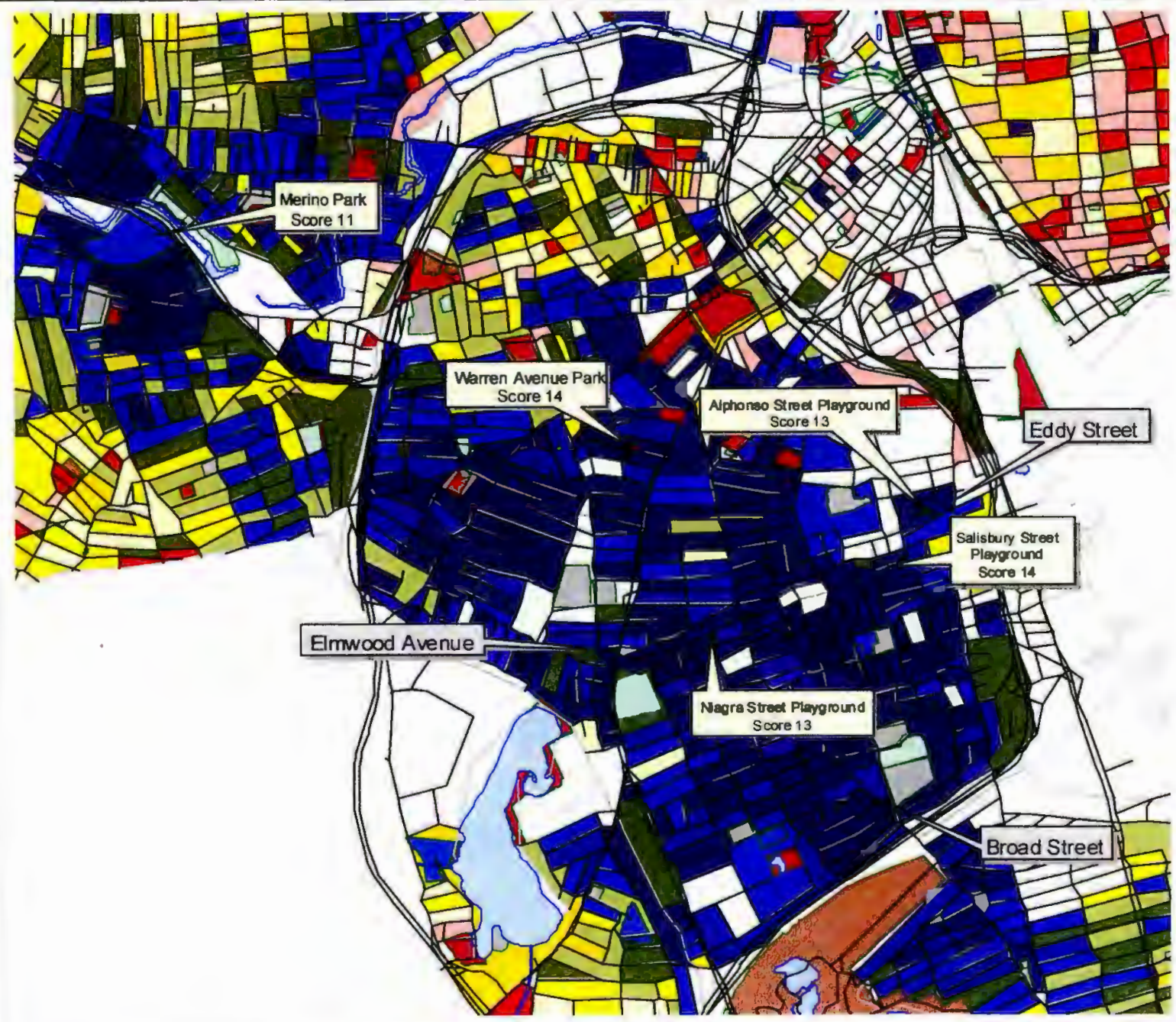

Non-white population as a percent of total population Less than $10 \%$

$10-20 \%$

$20-30 \%$

$30-40 \%$

$40-50 \%$

$50-60 \%$

$60-70 \%$

$70-80 \%$

$80-90 \%$

$90-100 \%$

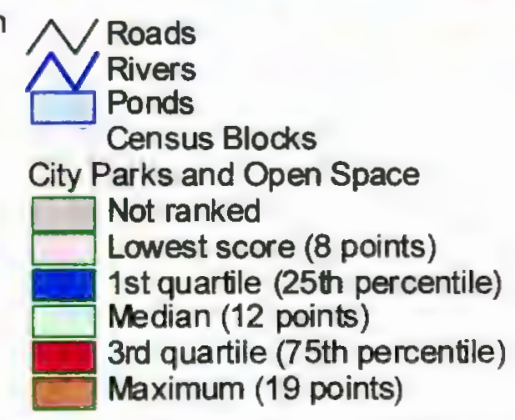

Source: Providence Plan

\& R! Geographic Information System

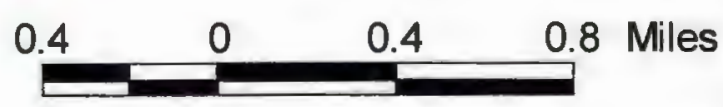


Map 30: Parks and Open Spaces

Between Elmwood Avenue, Broad Street and Eddy Street

Female-headed households with children under 18 and no husband present

Providence, RI, 2000

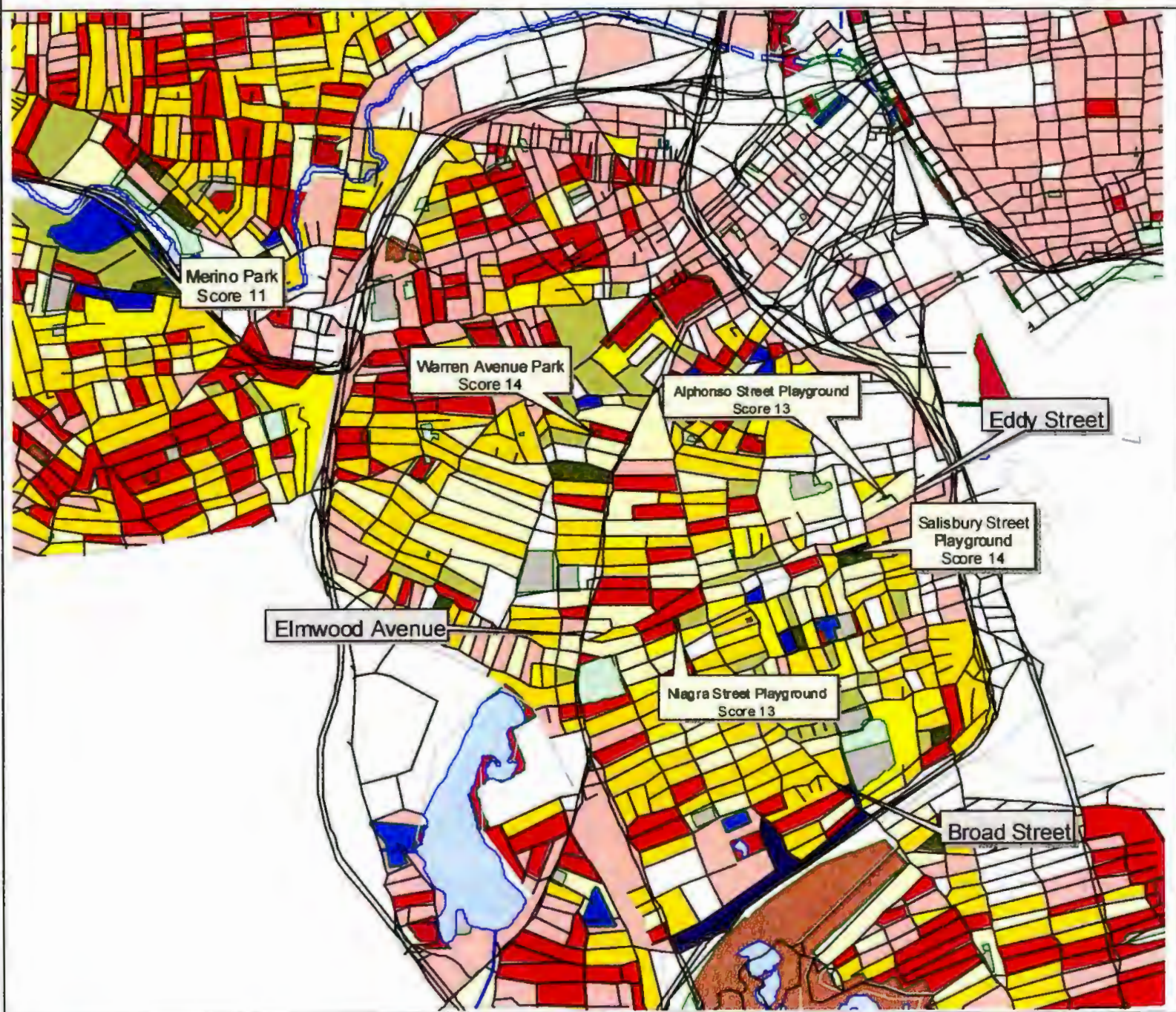

Female households with children under 18

and no husband present as a percent of total

less than $10 \%$

$10-20 \%$

$20-30 \%$

$30-40 \%$

$40-50 \%$

$50-60 \%$

$60-70 \%$

$70-80 \%$

$80-90 \%$

$90-100 \%$

Roads
Rivers
Ponds

Census Blocks

City Parks and Open Space

$\square$ Not ranked

Lowest score ( 8 points)

1st quartile (25th percentile)

Median (12 points)

3rd quartile ( 75 th percentile)

Maximum (19 points)

Source: Providence Plan

\& RI Geographic Information System $\begin{array}{lll}0.4 & 0 & 0.4\end{array}$

0.8 Miles 
An analysis of the city's budget for the amount of time and money devoted to these parks may reveal other issues associated with park degradation. Further questions that need to be answered include: how often does the city visit these smaller neighborhood parks for maintenance purposes, how much of the budget is allocated to maintenance of neighborhood parks as opposed to larger city parks like Roger Williams Park, and how do the residents that use the park feel about its condition?

Security seemed to be an issue in the area between Broad Street and Eddy Street as well but also off Elmwood Avenue (Map 29 and 30). There was a small group of men at Mattie Street Totlot drinking beer when the field visit was made. I did not stop because I was alone and felt uncomfortable taking notes and pictures of the park, even during the early afternoon. Both Salisbury Street Totlot and Niagara Street Playground were locked, I assume due to past problems. Additionally Merino Park in the western part of the city is another park that was not accessible because the gate was locked across the road leading to the park. Although there appears to be issues of security at these parks, locked gates are inhibiting access by potential users. All three of these parks are in census blocks with high percentages of nonwhite populations. Merino Park is adjacent to a large area of public housing developments along Hartford Avenue. These dense areas need access to public open space because they lack private space in such developments.

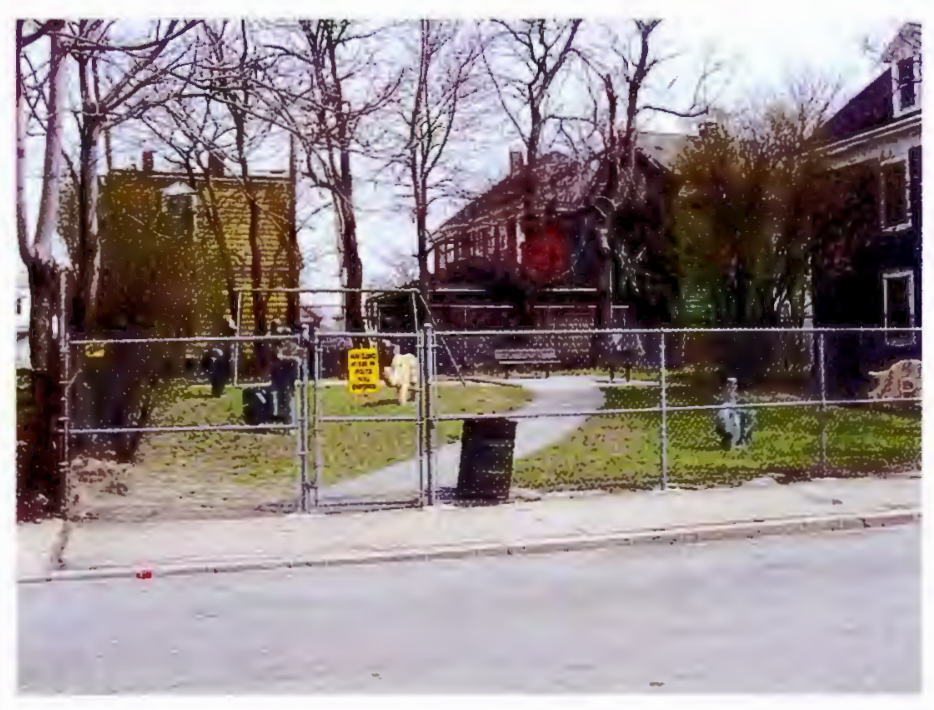

Niagara Street Park 


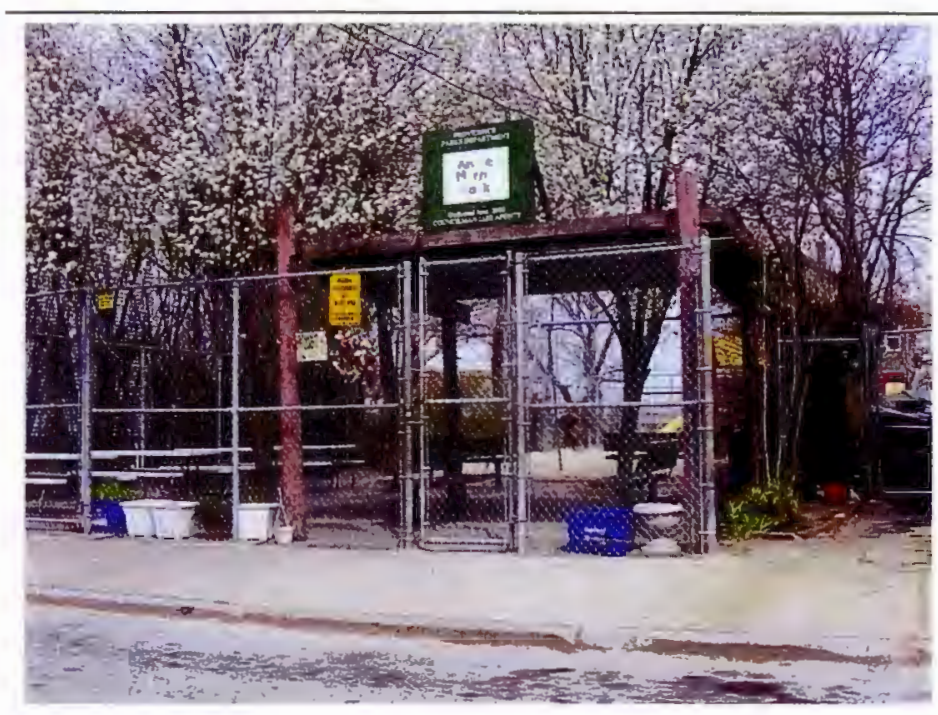

Salisbury Street Totlot

Also observed during field visits are the land uses adjacent to parks. Most are within neighborhoods and surrounded by residences. Others are on small parcels of land, probably unsuitable for any other use, and difficult to spot, such as Waldo Street Totlot, Salisbury Street Totlot and Morris Avenue Totlot. This is not necessarily a negative aspect, just an observation. Alphonso Street Park is across from a vacant lot littered with trash and a parking lot for a medical building on Eddy Street. A conversation with a neighbor indicated that the lot had once contained a house, which became dilapidated and was torn down. The woman who lived in the house had passed away years before and the family, in her opinion, has not done anything with the lot since. Narragansett Electric was next to Sackett Street Park. Any negative impact this would have on the park was unclear, but the equipment stored in the lot did not add to the aesthetic quality of the park. Warren Avenue Park was located in an area of light industrial uses and surrounded by boarded up homes.

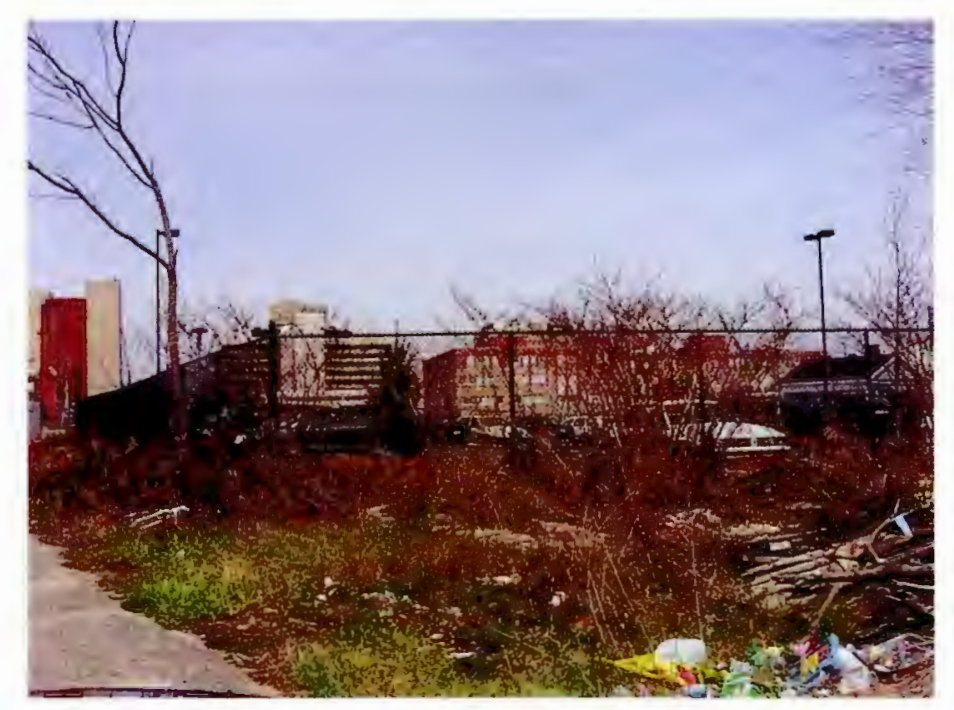

Lot across from Alphonso Street Park 


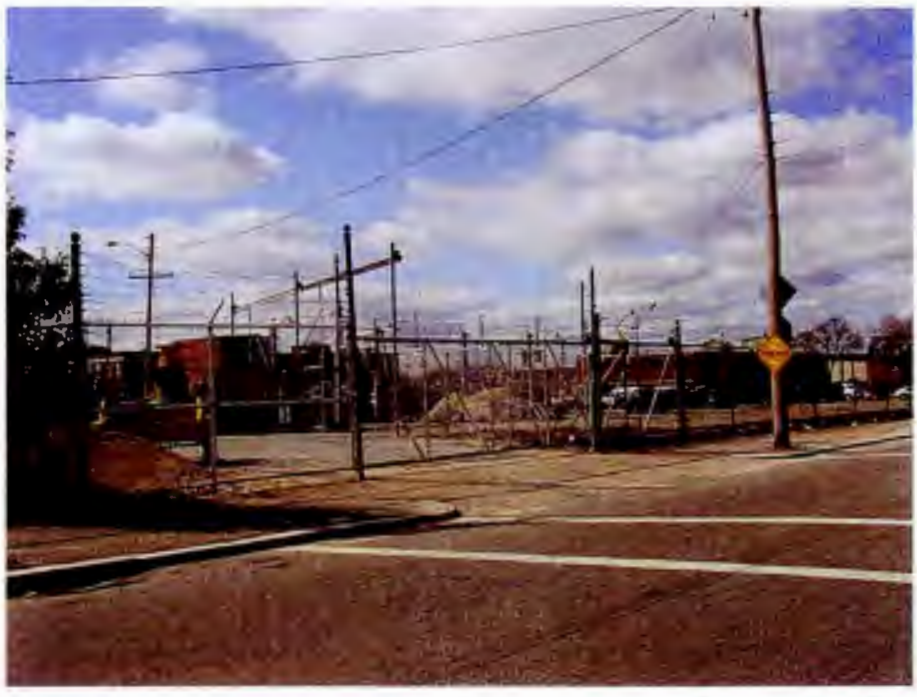

Narragansett Electric next to Sackett Street Park

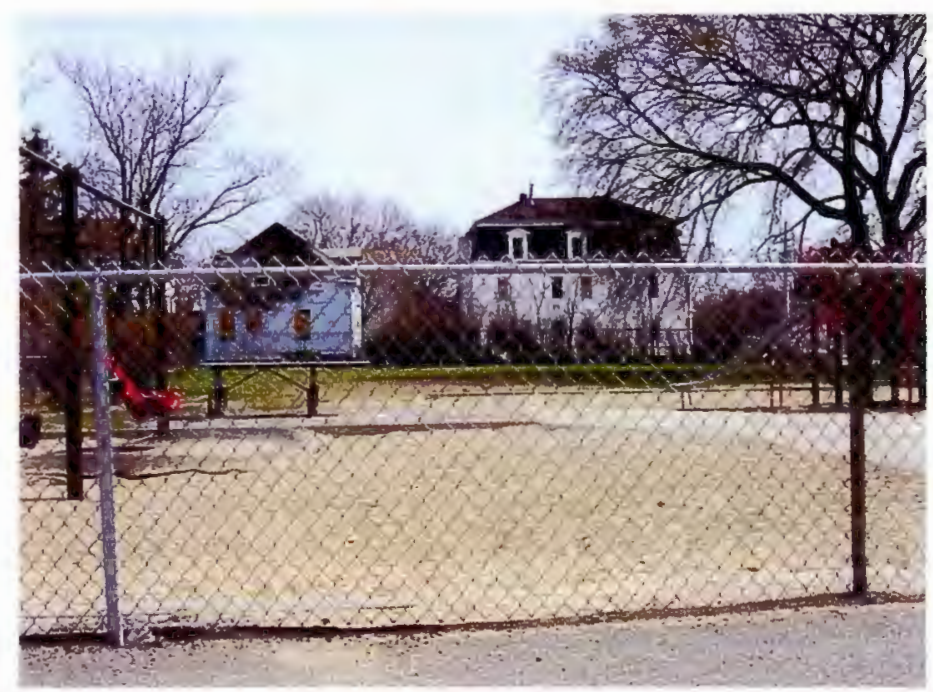

Warren Avenue Playground

Good aspects of parks and open spaces include new play equipment, protection from street activity and increased opportunities to interact with natural settings. As previously mentioned, most of the playground swings, slides and other equipment have been replaced. All parks with playgrounds or totlots, ball fields or basketball courts are screened from the road by either a fence or vegetation. Barriers from street traffic are absent for parks with just benches or sitting areas such as Mansion Park, Constance Witherby Park and India Point Park. Parks that have grassy lawns and sitting areas along with playgrounds have play equipment located far from the street, such as Lippitt Memorial Park and Dexter Training Grounds. 
I discovered more opportunities to interact with nature in the city than I anticipated. Blackstone Park and Neutaconkanut Park and Uplands both provide natural wooded areas with trails. They are both high points in the city with steep slopes, probably unsuitable for any other type of development had they not been designated as open space. Although frequently mowed, the Pleasant Valley Parkway is an area where runoff treatment is combined with providing open space. There are opportunities to observe small natural systems in the free-flowing water and grasses.

Improving the quality of the city's rivers and waterfront has been a focus of economic redevelopment in neighborhoods as well as downtown. The Woonasquatucket River and Greenway are the focus of neighborhood revitalization by increasing open space and recreation opportunities in the lower-income areas of the city with the idea of stimulating community-based economies as well. Within the past 5 years, the confluence of the Woonasquatucket and the Moshassuck River into the Providence River has been re-exposed. They were re-routed, road decking was removed and a linear park has been developed. The waterfront has also been the focus of many proposals in the city to reestablish natural systems, such as the wetland grasses along the Riverwalk. Natural areas will also increase with the continued development of the Woonasquatucket Greenway at Riverside Mills and other natural areas along Route 6.

In summary, the quantity of parks and open space within the City of Providence is fairly equitable statistically, and will continue to be more so as new parks are created.

Socioeconomic characteristics used in this study did not predict the size of a park or open space. However, the quality of these parks and the safety associated with specific sites is worse in particular neighborhoods. Areas with higher percentages of non-white Hispanic and non-white populations along with high percentages of single-parent households have lower quality parks. By lower quality, it was meant that these parks contained more litter, giass and graffiti and safety concerns are evident through locked park gates and suspicious behavior. Statistically, the socioeconomic characteristics explain 35 percent of the lower ranking scores. 


\section{Recommendations}

Recommendations are divided into two categories. The first discusses the maintenance and exploration of parks and open spaces for improved quality of life, better environmental management and opportunities to interact with natural settings. The second category recommends further research that is needed regarding equity in urban parks and open space in support of this study.

\section{Maintain existing parks and open spaces and explore new opportunities}

Parks and open spaces that provide outdoor recreation in a safe environment should be maintained for future users. This can be achieved through funding allocation by the city's budget and time from the Parks Department. It is also important to engage residences in the process to ensure their needs are met and to increase pride in the neighborhood. Existing preserved natural features should be maintained to improve environmental integrity, which increases the quality of life in surrounding communities. Examples include continued monitoring of the Woonasquatucket River and the Providence River, but also keeping Neutaconkanut Park and Uplands and Blackstone Park open to the public for natural exploration.

New opportunities in parks and open spaces exist in many forms. New parks are continuing to be created, such as Riverside Mills and Pleasant Street Park. These parks have been developed in areas with high minority populations and indicators of low-income status such as single-parent households. This should continue. As a part of this effort, a "green" network of parks and open spaces can further support creation as well as link neighborhoods together. The Woonasquatucket Greenway Project is an excellent model for linking neighborhoods together and incorporating green space into low-income areas. The greenway begins at Waterplace Park at Capital Center and follows the Woonasquatucket River through the neighborhoods of Valley, Olneyville, Manton, and Hartford. Low-income househoids and minority populations dominate all of these areas. New green spaces are being created along the route on brownfields that were previously mill buildings, like Riverside Mills. 
The identification of natural areas should be explored. An example of this is the rich plant and wildlife diversity located along Route 6 and its incorporation into the Woonasquatucket Greenway. Abandoned lots in residential neighborhoods and undisturbed areas along highways and in industrial or commercial parks can give rise to increase biodiversity. These are great opportunities to observe natural systems. They should be integrated into the city's network of parks and open spaces.

New elements of park design should also be explored, such as the incorporation of natural areas into parks. These areas can reduce city expenditures by reducing maintenance costs and the need for runoff treatment systems. For example, wetlands act as natural filtration systems by capturing suspended solids before discharged into water features. Arcata, California, uses wetlands as part of their wastewater treatment process. Additionally, wetlands provide innovative ways for flood control, storing stormwater based on their natural capacity. Natural features in parks also provide opportunities to discover nature. Wetlands are habitat for a wide array of plant and animals as well as wildfiower meadows, which can also beautify an area as much as a carefully landscaped arrangement. Pleasant Valley Parkway in Providence filters runoff from Academy Avenue and provides a linear greenway through the neighborhood. Combining the roles of parks reduces costs associated with flood control and treatment of urban runoff but also leads to opportunities of natural discovery (Spirn 1984).

\section{Further Research}

The topics discussed in this study are only a small component of a larger picture. Further research needs to be done to support the work presented here. Perhaps the regression model did not support my hypothesis because I used the wrong statistical analysis. For example, Ttests test whether two population means are equal based on the results observed in two independent samples. The social and economic characteristics of census blocks within 660 feet of a park or open space can be compared to those of blocks more than 660 feet. Additionally, when the economic subjects from the US Census are released, they may show a correlation between income and quantity of parks. A stronger relationship may also appear when testing the quality of the parks with the scores generated in this study. 
Another way to analyze parks and open space is to survey users. Users can provide a wealth of information such as how often they use the park, what are safety concerns and strengths and weaknesses of a park. Surveying can also give insight into the needs of the community and if the existing resources meet those needs.

Finally, the political relationships and resources for maintenance within the study area might influence the distribution of parks and open spaces. If these relationships could be analyzed, park development in the city could be understood at an even different level. Factors that could be looked at may include city budgets, allocation of funding, projects supported by various councilpersons or activities of grassroots and neighborhood organizations.

\section{Final Thoughts}

Overall, the hypothesis presented here is a difficult question to answer because there are many forces that affect the number of parks and services a city has, as well as the quality of those associated with a neighborhood. This paper will touched upon some of these issues; however, it was not the main focus of the research. The primary analysis centered on if a correlation exists in a snapshot of a city and to made assumptions based on available literature and interviews with municipal and other interested individuals as to why such a correlation does or does not exist.

Parks and open space contribute greatly to the quality of life in a community by increasing environmental health, providing space for those who lack private space and offering opportunities to interact with and observe nature. Parks and open spaces act as revitalization catalysts leading to increased property values, desirability of an area and civic pride. One of the objectives of a municipality is to protect the safety and welfare of its residents, and creating and maintaining parks and open spaces contribute to this effort enormously.

The City of Providence was a case study that deserves further investigation. The statistical model disproved the hypothesis that lower income, minority areas would have less parks and open spaces than middle and upper income areas with fewer minority populations. Field 
observations showed that parks and open spaces in lower income minority areas were littered with more trash and had problems with graffiti. There were also some inferred concerns over safety such as locked parks during the daytime hours. This study does not identify all the factors that contribute to the difference in quality of parks or open space. The recommendations provided in this study offer some avenues to increase the knowledge regarding equity in urban parks. It is important to note that city efforts have increased the distribution of these assets with the creation of new parks and it is hoped that these activities will continue. 


\section{BIBLIOGRAPHY}

Boerner-Ein, D. Urban Open Space: Color It Valuable. American Forests 97, iss. 1/2 (1991): 61.

Bugliarello, George and Richard G. Chavez. Urban Knowledge: Parks and Social and Economic Development Strategies. Parks and Recreation 123, no. 2 (1997): 35.

Bullard, Robert D. and William J. Clinton. Overcoming Racism in Environmental Decisionmaking. Environment 36, iss. 4 (1994): 10.

Camacho, David E., editor. Environmental Injustices, Political Struggles: Race, Class and the Environment. Durham: Duke University Press, 1998.

Carr, Stephen, Mark Francis, Leanne G. Rivlin, and Andrew M. Stone. Public Space. New York: Cambridge University Press, 1992.

City of Providence. Providence 2000: The Comprehensive Plan. July 1993.

Clayton, Susan. Models of Justice in the Environmental Debate. Journal of Sociai Issues 56 , no. 3 (2000): 459-474.

Cooper Marcus, Clare and Carolyn Francis. People Places: Design Guidelines for Urban Open Space. New York: Van Nostrand Reinhold, 1990.

Cranz, Galen. The politics of park design: A history of urban parks in America. Cambridge: The MIT Press, 1982.

Campbell, Scott. Green Cities, Growing Cities, Just Cities?: Urban Planning and the Contradictions of Sustainable Development." Journal of the American Planning Association 62, iss. 2 (1996): 296.

Dwyer, John F. The Deep Significance of Urban Trees and Forest. In The Ecological City: Preserving and Restoring Urban Biodiversity, ed. Rutherford H. Platt, Rowan A.

Rowntree, and Pamela C. Muick. Amherst: The University of Massachusetts Press, 1994.

Garvin, Alexander. Urban Parks and Open Space. Washington DC: Urban Land Institute, 1997.

Harnik, Peter. Inside City Parks. Washington DC: Urban Land Institute, 2000.

Haughton, Graham. Environmental Justice and the Sustainable City." Journal of Planning Education and Research 18, iss. 3 (1998): 233-243. 
Hayden, Dolores. The Power of Place: Urban Landscapes as Public History. Cambridge: The MIT Press, 1995.

Hough, Michael. City Form and Natural Processes: Towards an Urban Vernacular. New York: Van Nostrand Reinhold: 1984.

Design with City Nature: An Overview of Some Issues. In The Ecological City: Preserving and Restoring Urban Biodiversity, ed. Rutherford H. Platt, Rowan A.

Rowntree, and Pamela C. Muick. Amherst: The University of Massachusetts Press, 1994.

Kibel, Paul Stanton. The Urban Nexus: Open Space, Brownfields, and Justice. Boston College Environmental Affairs Law Review 25, iss. 3 (1998): 589.

Knack, Ruth Eckdish. Dig These Gardens: Nature in the City is Making a Comeback, With Help of a Few Good Friends," Planning 59, no. 7 (July 1994): 22.

Laituri, Melinda, and Andrew Kirby. Finding Fairness in America's Cities? The Search for Environmental Equity in Everyday Life." Journal of Social Issues 50, no. 3 (1994): 121139.

Lerner, Steve and William Poole. Economic Benefits of Parks and Open Space: How Land Conservation Helps Communities Grow Smart and Protect the Bottom Line. Washington, DC: The Trust For Public Land, 1999.

Mitchell, J. T., D. S. K. Thomas, and S. L. Cutter. Dumping in Dixie Revisited: The Evolution of Environmental Justice in South Carolina. Social Science Quarterly 80, iss. 2 (1999): 229-243.

Platt, Rutherford H., Rowan A. Rowntree and Pamela C. Muick, eds. The Ecological City: Preserving and Restoring Urban Biodiversity. Amherst: University of Massachusetts Press: 1994.

Solecki, W. D. and J. M. Welch. Urban Parks: Green Spaces or Green Walls? Landscape and Urban Planning 32, no. 2 (1995): 93.

Spirn, Anne Whiston. The Granite Garden: Urban Nature and Human Design. New York: Basic Books, 1984.

Stretesky, Paul. Environmental Justice: An Analysis of Superfund Sites in Florida." Social Problems 45, iss. 2 (May.1998): 268.

Tarrant, M. A. and H. K. Cordell. Environmental Justice and the Spatial Distribution of Outdoor Recreation Sites: An Application of Geographic Information Systems. Journal of Leisure Research 31, iss. 1 (1999): 18-34. 
Urban Design Group, Inc. Woonasquatucket River Greenway Plan Providence, Rhode Island. Providence, Rhode island: The Providence Plan and The Woonasquatucket River Greenway Project Task Force, 1997.

Weinberg, Adam S. The Environmental Justice Debate: New Agendas for a Third Generation of Research." Society and Natural Resources 11, iss. 6 (1998): 605.

Young, Terence. Modern urban parks. Geographical Review 85, no. 4 (1995): 535. 
ATTACHMENTS 


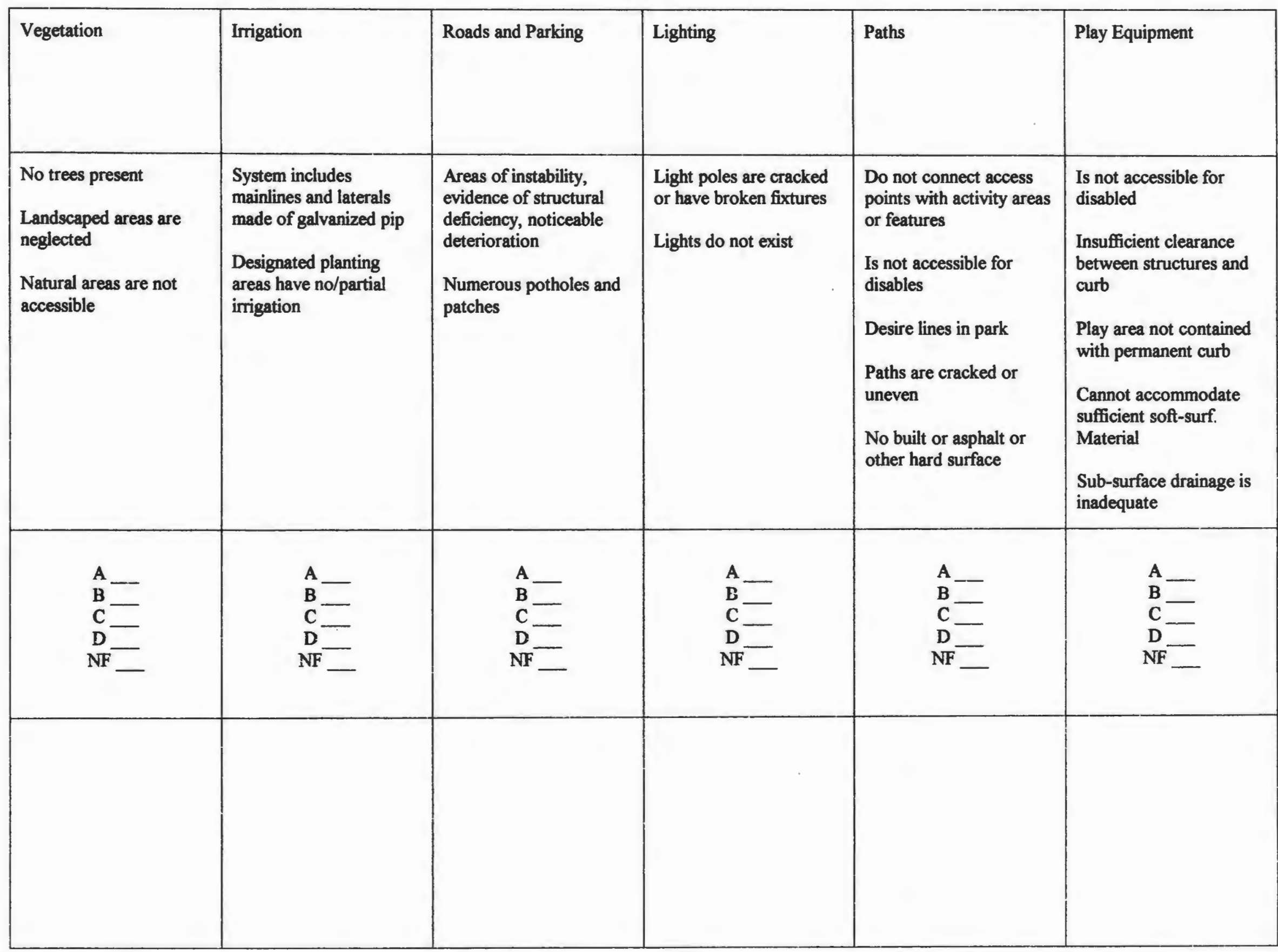




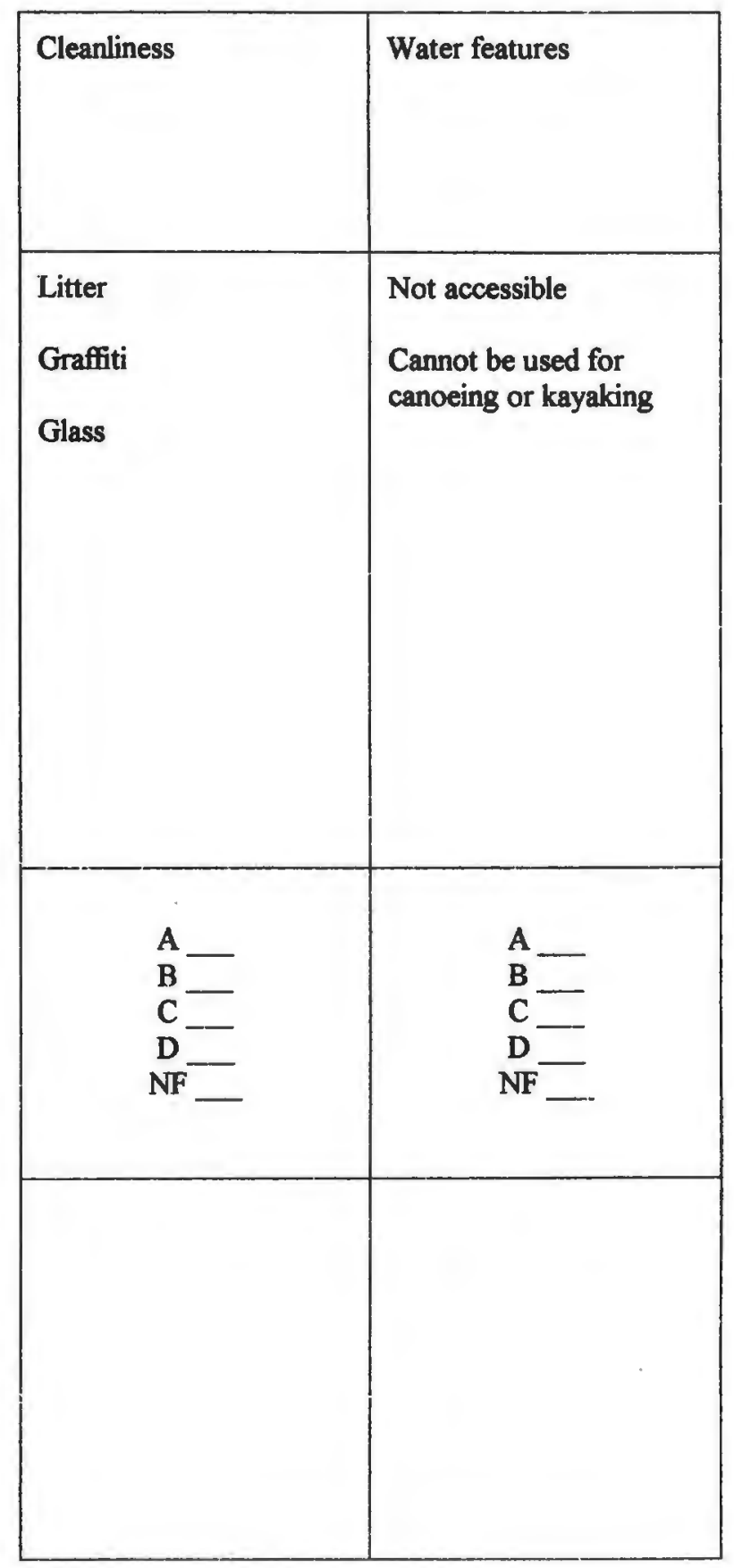




\begin{tabular}{|c|c|c|c|c|c|c|c|c|c|c|c|c|c|}
\hline & & & Clomenlln & & & & & & & & & & \\
\hline PARKNAME & AREA (SF) & AREA (AC) & Litter & Oraffiti & Qbes: & $\begin{array}{l}\text { Socurtty (locked artes, } \\
\text { other activitiea) }\end{array}$ & $\begin{array}{l}\text { Molural } \\
\text { fentures }\end{array}$ & As (4 pts) & Bs (3 pts) & Cs (2 pts) & $D=(1 \mathrm{pts})$ & MFs (O pts) & $\begin{array}{l}\text { Total } \\
\text { score }\end{array}$ \\
\hline Daniel Ave. Plapround & $100 \mathrm{mom}$ & & & & & & & & & & & & \\
\hline Francliscan Park & $-\frac{106393.893}{133821.046}$ & 2.442 & A & A & A & A & $\mathbf{B}$ & 4 & 1 & 0 & 0 & $\underline{0}$ & 19 \\
\hline Gladys Potter Park & $\frac{133821.046}{21837.214}$ & $\frac{3.072}{0.497}$ & A & A & A & A & B & 4 & 1 & 0 & 0 & $\overline{0}$ & 19 \\
\hline Roger Willams Park & 21637.214 & 0.497 & $A$ & A & A & A & B & 4 & 1 & 0 & 0 & 0 & 19 \\
\hline Tripos Momorlal Goll Couren & $\begin{array}{r}205041.283 \\
14798.031\end{array}$ & 4.728 & A & A & A & A & B & 4 & 1 & 0 & 0 & o & 19 \\
\hline Wenskuck Park & $\frac{14798.031}{147034}$ & 0.340 & A & A & A & A & B & 4 & 1 & 0 & 0 & 0 & 19 \\
\hline & 147481.454 & 3.386 & A & A & A & A & B & 4 & 1 & 0 & 0 & o. & 19 \\
\hline Point Stroet Landing South & 532743.602 & 12.230 & $\mathbf{A}$ & A & A & $\bar{A}$ & c & 4 & 0 & 1 & 0 & 0 & 19 \\
\hline Ellery St. Perk & 12000 n & & & & & & & & & & & & \\
\hline Mt. Ploasant Memorial Park & $\frac{12933.355}{167242.967}$ & $\frac{0.297}{3839}$ & $\frac{8}{4}$ & A & B & A & $B$ & 2 & 3 & 0 & 0 & 0 & 17 \\
\hline & & & & A & A & C & B & 3 & 1 & 1 & 0 & o. & 17 \\
\hline Blackstone Park & 1865453.583 & 42.825 & A & A & $\bar{A}$ & $N F$ & A & 4 & 0 & 0 & 0 & 1 & 16 \\
\hline Buttonhols Golf Coureo & 73315.310 & 1.683 & $\bar{A}$ & A & $\bar{A}$ & A & NF & $4^{-1}$ & 0 & 0 & 0 & 1 & 16 \\
\hline Clarence st. Playpround & 34003.820 & 0.801 & A & $\mathbf{A}$ & A & A & NF & 4 & $\underline{0}$ & 0 & 0 & 1 & 16 \\
\hline Collier Point Park & 40118.333 & 0.921 & A & A & A & A & NF & 4 & $\underline{0}$ & 0 & 0 & 1 & 16 \\
\hline Cranoton Street Tottol & 219978.960 & 5.050 & A & A. & A & $A$ & $\mathrm{NF}$ & 4 & 0 & 0 & 0 & 1 & 16 \\
\hline Davoy Lopes Rec. Ctr. / Pool / Park & 51222.850 & 1.178 & A & $\bar{A}$ & A & $\bar{A}$ & INF & 4 & $\overline{0}$ & 0 & $\overline{0}$ & 1 & 16 \\
\hline Drummond Fiold & 3645.283 & 0.084 & A & A & A & A & NF & 4 & 0 & D. & 0 & 1 & 16 \\
\hline Esck Hopkins Homestood & 24024.028 & 0.552 & A & A & A & $\bar{A}$. & NF & 4 & 0 & 0 & 0 & 1 & 16 \\
\hline Fargnoll Park & 49555.797 & 1.138 & A & A & A & A & $\mathrm{MF}$ & 4 & 0 & 0 & 0 & 1 & 16 \\
\hline Floot Skoting Conter & 3007.351 & 0.069 & A & $A$ & A & $\therefore$ & NF & 4 & 0 & 0 & $\underline{0}$ & 1 & 16 \\
\hline Knipht St. Playpround af Zucco & 92797.482 & 2.130 & A & $\mathbf{A}^{-}$ & A & A & MF & 4 & 0 & 0 & 0 & 1 & 16 \\
\hline Morris Avo. Totiol & 884045.661 & 20.295 & A & A & $A$ & $\overline{\mathbf{A}}$ & NF & 4 & 0 & c & 0 & 1 & 16 \\
\hline Nettuan Bishop Courts & 200294.919 & 4.508 & $\mathbf{A}$ & A & $\mathbf{A}$ & A & MF & 4 & 0 & 0 & 0 & 1 & 16 \\
\hline Noutuconkanut PankJ Uplands & 227232.984 & 5.217 & A & A & $\mathbf{A}$ & NF & $A$ & 4 & 0 & 0 & 0 & 1 & 16 \\
\hline Ninth Streot Park & 6047.286 & 0.139 & A & A & A & $A$ & NF & 4 & 0 & 0 & 0 & 1 & 16 \\
\hline Nerth Burial Ground & 10526.276 & 0.242 & A & $\bar{A}$ & A & A & MF & 4 & 0 & 0 & c & 1 & 16 \\
\hline Reservoli Ave. School & 30009.745 & 0.806 & A & A & A & A & NF & 4 & 0 & 0 & 0 & 1 & 16 \\
\hline Swen Polnt Comotory & 610625.740 & 14.018 & $\bar{A}$ & $\bar{A}$ & $\mathbf{A}$ & A & $\mathrm{NF}$ & 4 & 0 & 0 & 0 & 1 & 16 \\
\hline Bhackatono Blvd. Park & 787479.77 & 18.078 & A & A & A & NF & B & 3 & 1 & 0 & 0 & 1 & 15 \\
\hline Canada Pond Management Area & 380926.792 & 8.883 & $B$ & $\bar{A}$ & $\bar{A}$ & NF & A & 3 & 1 & 0 & 0 & 1 & 15 \\
\hline Collyer Pank & 357998.482 & 8.219 & B & A & A & A & $\mathbf{N F}$ & 3 & 1 & 0 & 0 & 1. & 15 \\
\hline Constence Witherby Park & 9088.702 & 0.200 & A & A & $\bar{A}$ & NF & $B$ & 3 & 1 & 0 & 0 & 1 & 15. \\
\hline Davis Pank & 83317.512 & 2.142 & $A$ & $B$ & $\mathbf{A}$ & A & NF & 3 & 1 & 0 & 0 & 1 & 15 \\
\hline Dexter Truhing Grounds & 11041.550 & 0.253 & A & A & A & NF & $B$ & 3 & 1 & 0 & 0 & 1 & 15 \\
\hline Josin Ploypround & 235687.725 & 5.411 & B & A & A & A & NF & 3 & 1 & 0 & 0 & 1 & 15 \\
\hline Lipplete Memonal Fark & 150682.438 & 3.597 & A & $\bar{A}$ & $\bar{A}$ & $\mathrm{NF}$ & $B$ & 3 & 1 & 0 & 0 & 1 & 15 \\
\hline M.E. Sharpe Momortal Park & 410472.887 & 8.423 & $\mathbf{A}$ & A & A & NF & $\bar{B}$ & 3 & 1 & 0 & 0 & 1 & 15 \\
\hline Manaion Park & 12652.238 & 0.280 & A & $\mathbf{A}$ & A & NF & 8 & 3 & 1 & 0 & 0 & 1 & 15 \\
\hline Memortal Park & 5578.991 & 0.128 & A & A & A. & NF & 8 & 3 & 1 & 0 & 0 & 1 & 15 \\
\hline Puterson Puark & 500858.615 & 11.684 & A & A & A & NF & 8 & 3 & 1 & 0 & 0 & 1 & 15 \\
\hline Plecsant Valloy Parkmy & 14076.809 & 0.323 & A & A & A & NF & $\mathbf{B}$ & 3 & 1 & 0 & 0 & 1 & 15 \\
\hline Reoment Ave. Playround & 67509.407 & 1.552 & A & A & $\mathbf{A}$ & MF & B & 3 & 1 & 0 & 0 & 1 & 15. \\
\hline Roger Willieme Lending & 1954.050 & 0.045 & $A$ & A & A & NF & 8 & 3 & 1 & 0 & 0 & 1 & 15 \\
\hline Rogar Willimems Memortal Park & 40107.278 & 0.821 & A & A & A & NF & 8 & 3 & 1 & $\overline{0}$ & 0 & 1 & 15 \\
\hline Sectione St. School Pgrd. & 12278.508 & 0.282 & A & A & A & NF & $B$ & 3 & 1 & 0 & 0 & 1 & 15 \\
\hline Silver Lk Rec. Ctr. I Almepno Pool & 4204.616 & 0.007 & A & A & A & NF & B & 3 & 1 & 0 & 0 & 1 & 15 \\
\hline
\end{tabular}




\begin{tabular}{|c|c|c|c|c|c|c|c|c|c|c|c|c|c|}
\hline & & & Claen $/ n$ & & & & & & & & & & \\
\hline PARKMANE & AREA (SF) & AREA (AC) & Litter & Oraniti & Glass & $\begin{array}{l}\text { Securtty (locked gates, } \\
\text { other activities) }\end{array}$ & $\begin{array}{l}\text { Natura } \\
\text { features }\end{array}$ & As (4 pts) & Bs (3 pts) & $\mathrm{Cs}$ (2 pts) & $D_{2}$ (1 $\left.p t s\right)$ & NFs (0 pts) & $\begin{array}{l}\text { Total } \\
\text { score }\end{array}$ \\
\hline Station Park & 15612.516 & 0.450 & A & A & $\bar{A}$ & $\mathrm{NF}$ & $\mathrm{B}$ & 3 & 1 & 0 & 0 & 1 & 15 \\
\hline Summit Avanue Park & 186941.259 & 4.292 & A & A & $A$ & NF & B & 3 & 1 & 0 & 0 & 1 & 15 \\
\hline Voancio St. Pieyground & 6658.162 & 0.153 & A & $\bar{A}$ & A & NF & B & 3 & 1 & 0 & 0 & 1 & 15 \\
\hline Waldo St. Totilot & 41221.833 & 0.946 & $B$ & A & A & A & NF & 3 & 1 & 0 & 0 & 1 & 15 \\
\hline Wost Park & 38451.079 & 0.883 & A & A & A & NF & $B$ & 3 & 1 & 0 & 0 & 1 & 15 \\
\hline Bople Square & 3371,0 & & & & & A & NF & 2 & 2 & 0 & & & \\
\hline John Donigian Mernorial Park & $\begin{array}{r}3275.129 \\
311627.662\end{array}$ & $\begin{array}{r}0.075 \\
7.154\end{array}$ & $\frac{B}{A}$ & $A$ & $B$ & $\frac{A}{\text { NF }}$ & $\frac{\mathrm{Nr}}{\mathrm{C}}$ & $\frac{2}{3}$ & $\frac{2}{0}$ & $\frac{0}{1}$ & $\frac{0}{0}$ & 1 & 14 \\
\hline Laurel Hill Ave. Playpround & 23055.743 & 0.529 & B & $\frac{A}{A}$ & B & A & NF & 2 & 2 & $\frac{1}{0}$ & $\frac{0}{0}$ & $\frac{1}{1}$ & 14 \\
\hline Mashapaug Pond & 9283.921 & 0.213 & A & A & $A$ & $\mathrm{NF}$ & c & 3 & 0 & $\frac{T}{1}$ & 0 & $\frac{1}{1}$ & $\frac{14}{14}$ \\
\hline & & & & & & & & & & & & & \\
\hline Murphy-Trainer $\bar{P}_{\text {wark }}$ & 10675.662 & 0.245 & $A$ & C & 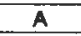 & NF & A & 3 & 0 & 1 & 0 & 1 & 14 \\
\hline Preston \& lves Ptyr. & 8477.401 & 0.149 & $B$ & $\bar{A}$ & $A$ & NF & $B$ & 2 & 2 & 0 & 0 & 1 & 14 \\
\hline Prospect Terrece & 497602.053 & 11.425 & B & A & A & $\mathrm{NF}$ & B & 2 & 2 & 0 & 0 & 1 & 14 \\
\hline Riverwalk & 367864.774 & 8.440 & $A$ & $A$ & $A$ & NF & c & 3 & 0 & 1 & 0 & 1 & 14 \\
\hline Sallsbury Stroed Todot & 93063.549 & 2.137 & A & A & $\bar{A}$ & c & NF & 3 & 0 & 1 & 0 & 1 & 14 \\
\hline Warren Avo. Pleyground & 1071233.242 & 24.592 & B & $\mathbf{A}$ & B & $\bar{D}$ & $B$ & 1 & 3 & 0 & 1 & 0 & 14 \\
\hline Waterptecos Park & 3942.614 & 0.091 & A & A & A & NF & C & 3 & 0 & 1 & 0 & 1 & 14 \\
\hline Apphonso Street Totlot & 5130.332 & 0.118 & B & B & B & A & NF & 1 & 3 & 0 & 0 & 1 & 13 \\
\hline Bacter St. Park & 6517.048 & 0.150 & c & A & B & $\hat{A}$ & $\mathrm{NF}$ & $\frac{1}{2}$ & $\frac{1}{3}$ & 1 & $\frac{0}{0}$ & $\frac{1}{1}$ & 13 \\
\hline Candaco St. Playpround & 884810.308 & 20.312 & B & 8 & $B$ & A & NF & 1 & 3 & 0 & 0 & 1 & 13 \\
\hline Contral-Classical High and Filds & 25590.804 & 0.587 & $B$ & A & $A$ & c & NF & 2 & 1 & 1 & 0 & 1 & 13 \\
\hline Mashapeng Pond Shoreline & 82890.158 & 2.132 & B & A & A & NF & c & 2 & 1 & 1 & 0 & $\frac{1}{1}$ & 13 \\
\hline Nlegre Stroet Park & 3573549.027 & 82.037 & A & B & A & $c$ & NF & 2 & 1 & 1 & 0 & 1 & 13 \\
\hline St. Ann's Piaza & 337781.545 & 7.754 & $\bar{B}$ & $\bar{A}$ & $A$ & $c$ & NF & 2 & 1 & 1 & 0 & 1 & 13 \\
\hline Viscotosi Park & 268135.460 & 6.156 & B & A & $B$ & $\mathrm{NF}$ & B & 1 & 3 & 0 & 0 & 1 & 13 \\
\hline Abbott Park & 7497.164 & 0.172 & $\bar{A}$ & A & A & MF & NF & 3 & 0 & $\overline{0}$ & 0 & 2 & 12 \\
\hline Asa Meseer Schoof & 44864.573 & 1.030 & A & A & $A$ & NF & NF & 3 & 0 & 0 & 0 & $\frac{2}{2}$ & $\frac{12}{12}$ \\
\hline Biltmoro Park & 45447.173 & 1.043 & A & A & $A$ & NF & NF & 3 & 0 & 0 & 0 & 2 & 12 \\
\hline Brassil Memorial Padk & 17807.189 & 0.400 & A & A & A & NF & $\mathrm{NF}$ & 3 & 0 & 0 & 0 & 2 & 12 \\
\hline Brown St. Playground & 11786.110 & 0.271 & A & $A$ & $A$ & NF & NF & 3 & 0 & 0 & 0 & 2 & 12 \\
\hline Burnatdo Park & 37299.029 & 0.856 & A & A & $\bar{A}$ & NF & MF & 3 & 0 & 0 & 0 & 2 & 12 \\
\hline Cethedral Square & 25614.293 & 0.588 & A & A & A & $\mathbf{M F}$ & $\mathbf{N F}$ & 3 & 0 & 0 & 0 & 2 & 12 \\
\hline Corbo Square & 879298.665 & 20.188 & $A$ & A & $A$ & MF & NF & 3 & 0 & 0 & 0 & 2 & 12 \\
\hline Corliss Landing & 71321.242 & 1.637 & $\mathrm{C}$ & A & $A$ & NF & c & 2 & 0 & 2 & 0 & 1 & 12 \\
\hline Corliss Park & 28112.712 & 0.599 & A & A & $\bar{A}$ & NAF & $\mathrm{NF}$ & 3 & 0 & 0 & 0 & 2 & 12 \\
\hline DePasquale Plaza & 480271.712 & 11.026 & A & A & A & $\mathrm{NF}$ & NF & 3 & 0 & 0 & 0 & 2 & 12 \\
\hline Diamond Strout Playground & 429727.700 & 9.842 & c & $B$ & $B$ & $A$ & NF & 1 & 2 & 1 & 0 & 1 & 12 \\
\hline Fenner Square & 127443.086 & 2.826 & $A$ & A & $\frac{a}{A}$ & NF & NF & $\frac{5}{3}$ & 0 & 0 & 0 & 2 & 12 \\
\hline Fox Point Basoball Fild & $5 e 745.743$ & 1.303 & A & $A$ & $A$ & NF & NF & 3 & 0 & 0 & 0 & 2 & 12 \\
\hline Fox Point Fialds & 87552.013 & 2.010 & $A$ & $A$ & A & NF & $\mathrm{NF}$ & 3 & 0 & 0 & 0 & $\frac{2}{2}$ & 12 \\
\hline Hope Hiph Sshool/Grounds & 95174.500 & 2.185 & $A$ & $A$ & $A$ & NF & $\mathrm{NF}$ & 3 & 0 & 0 & 0 & 2 & 12 \\
\hline Heptens square & 278861.438 & 6.402 & A & $\bar{A}$ & A & MF & $\overline{N F}$ & 3 & 0 & 0 & 0 & 2 & 12 \\
\hline Indis Point Park & 46850.212 & 1.076 & $B$ & B & $B$ & $\mathbf{N F}$ & 8 & a & 4 & 0 & 0 & 1 & 12 \\
\hline Joseph Willeme Fiedd & 210234.443 & 4.826 & $A$ & A & $A$ & NF & $\mathrm{NF}$ & 3 & 0 & 0 & 0 & 2 & 12 \\
\hline Locust Grove Cometery & 262632.994 & 6.029 & A & A & A & NF & $\mathrm{NF}$ & 3 & 0 & 0 & 0 & 2 & 12 \\
\hline
\end{tabular}




\begin{tabular}{|c|c|c|c|c|c|c|c|c|c|c|c|c|c|}
\hline & & & Cicenlin & & & & & & & & & & \\
\hline PARKNAMIE & AREA (SF) & AREA (AC) & Litter & Gramti & Qlags: & $\begin{array}{l}\text { Securthy (locked aates, } \\
\text { other activitios) }\end{array}$ & $\begin{array}{l}\text { Netural } \\
\text { fentures }\end{array}$ & As (4 pts) & Bs (3 pts) & Cs (2 pts) & Ds (1 pts) & NFs $(0 \mathrm{pts})$ & $\begin{array}{l}\text { Total } \\
\text { score }\end{array}$ \\
\hline Market Square & 85484.511 & 1.962 & $A$ & $A$ & A & NF & $\mathrm{NF}$ & 3 & 0 & 0 & 0 & 2 & 12 \\
\hline MLK Ployground & 11715.554 & 0.269 & A & A & A & NF & NF & 3 & 0 & 0 & 0 & 2 & 12 \\
\hline Mount Ploasant High School & 4012.580 & 0.092 & $A$ & $A$ & $A$ & $\mathrm{MF}$ & NF & 3 & 0 & 0 & 0 & 2 & 12 \\
\hline 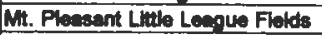 & 1000836.164 & 25.042 & $A$ & A & A & $\mathrm{NF}$ & NF & 3 & 0 & 0 & 0 & 2 & 12 \\
\hline Nathaniel Green School & 91319.934 & 2.096 & $A$ & $A$ & $A$ & NF & NF & 3 & 0 & 0 & 0 & 2 & 12 \\
\hline Richardson Park & 35812.300 & 0.822 & B & A & $B$ & c & NF & 1 & 2 & 1 & 0 & 1 & 12 \\
\hline Ridpe St. Playpround & 234733.460 & 5.389 & $A$ & $A$ & $A$ & $\mathrm{NF}$ & $\mathrm{NF}$ & 3 & 0 & 0 & 0 & 2 & 12 \\
\hline Riveraide Mitts Park & 27435.929 & 0.630 & 8 & $A$ & $B$ & $\mathrm{NF}$ & c & 1 & 2 & 1 & 0 & 1 & 12 \\
\hline Rochambeau Square & 143679.851 & 3.298 & $A$ & A & $A$ & $\mathrm{NF}$ & $\mathrm{NF}$ & 3 & 0 & 0 & 0 & 2 & 12 \\
\hline Scalabrini Plavea & 234950.789 & 5.394 & A & $A$ & A & NF & NF & 3 & 0 & 0 & 0 & 2 & 12 \\
\hline Silver Lelko Momortal Park & 106270.779 & 2.440 & A & A & $A$ & $\mathrm{NF}$ & $\mathrm{NF}$ & 3 & 0 & 0 & 0 & 2 & 12 \\
\hline St. John's Park & 6093.306 & 0.154 & $\bar{A}$ & $A$ & A & NF & NF & 3 & 0 & 0 & 0 & 2 & 12 \\
\hline Stete House Lam & 101065.140 & 2.320 & A & A & $\bar{A}$ & NF & NF & 3 & 0 & 0 & 0 & 2 & 12 \\
\hline Trinlty Mows & 6252258.648 & 143.532 & A & A & A & NF & NF & 3 & 0 & 0 & 0 & 2 & 12 \\
\hline Wallace St. Playground & 3900.650 & 0.092 & A & A & $A$ & NF & NF & 3 & 0 & 0 & 0 & 2 & 12 \\
\hline Washington Park Square & 15479.524 & 0.355 & $A$ & $A$ & $A$ & NF & NF & 3 & 0 & 0 & 0 & 2 & 12 \\
\hline Weat Broedway School Grounds & 181159.226 & 4.159 & A & A & $A$ & $\mathrm{NF}$ & $\mathrm{NF}$ & 3 & 0 & 0 & 0 & 2 & 12 \\
\hline Windwill St. SchoolvGrounds & 155716.528 & 3.575 & A & $A$ & A & $\mathrm{NF}$ & NF & 3 & 0 & 0 & 0 & 2 & 12 \\
\hline & & & & & & & & & & & & & \\
\hline Chalkstone/Oaldand & 2368.805 & 0.054 & B & A & B & NF & D & 1 & 2 & 0 & 1 & 1 & 11 \\
\hline Gano St. Park & 1932.003 & 0.044 & A & B & A & $\mathrm{NF}$ & NF & 2 & 1 & 0 & 0 & 2 & 11 \\
\hline Garbeld Squere & 507150.600 & 11.643 & B & $\bar{A}$ & A & NF & NF & 2 & 1 & 0 & 0 & 2 & 11 \\
\hline Harriot \& Saylos Park & 52475.023 & 1.205 & C & B & c & A & NF & 1 & 1 & 2 & 0 & 1 & 11 \\
\hline Hopkins Park & 771691.233 & 17.716 & B & A & A & $\mathrm{MF}$ & NF & 2 & 1 & 0 & 0 & 2 & 11 \\
\hline Kennedy Plaza & 97358.854 & 2.235 & B & A & A & NF & NF & 2 & 1 & 0 & 0 & 2 & 11 \\
\hline Lennon Park & 63828.028 & 1.465 & $A$ & $\theta$ & $A$ & NF & $\mathrm{NF}$ & 2 & 1 & 0 & 0 & 2 & 11 \\
\hline Muttio Smith Tottot & 329887.638 & 7.573 & B & $A$ & $B$ & $D$ & $\mathrm{NF}$ & $\frac{1}{1}$ & 2 & 0 & $\frac{1}{1}$ & 1 & 11 \\
\hline Merino Park & 61572.095 & 1.414 & B & B & B & c & NF & 0 & 3 & 1 & 0 & 1 & 11 \\
\hline Pearl Strest Park & 72817.943 & 1.672 & B & A & A & $\mathrm{NF}$ & $M F$ & 2 & 1 & 0 & 0 & 2 & 11 \\
\hline Sackett St. Park & 18307569.136 & 420.293 & B & A & A & $\mathrm{NF}$ & $\mathrm{NF}$ & 2 & $i$ & 0 & 0 & 2 & 11 \\
\hline Amos Earloy Park & $\overline{156733.870}$ & 3.598 & $\bar{B}$ & A & $B$ & HF & $\overline{\mathrm{MF}}$ & 1 & 2 & 0 & 0 & 2 & 10 \\
\hline Freomen Park & 145653.323 & 3.344 & E & A & B & NF & $\mathrm{NF}$ & 1 & 2 & 0 & 0 & 2 & 10 \\
\hline JT OWens Park & 586094.920 & 13.476 & A & C & $A$ & $\mathrm{NF}$ & NF & 2 & 0 & 1 & 0 & 2 & 10 \\
\hline & & & & & & & & & & & & & \\
\hline Ardoene Park & 155577.590 & 4.490 & B & 8 & $B$ & NF & $\mathrm{PAF}$ & 0 & 3 & 0 & 0 & 2 & 9 \\
\hline Billy Taylor Park & 8486.080 & 0.185 & $B$ & B & B & NF & $\mathrm{NF}$ & 0 & 3 & 0 & 0 & 2 & 9 \\
\hline Columbus square & 113485.460 & 2.605 & B & 8 & $B$ & $\mathrm{AF}$ & $\mathrm{NF}$ & 0 & 3 & 0 & 0 & 2 & 8 \\
\hline Proto-Motcelli Field & 13306.178 & 0.305 & $B$ & 8 & $B$ & $\mathrm{NF}$ & $\mathrm{MF}$ & 0 & 3 & 0 & 0 & 2 & 9 \\
\hline & & & & & & & & & & & & & \\
\hline Ascham St. Park & 73799.362 & 1.694 & B & C & B & NF & $\mathbf{N F}$ & 0 & 2 & 1 & 0 & 2 & 8 \\
\hline Cohumbla Park & 114402.288 & 2.626 & 8 & $\mathrm{c}$ & $B$ & NF & NF & 0 & 2 & 1 & $\underline{0}$ & 2 & 8 \\
\hline Obediah Brown Filids & 217339.537 & 4.909 & c & A & c & $\mathrm{NF}$ & $\mathrm{NF}$ & 1 & 0 & 2 & 0 & 2 & 8 \\
\hline 128 & 4627352.000 & 106.229 & & & & & & & & & & & \\
\hline Ciky's physical zizo & 66326666.408 & 4270.123 & & & & & & & & & & & \\
\hline & 524347400.000 & 12037.36 & & & & & & & & & & & \\
\hline$\%$ of partss and open spece & 10.552 & 10.552 & & & & & & & & & & & \\
\hline Acreange per 1,000 rouldents & 7.318 & & & & & & & & & & & & \\
\hline Citys total population & 173618 & & & & & & & & & & & & \\
\hline
\end{tabular}


Social and Economic Indicators and park size

with parks and owner occupied
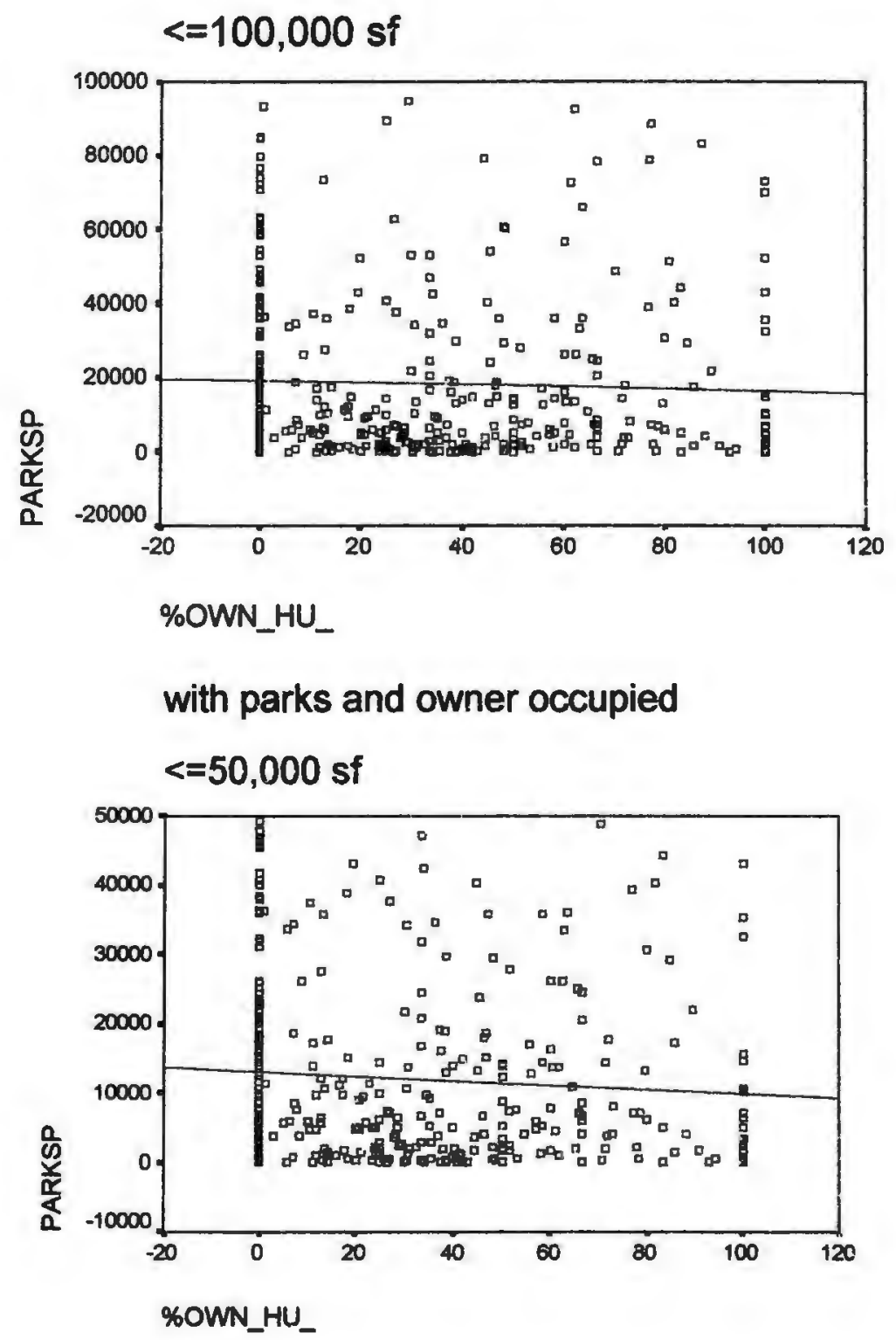


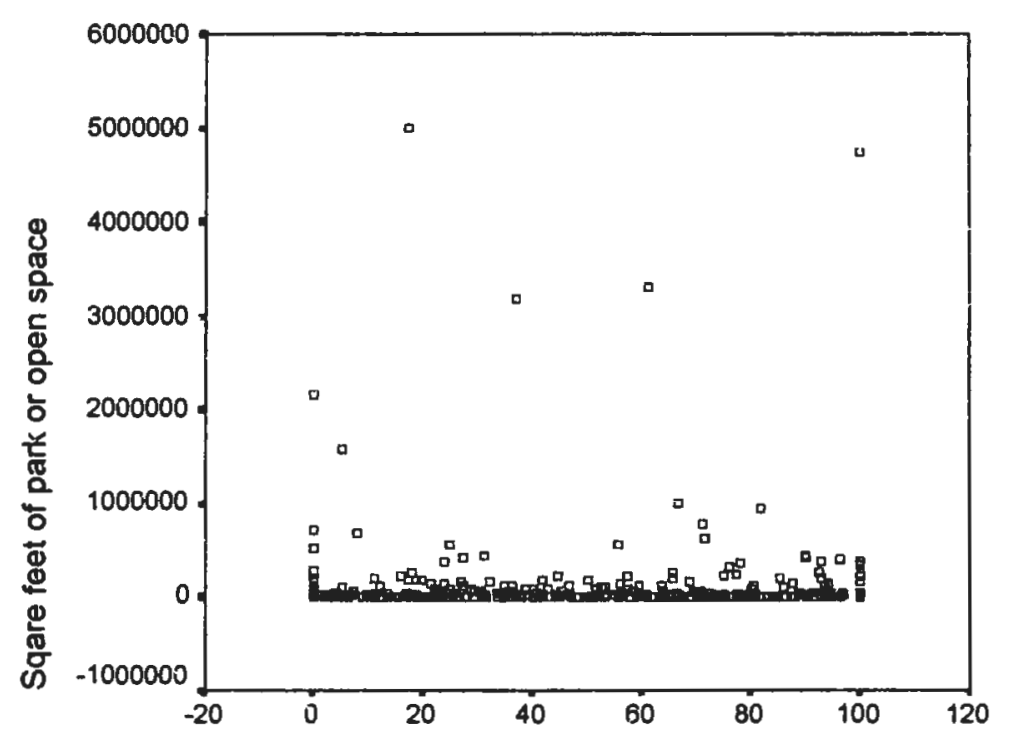

Percent of population non-white

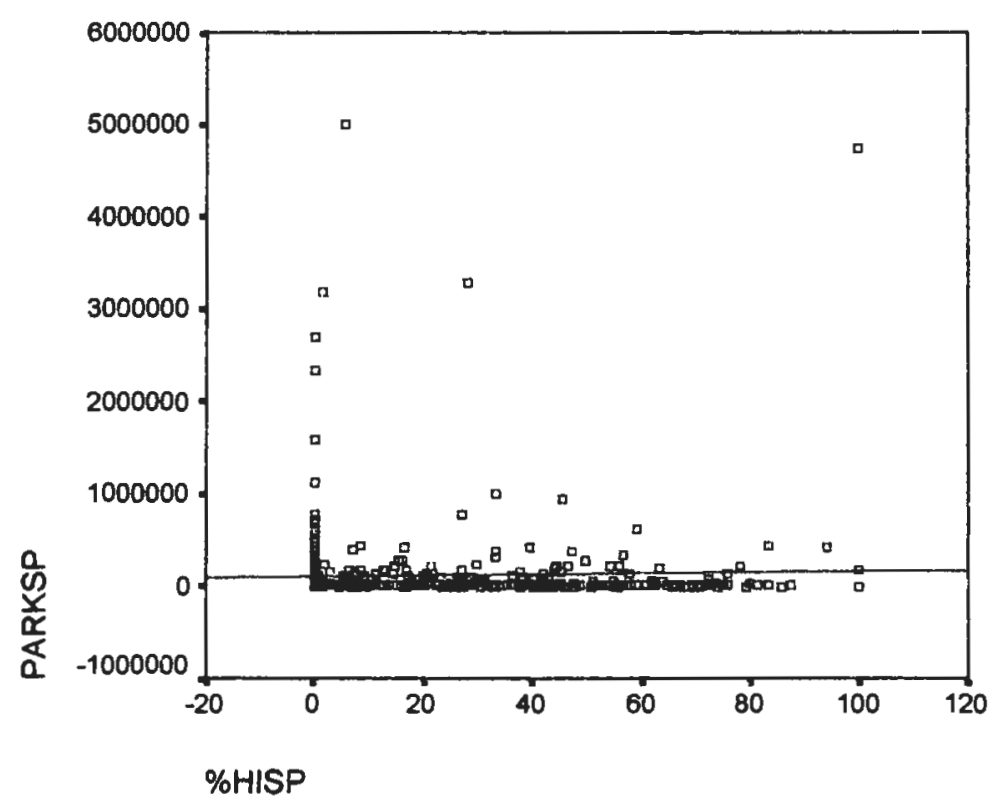




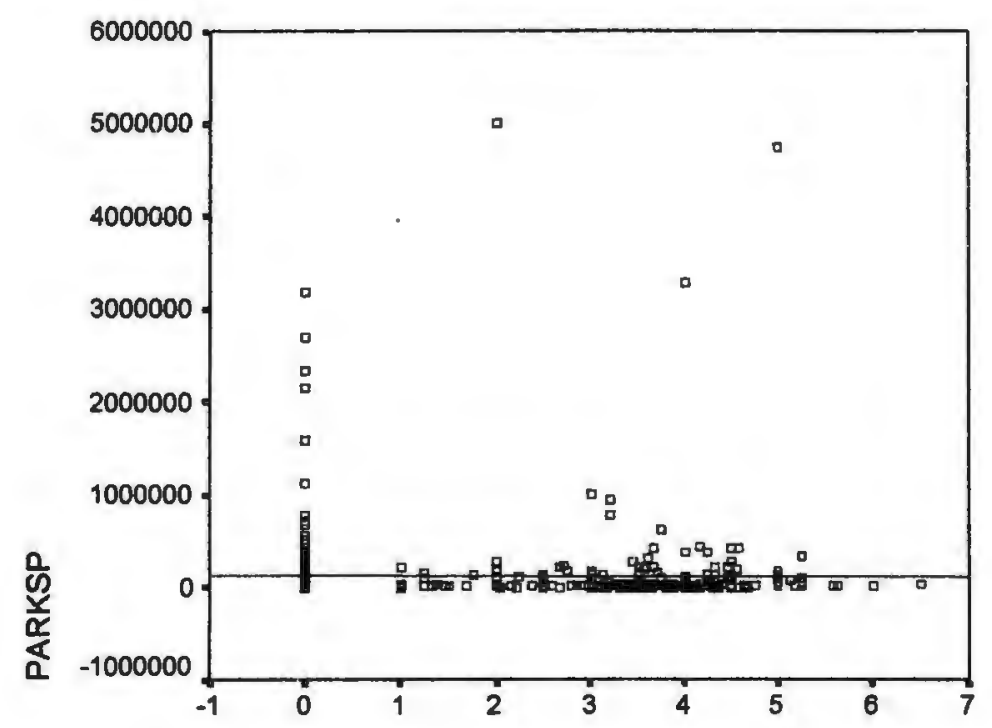

AHS_HIS

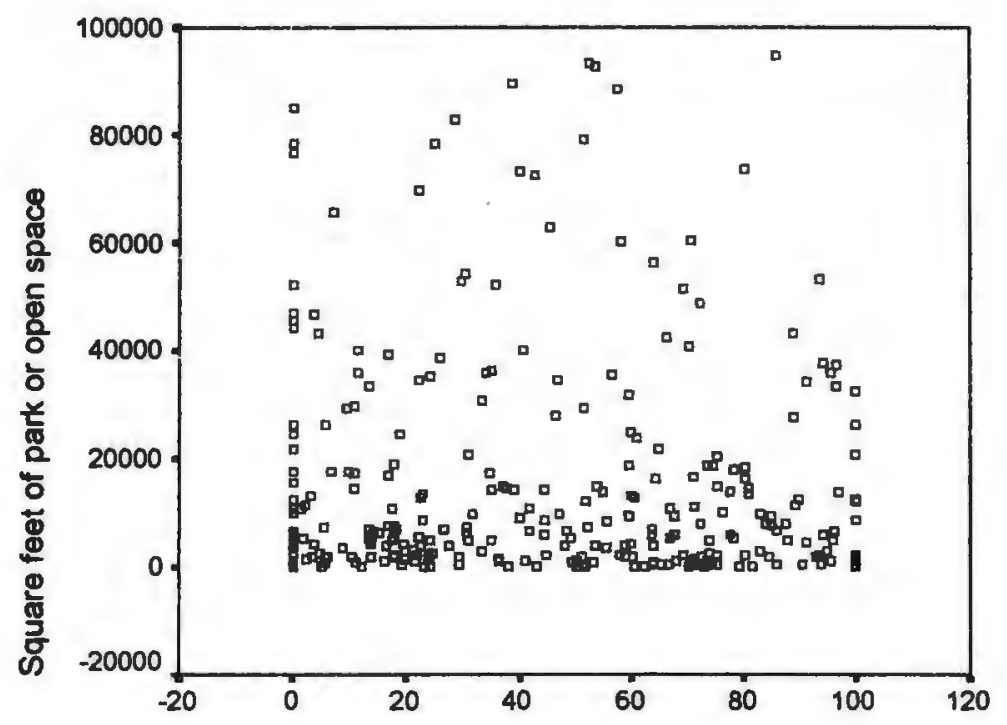

Percent of population non-white 

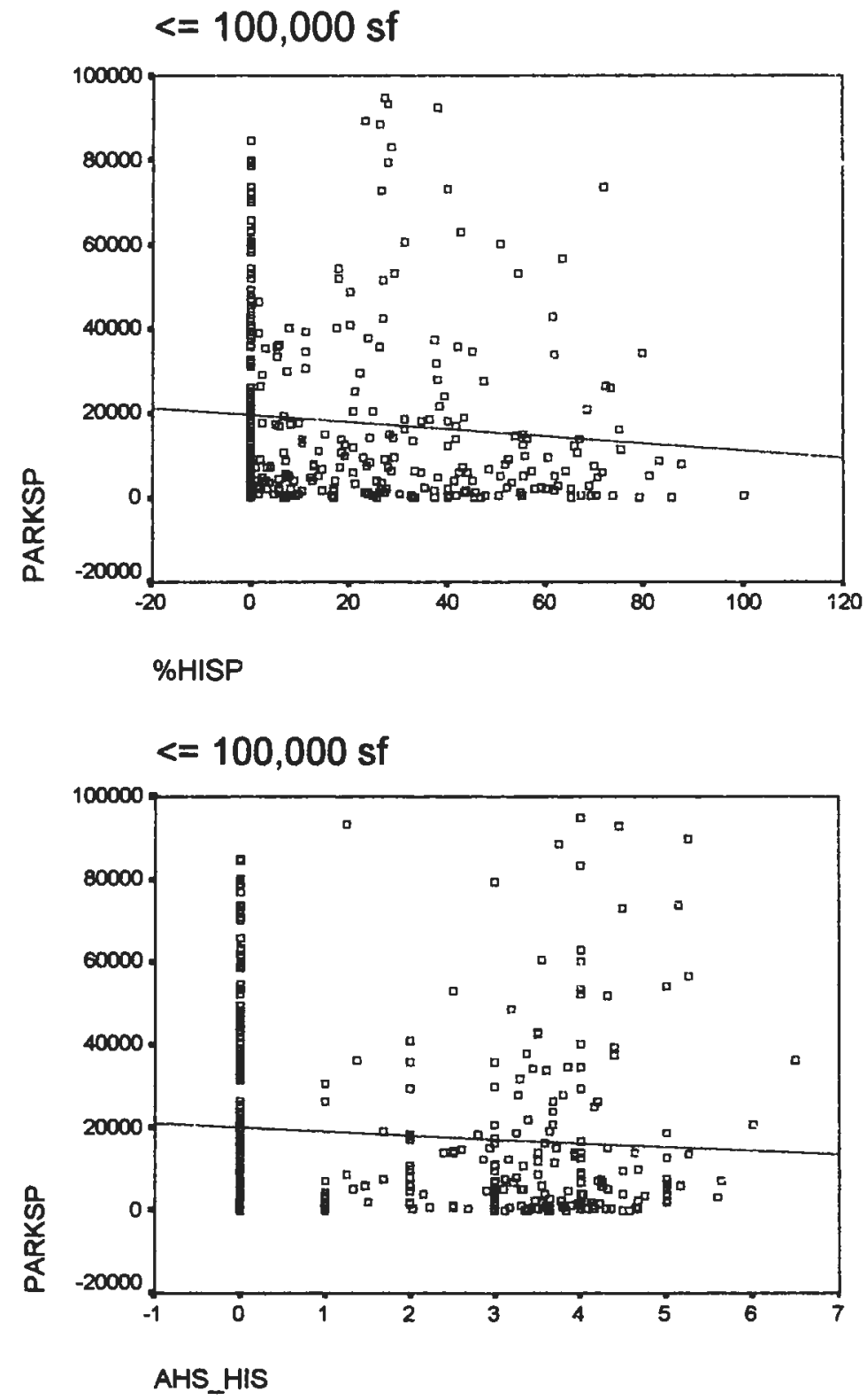


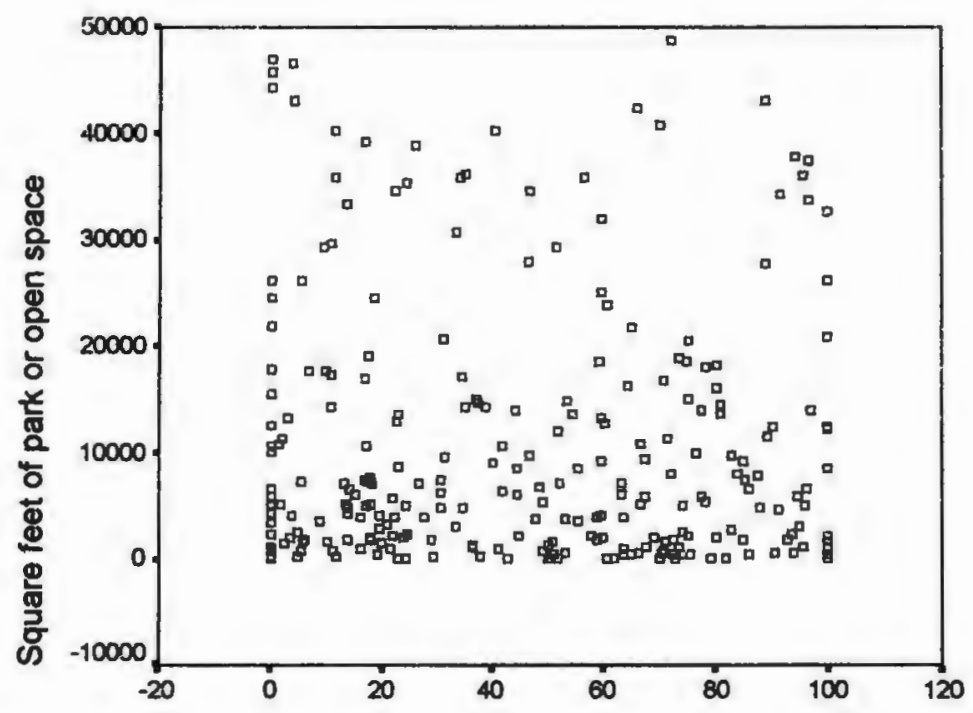

Percent of population non-white

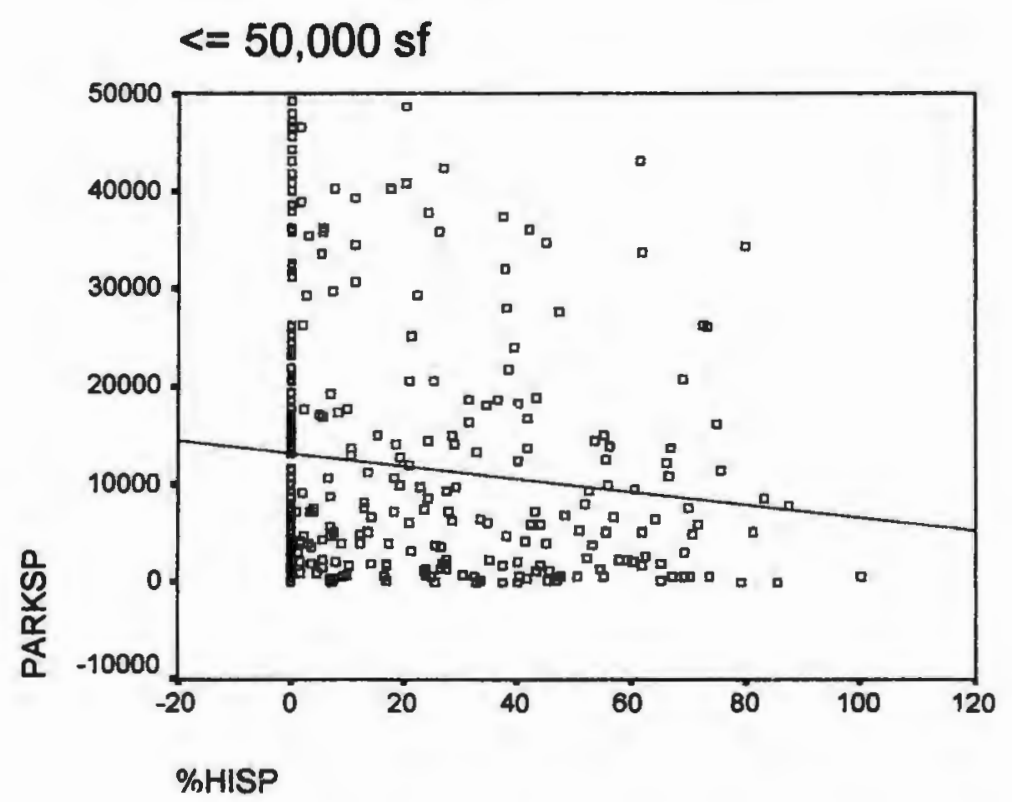




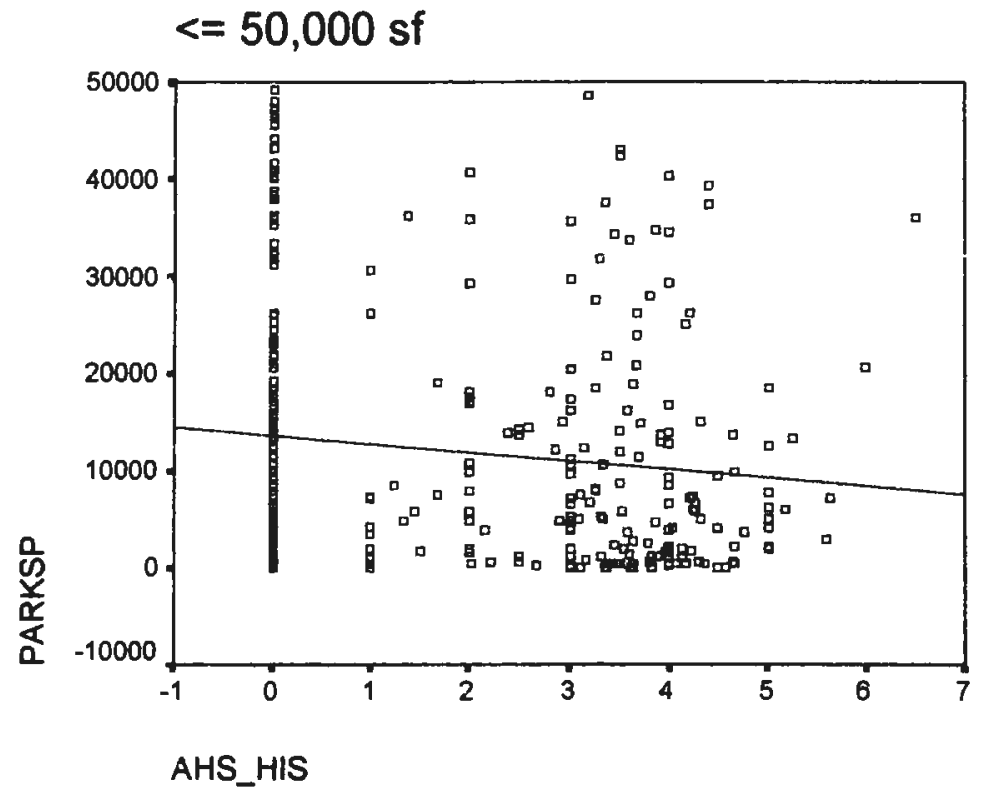

Variables Entered/Removed ${ }^{\text {b }}$

\begin{tabular}{|c|c|c|c|}
\hline Model & Variables Entered & $\begin{array}{l}\text { Variables } \\
\text { Removed }\end{array}$ & Method \\
\hline 1 & $\begin{array}{l}\text { UND18PER, } \\
\text { \%RENT_HU,-, } \\
\text { \%VAC_HU_,DENSITY, } \\
\text { AHS_WHT, AHS_HIS, } \\
\% \text { \%ISP,\%NHWHITE }\end{array}$ & & Enter \\
\hline
\end{tabular}

a. Tolerance $=.000$ limits reached.

b. Dependent Vaniable: PARKSP

\begin{tabular}{|l|r|r|r|r|}
\hline Model & \multicolumn{1}{|c|}{$\mathbf{R}$} & R Square & $\begin{array}{l}\text { Adjusted } \\
\text { R Square }\end{array}$ & $\begin{array}{r}\text { Std. Error of } \\
\text { the Estimate }\end{array}$ \\
\hline 1 & $.215^{\mathrm{a}}$ & .046 & .022 & 469861.03 \\
\hline
\end{tabular}

a. Predictors: (Constant), UND18PER, \%RENT_HU_, $\%$ VAC_HU_, DENSITY, AHS_WHT, AHS_HIS, \%HISP, \%NHWHITE

ANOVA'

\begin{tabular}{|ll|r|r|r|r|r|}
\hline Model & & $\begin{array}{c}\text { Sum of } \\
\text { Squares }\end{array}$ & \multicolumn{1}{c|}{ df } & Mean Square & \multicolumn{1}{c|}{$F$} & Sig. \\
\hline 1 & Regression & $3.4 \mathrm{E}+12$ & 8 & $4.274 \mathrm{E}+11$ & 1.936 & $.054^{9}$ \\
& Residual & $7.0 \mathrm{E}+13$ & 319 & $2.208 \mathrm{E}+11$ & & \\
& Total & $7.4 \mathrm{E}+13$ & 327 & &. & \\
\hline
\end{tabular}

a. Predictors: (Constant), UND18PER, \%RENT_HU_, \%VAC_HU_, DENSITY, AHS_WHT, AHS_HIS, \%HISP, \%NHWHITE

b. Dependent Variable: PARKSP 
Coefficients ${ }^{a}$

\begin{tabular}{|c|c|c|c|c|c|c|}
\hline \multirow{2}{*}{\multicolumn{2}{|c|}{ Model }} & \multicolumn{2}{|c|}{$\begin{array}{c}\text { Unstandardized } \\
\text { Coefficients }\end{array}$} & \multirow[t]{2}{*}{$\begin{array}{c}\begin{array}{c}\text { Standardi } \\
\text { zed } \\
\text { Coefficie } \\
\text { nts }\end{array} \\
\text { Beta } \\
\end{array}$} & \multirow[b]{2}{*}{$t$} & \multirow[b]{2}{*}{ Sig. } \\
\hline & & $B$ & Std. Error & & & \\
\hline \multirow[t]{9}{*}{1} & (Constant) & 375731.6 & 213766.7 & & 1.758 & .080 \\
\hline & $\%$ HISP & 1100.932 & 2047.049 & .056 & .538 & .591 \\
\hline & \%NHWHITE & -457.161 & 1685.624 & -.030 & -.271 & .786 \\
\hline & $\%$ VAC_HU_ & -5024.451 & 3110.830 & -.092 & -1.615 & .107 \\
\hline & \%RENT_HU_ & 101.419 & 1140.869 & .006 & .089 & .929 \\
\hline & AHS_WHT & -89199.2 & 37830.43 & -.147 & -2.358 & .019 \\
\hline & AHS_HIS & -13313.0 & 20491.81 & -.049 & -.650 & .516 \\
\hline & DENSITY & -291.322 & 149.507 & -.115 & -1.949 & .052 \\
\hline & UND18PER & 3933.136 & 2645.831 & .106 & 1.487 & .138 \\
\hline
\end{tabular}

a. Dependent Vanable: PARKSP

Excluded Variables ${ }^{b}$

\begin{tabular}{|c|c|c|c|c|c|c|}
\hline \multirow{2}{*}{\multicolumn{2}{|c|}{ Model }} & \multirow[b]{2}{*}{ Beta In } & \multirow[b]{2}{*}{$t$} & \multirow[b]{2}{*}{ Sig. } & \multirow{2}{*}{$\begin{array}{c}\text { Partial } \\
\text { Correlation }\end{array}$} & $\begin{array}{c}\text { Collinearit } \\
y \\
\text { Statistics }\end{array}$ \\
\hline & & & & & & Tolerance \\
\hline & $\%$ NONWH & $82.390^{9}$ & 1.288 & .199 & .072 & $7.287 E-07$ \\
\hline & $\% O W N$ HU & $-121.319^{a}$ & -.596 & .552 & -.033 & 7.219E-08 \\
\hline
\end{tabular}

a. Predictors in the Model: (Constant), UND18PER, \%RENT_HU_, \%VAC_HU_. DENSITY, AHS_WHT, AHS_HIS, \%HISP, \%NHWHITE

b. Dependent Variable: PARKSP 
Social and economic indicators with park ranking

Scores less than 12 and greater than 0

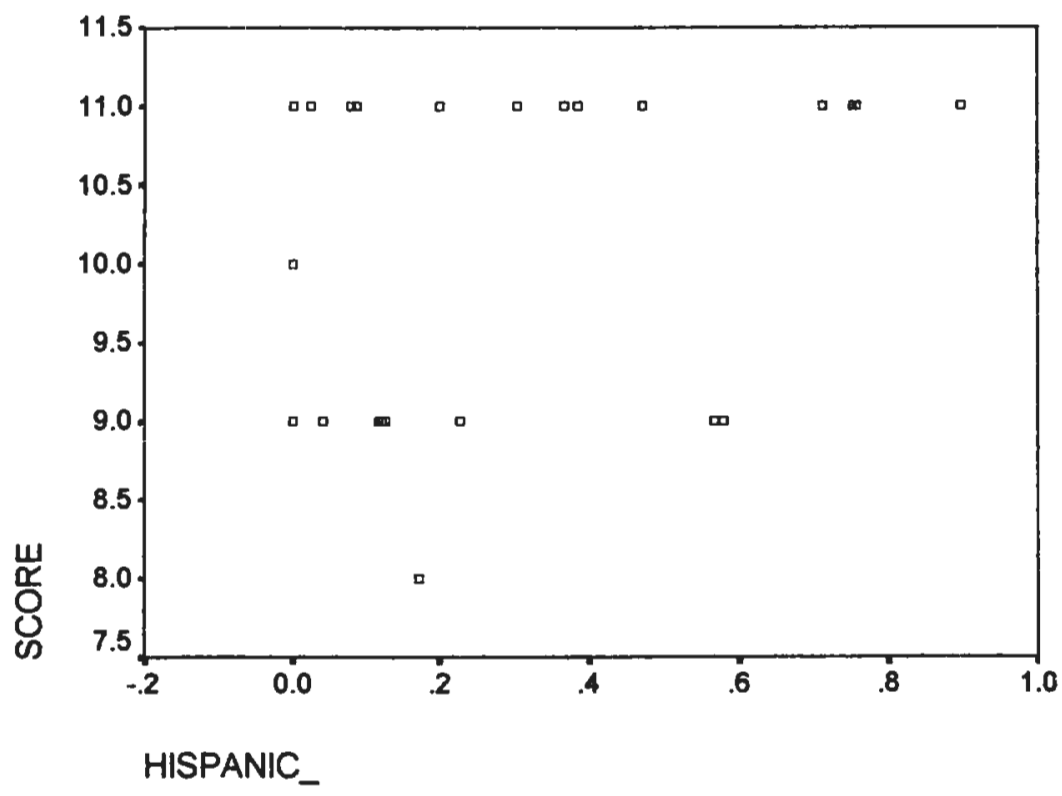

Scores less than 12 and greater than 0

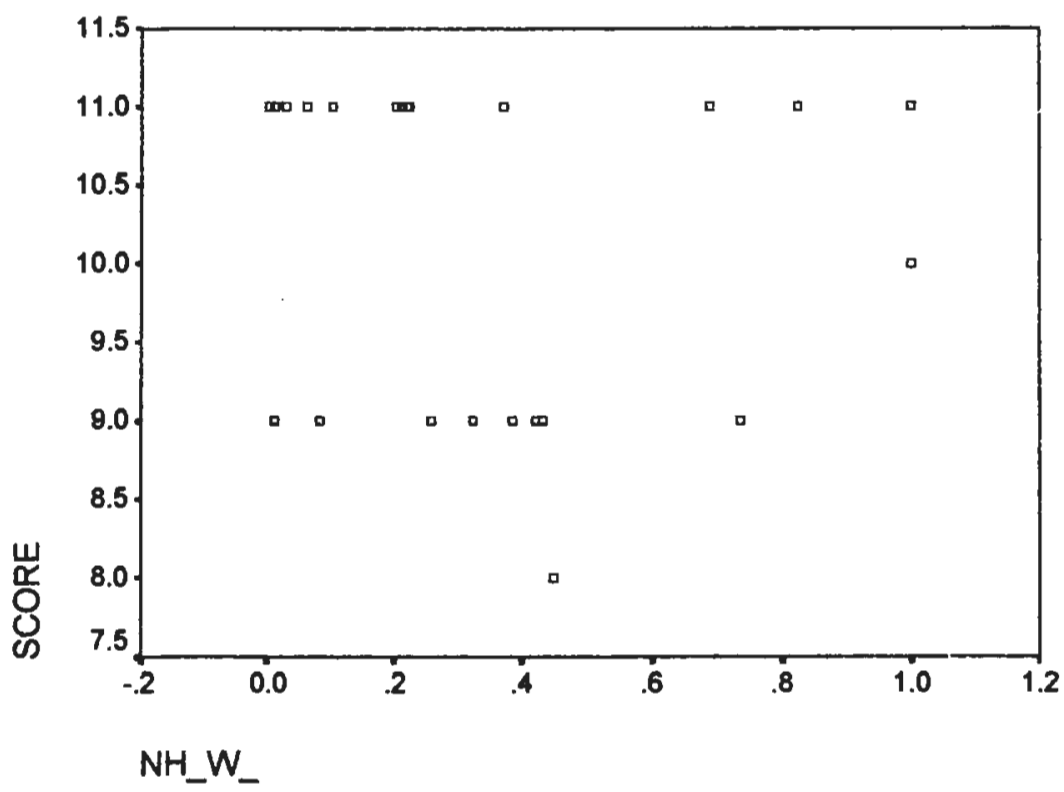


Scores less than 12 and greater than 0

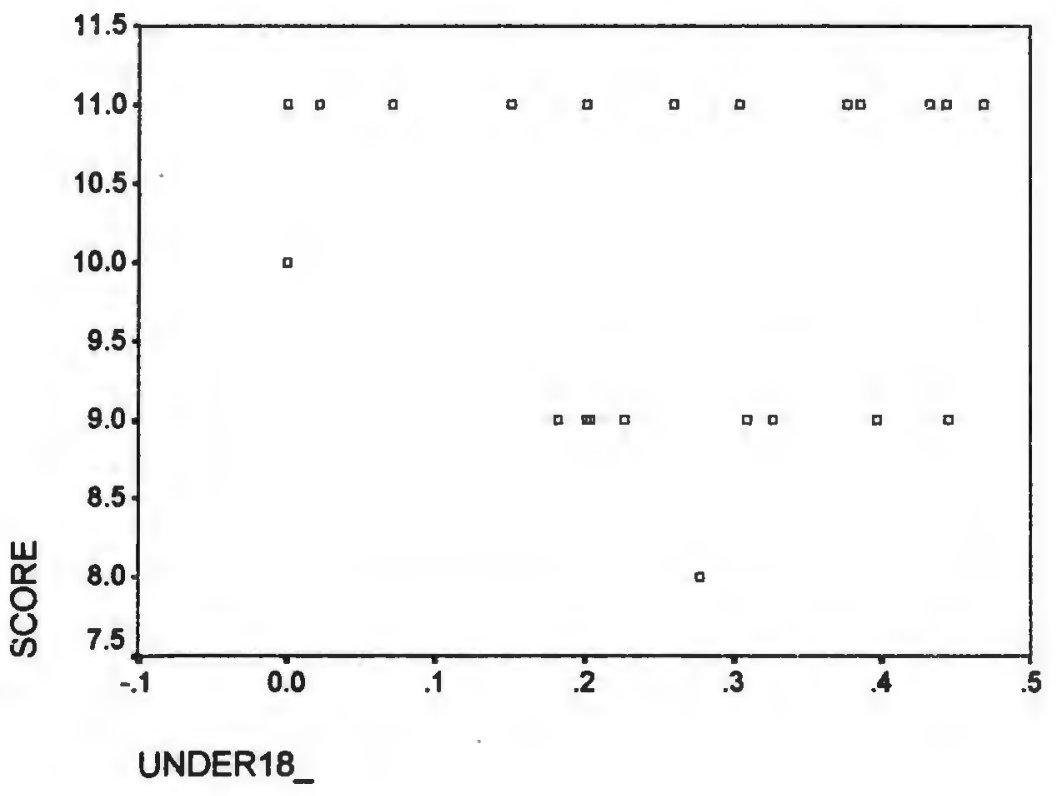

Scores less than 12 and greater than 0

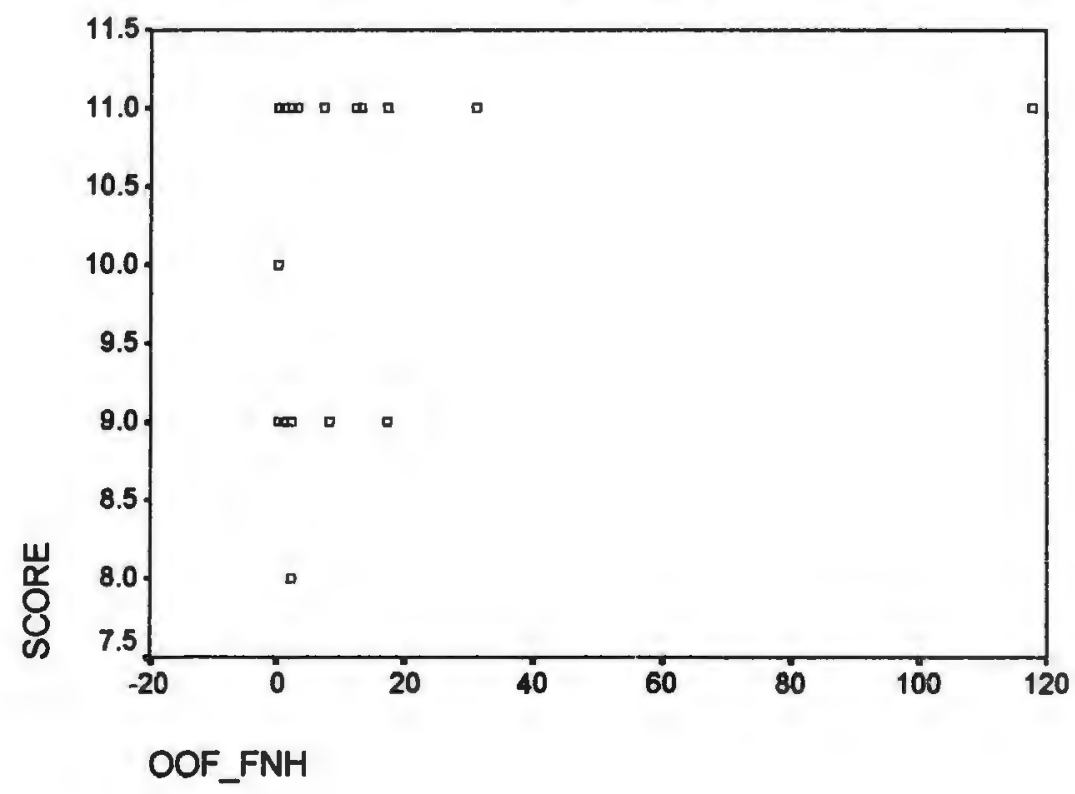


Scores less than 12 and greater than 0

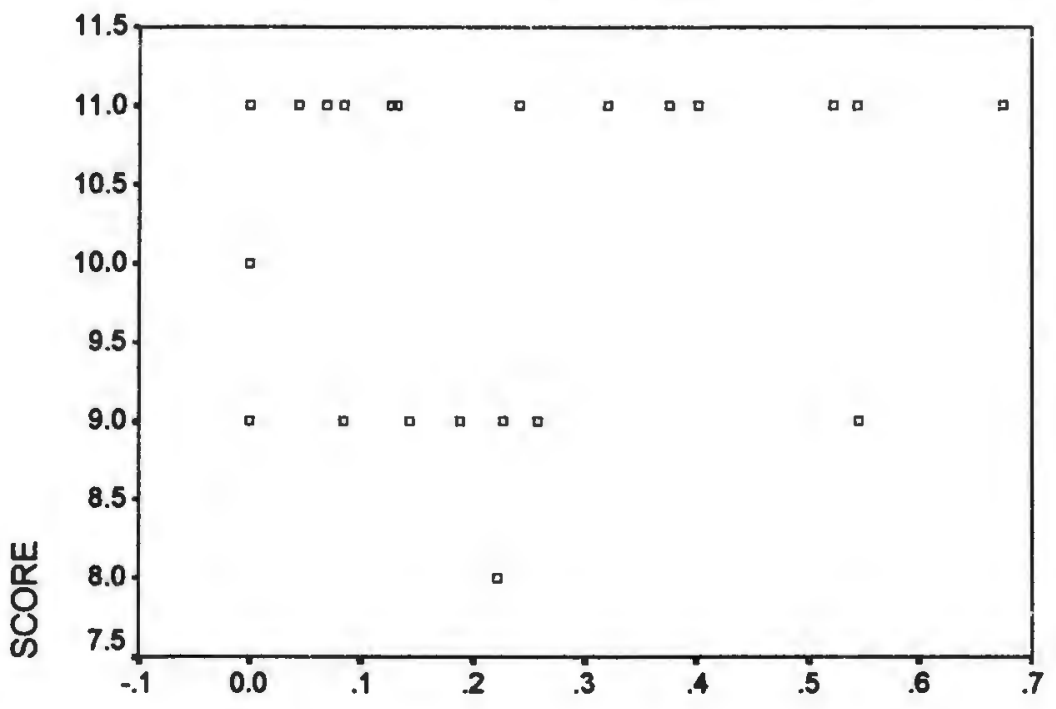

SINGPAR

Scores less than 12 and greater than 0

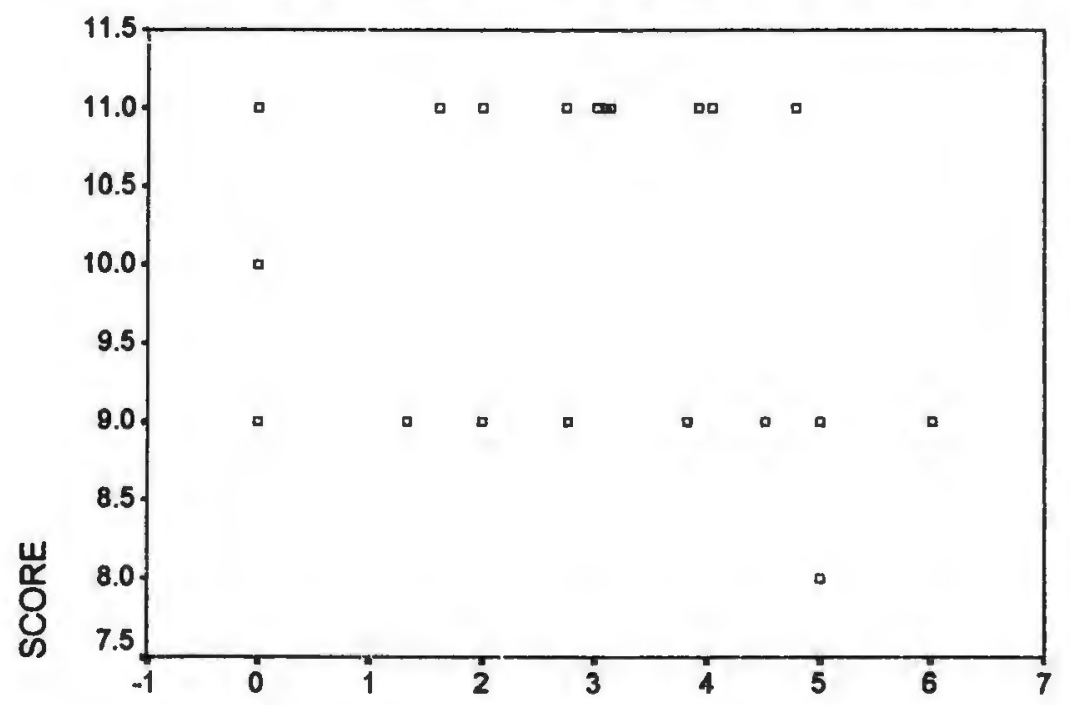

AHS_HIS 
Scores less than 12 and greater than 0

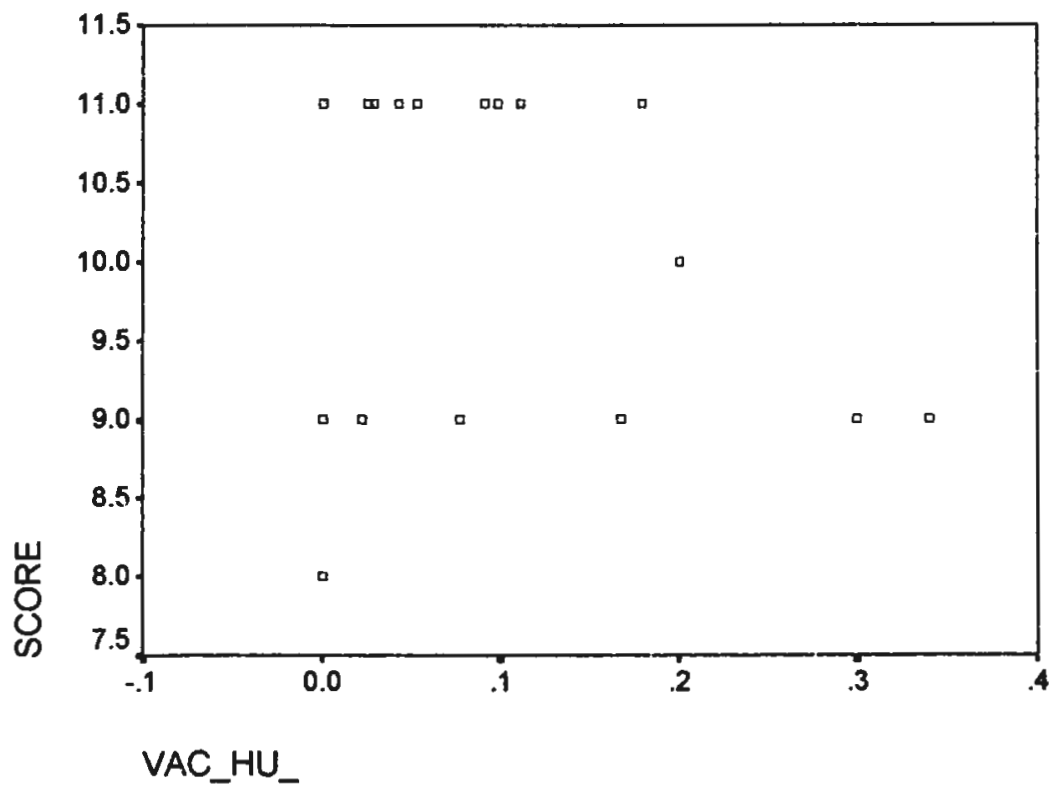

Regression - Scores less than 12, greater than 0

Variables Entered/Removed ${ }^{b}$

\begin{tabular}{|c|c|c|c|}
\hline Model & $\begin{array}{c}\text { Variables } \\
\text { Entered }\end{array}$ & $\begin{array}{l}\text { Variables } \\
\text { Removed }\end{array}$ & Method \\
\hline 1 & $\begin{array}{l}\text { NONWHIT } \\
\text { E, } \\
\text { VAC_HU,' } \\
\text { HISPANIC' } \\
\text {-'UNDER18 } \\
\text { S'INGPAR } \\
\text { _,FHHNH' }\end{array}$ & & Enter \\
\hline
\end{tabular}

a. All requested variables entered.

b. Dependent Variable: SCORE

Model Summary

\begin{tabular}{|l|r|r|r|r|}
\hline Model & $\mathrm{R}$ & $\mathrm{R}$ Square & $\begin{array}{c}\text { Adjusted } \\
\mathrm{R} \text { Square }\end{array}$ & $\begin{array}{r}\text { Std. Error of } \\
\text { the Estimate }\end{array}$ \\
\hline 1 & $.59^{\mathrm{2}}$ & .350 & .106 & 1.00 \\
\hline
\end{tabular}

a. Predictors: (Constant), NONWHITE, VAC_HU HISPANIC_, UNDER18_, SINGPAR_, FHHNH 
ANOVA ${ }^{\circ}$

\begin{tabular}{|ll|r|r|r|r|r|}
\hline Model & & $\begin{array}{c}\text { Sum of } \\
\text { Squares }\end{array}$ & df & Mean Square & $F$ & Sig. \\
\hline 1 & Regression & 8.609 & 6 & 1.435 & 1.435 & $.262^{a}$ \\
& Residual & 16.000 & 16 & 1.000 & & \\
& Total & 24.609 & 22 & & & \\
\hline
\end{tabular}

a. Predictors: (Constant), NONWHITE, VAC_HU_, HISPANIC_, UNDER18, SINGPAR, FHHNH

b. Dependent Variable: SCORE

\begin{tabular}{|c|c|c|c|c|c|c|}
\hline \multicolumn{7}{|c|}{ Coefficients $^{a}$} \\
\hline \multirow{2}{*}{\multicolumn{2}{|c|}{ Model }} & \multicolumn{2}{|c|}{$\begin{array}{l}\text { Unstandardized } \\
\text { Coefficients }\end{array}$} & \multirow[t]{2}{*}{$\begin{array}{c}\text { Standardi } \\
\text { zed } \\
\text { Coefficie } \\
\text { nts } \\
\text { Beta }\end{array}$} & \multirow[b]{2}{*}{$t$} & \multirow[b]{2}{*}{ Sig. } \\
\hline & & $\mathrm{B}$ & Std. Error & & & \\
\hline & (Constant) & 10.780 & .586 & & 18.394 & .000 \\
\hline & HISPANIC_ & 1.858 & 1.290 & .496 & 1.441 & .169 \\
\hline & SINGPAR_ & 5.139 & 6.049 & .974 & .850 & .408 \\
\hline & UNDER18_ & -3.678 & 2.561 &. .502 & -1.436 & .170 \\
\hline & VAC_HU_ & -2.696 & 2.291 & -.251 & -1.177 & .257 \\
\hline & FHHNH & -2.743 & 6.716 & -.488 & -.408 & .688 \\
\hline & NONWHITE & -1.000 & 1.313 & -.293 & -.762 & .457 \\
\hline
\end{tabular}

a. Dependent Variable: SCORE 